\title{
WestVirginiaUniversity
}

THE RESEARCH REPOSITORY @ WVU

Graduate Theses, Dissertations, and Problem Reports

2017

\section{Adapting Roof Support Methods for Anchoring Satellites on Asteroids}

Grant B. Speer

Follow this and additional works at: https://researchrepository.wvu.edu/etd

\section{Recommended Citation}

Speer, Grant B., "Adapting Roof Support Methods for Anchoring Satellites on Asteroids" (2017). Graduate Theses, Dissertations, and Problem Reports. 6699.

https://researchrepository.wvu.edu/etd/6699

This Thesis is protected by copyright and/or related rights. It has been brought to you by the The Research Repository @ WVU with permission from the rights-holder(s). You are free to use this Thesis in any way that is permitted by the copyright and related rights legislation that applies to your use. For other uses you must obtain permission from the rights-holder(s) directly, unless additional rights are indicated by a Creative Commons license in the record and/ or on the work itself. This Thesis has been accepted for inclusion in WVU Graduate Theses, Dissertations, and Problem Reports collection by an authorized administrator of The Research Repository @ WVU. For more information, please contact researchrepository@mail.wvu.edu. 


\title{
Adapting Roof Support Methods for Anchoring Satellites on Asteroids
}

\author{
Grant B. Speer \\ Thesis submitted \\ to the Statler College of Engineering and Mineral Resources \\ at West Virginia University
}

in partial fulfillment of the requirements for the degree of

Master of Science in

Mining Engineering

\author{
Brijes Mishra, Ph.D., Co-Chair \\ Thomas Evans, Ph.D., Co-Chair \\ Aaron Noble, Ph.D. \\ Department of Mining Engineering
}

Morgantown, West Virginia

2017

Keywords: bolt, roof, low-temperature rock mechanics, asteroid capture, asteroid mining, satellite, anchor

Copyright 2017 Grant B. Speer 


\section{Abstract \\ Adapting Roof Support Methods for Anchoring Satellites on Asteroids

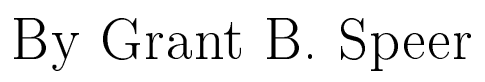

The use of anchorage in satellite and spacecraft design has been largely restricted to harpoon-inspired technology based on anticipated low strengths of cometary and asteroid material. Initial results from the Rosetta mission to comet $67 \mathrm{P} /$ ChuryumovGerasimenko, however, have demonstrated both larger-than-expected compressive strengths of cometary materials and the importance of adequate anchorage to mitigate the risk of mission failure. The field of rock mechanics can provide unique insight into the design of these satellite and lander anchors by drawing on existing roof bolt technology. This study compared the behavior of tensioned point anchor and untensioned fully grouted roof bolts with a polyurethane-anchored bolt under environmental conditions similar to those anticipated in space. These conditions include variation in possible material types as well as variations in regolith properties, anchorage length, and low operating temperatures.

Using a Box-Behnken experimental design, this study first compared the effects of anchor depth and rock strength on each of the three anchorage types in a competent rock strength regime. The study then examined the effects of compaction, water content, and temperature on each anchor type in a regolith environment. The subsequent data analysis identified one anchor type as the overall best anchor for these environments. This finding has led to a preliminary design recommendation to advise space agencies on satellite anchor construction based on the target orbital body's anticipated environmental and "exogeologic" conditions. 


\section{Acknowledgments}

I would first like to thank my advisor, Dr. Mishra. His advice and guidence both for this study and for developing me as a professional have been critical to my success. Even when I suffered the occasional setback, he believed in me when I did not.

Next, I would like to thank Dr. Noble. His critiques, advice, and outlook helped me to become a better scientist and to apply more rigourous analyses to all aspects of my life. He has mentored me for two years, and I am forever changed for the better thanks to his guidance.

I would like to extend special thanks to Dr. Evans, the West Virginia Robotic Technology Center, and the Satellite Servicing Projects Division at NASA Goddard Space Flight Center. Their support was critical and this study would not have been possible without their help.

Additionally, I would like to extend my gratitude to Dakota Faulkner and JENNMAR USA for all of their help and support. Without their assistance in providing materials, test equipment, and expertise, this study would not have been possible.

My peers at West Virginia University were critical to my success at every step of the way. Whether editing my work, assisting me in testing, or just acting as a sounding board for ideas, their assistance helped me to craft a better product. Thank you to Wesley Edge, Chris Vass, Xue Zhai, Hassan Amini, Scott Saber, and Neel Gupta.

Finally, my parents, brother, and my wife Rebecca have been the key to my success over the last two years. Their love, understanding, and support helped motivate me and kept me reaching for the stars. 


\section{Contents}

1 Introduction $\quad 1$

1.1 New Horizons for an Old Discipline . . . . . . . . . . . . 1

1.2 Motivation for Study . . . . . . . . . . . . . 2

2 Literature Review $\quad 4$

2.1 A Case Study of Anchoring Mechanisms Currently Used in Space Ap-

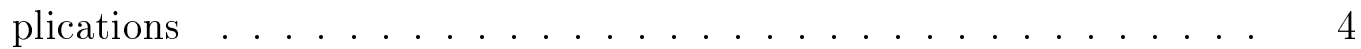

2.2 Roof Support and Anchoring . . . . . . . . . . . 8

2.2.1 Theories of Roof Bolting . . . . . . . . . . . 8

2.2.2 Bolt and Anchorage Types . . . . . . . . . . . 10

2.2.3 Bolt and Anchorage Failure Mechanisms . . . . . . . . . . 14

2.2.4 Bolt Design and Anchoring Test Method ......... 15

2.2.5 Resin and Bolt Performance in Extreme Environments . . . 18

2.3 Exogeologic Characteristics of Planetary Bodies . . . . . . . . 20

2.3.1 Mineralogy ..................... 20

2.3.2 Density and Porosity . . . . . . . . . . . . 22

2.3.3 Regolith Size Distribution ............ 24

2.3.4 Material Strength of Asteroids . . . . . . . . . . . . 25

2.3.5 Material Strength of Comets . . . . . . . . . . . . . 31

2.4 Summary of Knowledge Gaps . . . . . . . . . . . . . . . . . 33

3 Methodology 35

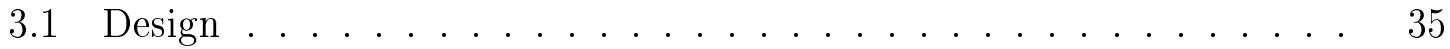


3.2 Comparison of Anchoring Methods in the Rock Strength Regime . . . 39

3.2 .1 Boulder Core Strength Tests . . . . . . . . . . . . . . 39

3.2.2 Boulder Pull Test Setup ． . . . . . . . . . . . . . . 42

3.3 Comparison of Anchoring Methods in the Regolith Strength Regime . 47

3.3.1 Regolith Simulant Preparation . . . . . . . . . . . . 47

3.3.2 Regolith Compactive Load Tests . . . . . . . . . . . . . 51

3.3 .3 Regolith Pull Test Setup . . . . . . . . . . . . . . . 55

4 Results and Analysis $\quad 62$

4.1 Data Analysis . . . . . . . . . . . . . . . . . 62

4.1 .1 Boulder Tests . . . . . . . . . . . . . . . 62

4.1 .2 Regolith Tests . . . . . . . . . . . . . . 66

4.2 Interpretation $\ldots \ldots \ldots \ldots \ldots \ldots \ldots \ldots \ldots \ldots$

4.2.1 Performance of Anchors . . . . . . . . . . . . . 73

4.2.2 Anchor Design Considerations . . . . . . . . . . . . 75

5 Conculsions and Recommendations $\quad 79$

5.1 Conclusions . . . . . . . . . . . . . . . . . . . 79

5.2 Future Work . . . . . . . . . . . . . . . . . 80

$\begin{array}{ll}\text { Bibliography } & 83\end{array}$ 


\section{List of Figures}

2.1 Philae Lander and Its Critical Anchoring Equipment (after Biele et al.

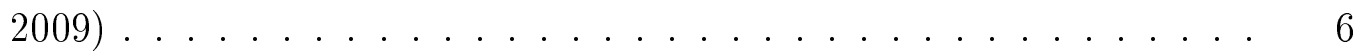

2.2 Ice Screw Design (after Ulamec and Biele 2009) $\ldots \ldots \ldots \ldots \ldots$

2.3 Roof Reinforcement Mechanisms (after Mark 2000) . . . . . . . 10

2.4 Bolt Installation Layout $\ldots \ldots \ldots \ldots$

2.5 Resin UCS as a Function of Temperature (After Bureau of Mines (1987)) 18

2.6 Lunar Regolith Cumulative Size Distributions (After McKay et al. 1991) 26

2.7 Compressive strengths of asteroids and meteorites . . . . . . . . 32

2.8 Tensile strengths of asteroids and meteorites . . . . . . . . . 32

3.1 Uniaxial Compressive Strength Testing . . . . . . . . . . . . 41

3.2 Bolt Design . . . . . . . . . . . . . . . . . . . 43

3.3 Pull Test System Setup . . . . . . . . . . . . . . . . 46

3.4 Bolts Installed in Diabase and Sandstone Boulders . . . . . . . . . 46

3.5 Limestone Boulder Pre- and Post-Failure . . . . . . . . . . 47

3.6 Particle Size Analysis Results of Asteroid Simulant _ . . . . . . . 48

3.7 Comparison of Asteroid Regolith Size Distributions with Lunar Regolith 51

3.8 Compaction Test Setup . . . . . . . . . . . . . . . . . . . . 53

3.9 Compactive Load Test Results As A Function Of Water Content . . . 55

3.10 Setup for Sample Compactive Loading . . . . . . . . . . . 56

3.11 Construction of Bolt Holes in Regolith . . . . . . . . . . 58

3.12 Low Temperature Regolith Configuration . . . . . . . . . . . . 60

3.13 Pull Test Loading Platform _. . . . . . . . . . . . . . 61 
4.1 Overall Success Rates for Anchor Types _. . . . . . . . . . 68

4.2 Comparison of Anchor Success Under Varying Conditions . . . . . . 72 


\section{List of Tables}

2.1 Roof Bolt Classifications (after Mark 2000; Peng 2008) . . . . . . . 11

2.2 Hold Time Variation with Temperature (After Orica International 2014) 19

2.3 Asteroid Mineralogy and Meteorite Analogs (After Nelson et al. (1993)) 22

2.4 Properties of Selected Asteroids and Comets (After Baer et al. (2011); Britt et al. (2006)) . . . . . . . . . . . . 24

2.5 Lunar Regolith Size Fractions in Wt.\% (After McKay et al. 1991) . . 26

2.6 Rock Mass Failure Criteria (after Holsapple (2009); Hudson and Har-

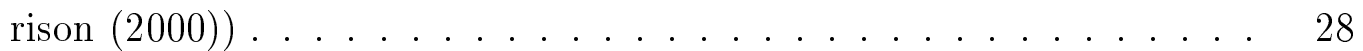

2.7 Material Strength of Asteroids, Meteorites, and Regolith by Strength

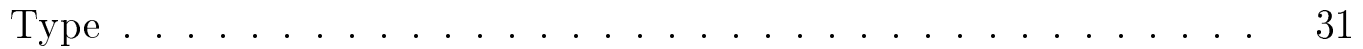

3.1 Summary of Test Conditions . . . . . . . . . . . . . 36

3.2 Box-Behnken Design Variable Key . . . . . . . . . . . . . . . 37

3.3 Boulder Test Series Box-Behnken Design . . . . . . . . . . . 38

3.4 Boulder Test Series Parameter Configurations . . . . . . . . . 38

3.5 Regolith Test Series Box-Behnken Design . . . . . . . . . . . . . . 40

3.6 Regolith Test Series Parameter Configurations . . . . . . . . . . 40

3.7 Boulder Uniaxial Compressive Strength Test Results . . . . . . . . 42

3.8 Particle Size Analysis Size Distributions _. . . . . . . . . . 49

3.9 Regolith Simulant Size Classes . . . . . . . . . . . . . 50

3.10 Regolith Masses . . . . . . . . . . . . . . 54

3.11 Compactive Load Test Results . . . . . . . . . . . 55

4.1 Boulder Pull Test Results . . . . . . . . . . . . . . . . . 64 
4.2 Average Bolt Behavior Relative to Rock Strength _ . . . . . . . 65

4.3 Average Bolt Behavior Relative to Anchor Depth . . . . . . . . 65

4.4 Failed Regolith Pull Tests . . . . . . . . . . . . . . . 67

4.5 Regolith Pull Test Results . . . . . . . . . . . . . . . . 69

4.6 Comparison of Bolt Types and Displacement in Regolith . . . . . . 69

4.7 Pull Test Success and Displacement Rates' Dependency on Water Con-

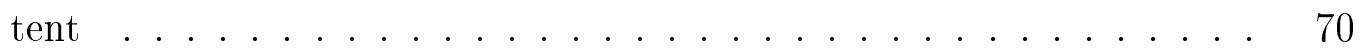

4.8 Pull Test Success and Displacement Rates' Dependency on Temperature 71

4.9 Pull Test Success and Displacement Rates' Dependency on Compactive

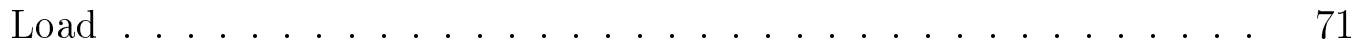

4.10 Summary of P-Test Results $\ldots \ldots \ldots \ldots \ldots$ 


\section{Chapter 1}

\section{Introduction}

\subsection{New Horizons for an Old Discipline}

The fields of mining engineering in general and rock mechanics in particular have long been concerned with what was below the ground, with little consideration given to that which lies above. As NASA plans its missions to Mars and SpaceX continues to lower launch costs into space, however, mining engineers have increasingly begun considering possible extraterrestrial applications for their field, including in the development of in situ resource utilization technologies and the potential mining of asteroids, the Moon, and Mars. One technology that could be readily adapted to space applications originates in roof support. Rather than preventing mine roofs from collapsing, however, roof support technology could instead be used to ensure equipment and operators stay tethered to the orbital body on which they are working instead of drifting into space. These anchors, in turn, would serve as a primary mission assurance safeguard against the failure of multi-million or multi-billion dollar missions and projects dependent on the success of a single satellite, lander, or operator. Working in a hard vacuum with minimal gravity and operating temperatures varying between $-373^{\circ} \mathrm{F}\left(-225^{\circ} \mathrm{C}\right)$ and $333^{\circ} \mathrm{F}\left(167^{\circ} \mathrm{C}\right)$ creates a whole new set of design challenges where mining engineers can expand upon rock mechanics and existing roof support methods to develop a new generation of anchoring technologies that can lead to advancements both in space and on Earth (Williams 2015b). 


\subsection{Motivation for Study}

Both the danger of mission failure and the role of anchorage in preventing it have direct consequences on missions to low-gravity bodies such as asteroids, comets, or Mars' moons Phobos and Deimos. The second component of the Asteroid Redirect Mission (ARM), the Asteroid Redirect Crewed Mission (ARCM), will involve astronauts working with, around, and on an asteroid boulder with negligible mass (Mazanek et al. 2016). This mission, and others like it, will require astronauts or satellites to anchor themselves and/or their equipment to the small body to ensure they do not drift away. This situation therefore presents a promising opportunity for the mining engineering community to provide its decades of knowledge of anchoring in rock to provide new perspectives to the space community in order to mitigate mission failure and ensure astronaut and equipment safety.

The field of rock anchoring has been a mainstay within the discipline of mining engineering for years, with bolting practices in mines beginning as early as 1940 (Peng 1998). The study of rock bolt design has led to multiple developments in drilling techniques and anchoring designs that have additionally increased mining engineers' understanding of rock mass behavior. These advancements have culminated in the development of the fully-grouted roof bolt, wherein a roof bolt is completely encased by a grouting resin to increase the compressive stresses applied to the rock by the bolt. Little is currently known, however, about how resins or bolts might behave in space environments. This thesis will therefore conduct an exploratory analysis of the application of mine roof support anchors for satellite anchoring on asteroids. The study will also provide an initial comparison between anchorage mechanisms to identify the mechanism most suitable for further study as a potential anchoring method. This thesis will therefore begin by surveying engineering literature in order to identify a case study of the need for innovation in anchoring for missions to small orbital bodies, as well as a discussion of roof support theory, the different types of roof bolt systems currently in use, and possible conditions with which an anchor may interact on an asteroid. It will then move into a discussion of the experimental 
design of this project in order to test multiple roof bolting techniques under different anchoring conditions that may be encountered in space. The experimental design and testing sections will then be followed by results and a comparative analyses of bolt and resin performances at different conditions that could possibly occur on a small orbital body, including novel findings in the use of roo bolt anchoring in these applications. The thesis will then conclude with recommendations on how to take this first-order examination to the next round of testing in order to provide NASA with a more robust anchor design. 


\section{Chapter 2}

\section{Literature Review}

\subsection{A Case Study of Anchoring Mechanisms Cur- rently Used in Space Applications}

Lander technology has a long history at NASA of unanchored support. Beginning with the Surveyor and Apollo missions to the Moon, landers have been consistently designed to land on footpads that structurally support the lander and sink into the regolith under the lander's weight, but provide no anchoring force (Rogers 1972; Williams 2006). Even the landers of today and tomorrow fall along this design, with NASA's Project Morpheus and Mighty Eagle both following the same Apollo-era pattern of circular strut-mounted platforms as lander footpads (Olansen et al. 2013, McGee et al. 2013). This design has stayed largely consistent primarily due to a lack of need for advanced anchoring. All of these systems were developed to land on the Moon or Mars, where gravity, respectively $16 \%$ and $36 \%$ of that on Earth, is still powerful enough to hold a lander on its surface (Williams 2015b). The same cannot be said, however, for asteroids and comets.

There have currently been two missions, one to an asteroid and the other to a comet, which contained a planned interaction with the planetary body's surface: Hayabusa, which returned a sample of the asteroid Itokawa, and Philae, which landed on the comet 67P/ Churyumov- Gerasimenko (Bertini 2013). The landing gear and 
anchoring strategies for these missions, however, have varied based on the mission's intent and location. Fujiwara et al. (2006) states, for instance, that Hayabusa was designed so that the satellite would not land, but only obtain a sample of Itokawa. The Philae lander, meanwhile, was specifically intended to anchor to the comet $67 \mathrm{P} /$ Churyumov- Gerasimenko (Ulamec and Biele 2009). The subsequent landing of Philae as a part of the Rosetta mission demonstrates the importance of reliable anchoring systems that can deploy on command (see Figure 2.1).

The first step in Philae's anchoring system involved firing a cold gas thruster as Philae approached 67P in order to minimize bouncing on the comet's surface (Biele et al. 2006). Philae's dual anchoring design called for ice screws (see Figure 2.2) with a double helix design in each of the three feet of Philae's landing tripod and two anchoring harpoons on the main body, all of which would deploy upon contact with the ground in order to provide redundant anchoring systems. The ice screws would drill into the comet using a pulley system activated upon touchdown in regolith with $1-100 \mathrm{kPa}$ compressive strength while the thruster continued to push the lander onto the comet surface. The harpoon, fired as the lander approached the comet, would anchor in the comet and the tether would retract to provide 5 to $25 \mathrm{~N}$ of anchoring tension. Previous laboratory tests had demonstrated that the harpoon could penetrate $\mathrm{H}_{2} \mathrm{O}$ ice with a penetration resistance of $10 \mathrm{MPa}$ and sintered $\mathrm{CO}_{2}$ ice with a penetration resistance of 6.5 MPa (Biele and Ulamec 2013; Biele et al. 2006; Kömle et al. 2001; Spohn et al. 2015). The ice screw systems were rated for $2 \mathrm{kPa}$ - $2 \mathrm{MPa}$ compressive strength, with possible mission failure should the compressive strength be less than $100 \mathrm{~Pa}$ or more than $2 \mathrm{MPa}$ (Biele and Ulamec 2013). 


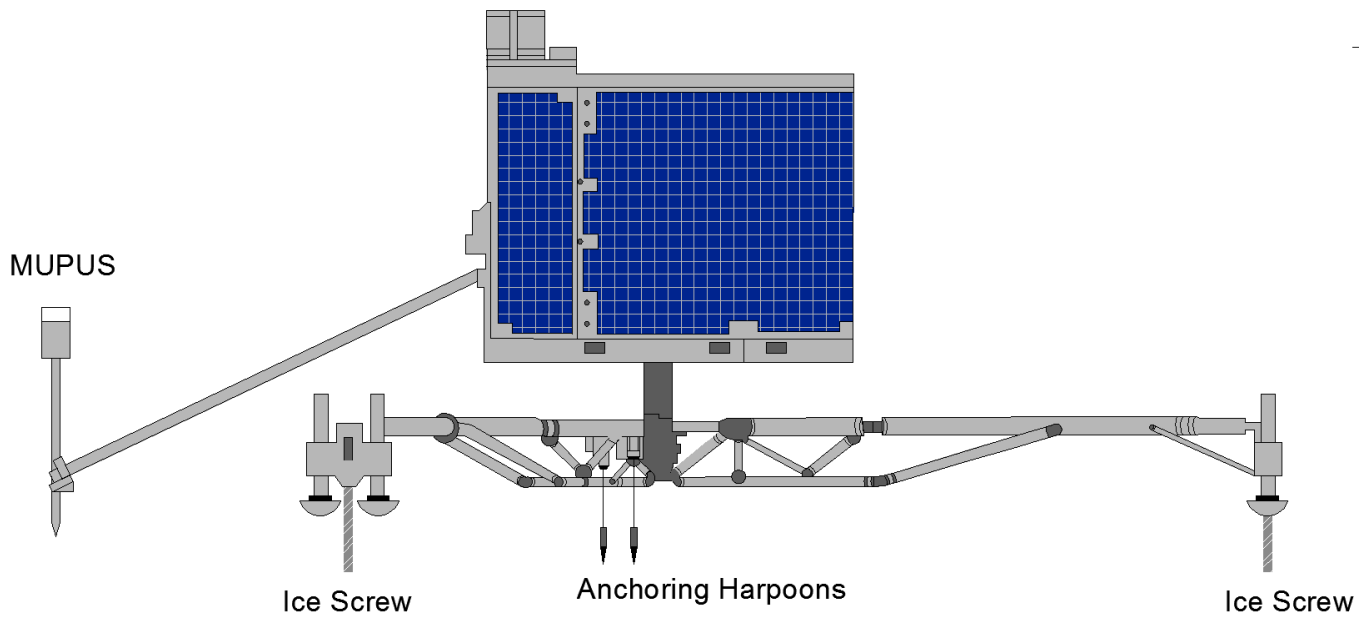

Figure 2.1: Philae Lander and Its Critical Anchoring Equipment (after Biele et al. 2009)

The Philae ground crew reported that several anomalies occured with the landing system that resulted in a subnominal landing and anchorage failure (Biele et al. 2015). As Philae approached touchdown, its cold gas thruster did not engage and its harpoons failed to deploy, thereby removing the main reaction force and anchors that would have counteracted possible bouncing dynamics. Upon contact, at least one ice screw deployed into the regolith approximately $50 \mathrm{~mm}$, while another lander foot's ice screw may have either penetrated the regolith up to $10 \mathrm{~mm}$ or made contact with a 1-m sized boulder. It is unknown if the third foot and ice screw penetrated the regolith due to a lack of lighting in images from Philae. It is known, however, that the ice screws did not penetrate the regolith with enough depth/anchoring force to successfully oppose the normal force applied to the lander by the comet, leading to the initiation of bouncing dynamics. The subsequent trajectory of Philae led to a potential collision with a crater rim, a second touchdown and bounce, and a final touchdown one hour and fifty-seven minutes later at its final resting place, Abydos. 


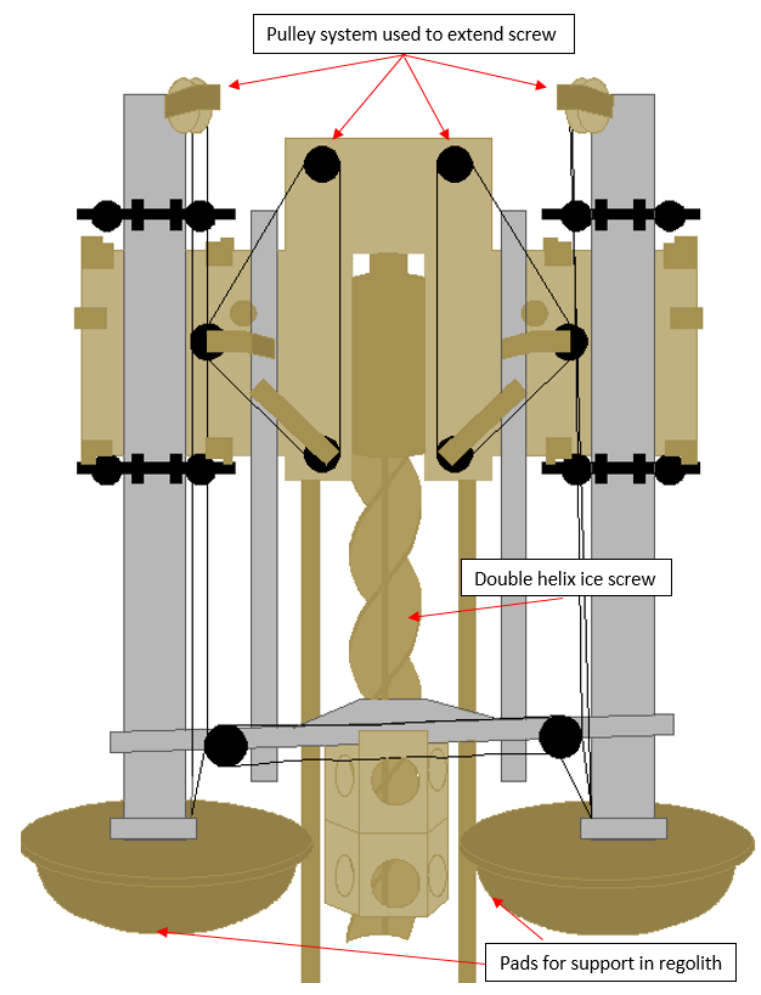

Figure 2.2: Ice Screw Design (after Ulamec and Biele 2009)

A thermal probe, the MUPUS-PEN, was designed to enter the regolith via a hammering mechanism and initiated hammering at an energy level of $0.49 \mathrm{~J}$ (Spohn et al. 2015). Hammering progress halted after penetrating the first $27 \mathrm{~mm}$ of the comet's surface (a possible dust layer) and was unable to further penetrate the comet's surface material at Abydos despite increasing the energy setting to $1.59 \mathrm{~J}, 2.17 \mathrm{~J}$, or $4.23 \mathrm{~J}$. As a result, the MUPUS team concluded that the local cometary surface had a resistance of penetration larger than $4 \mathrm{MPa}$ and a uniaxial compressive strength larger than $2 \mathrm{MPa}$. The Rosetta orbiter and Philae lander were able to subsequently complete their science missions with resounding success (Fantinati and Geurts 2015). However, the mission does provide some additional insight for future anchor design. Since the initial harpoon anchors failed to deploy, we may never know if they would have successfully penetrated the comet's surface. The entire mission itself cost $€ 1.4$ billion, or $\$ 1.86$ billion (European Space Agency 2014). Had Philae suffered irreperable damage from its various contacts with the surface of $67 \mathrm{P}$, or had the lander 
bounced in such a way that its trajectory led it to completely bounce away from the comet, the failure would have resulted in a major loss of the time and money invested in the project by the Rosetta team, as well as a loss of much of the previously anticipated scientific data. This case study therefore establishes the groundwork for a need for a robust anchoring plan when designing a satellite for small body operations.

\subsection{Roof Support and Anchoring}

\subsubsection{Theories of Roof Bolting}

Anchorage in underground mines, unlike on asteroids, has an extense history of trial and development. The exact nature of roof behavior after excavation has been studied since the adoption of roof bolts in coal mines in the 1940's, though bolting had earlier been applied in German coal mines in 1918 and lead-zinc mines in Missouri in the 1930's (Lang et al. 1979). Studying the nature of mine roof behavior has subsequently allowed for the development of mine roof support systems, the behavior of which will be examined in this study. Underground mines require extensive roof support in order to prevent the mine roof from collapsing under the weight of the overburden located above the mine. Multiple theories - elastic and plastic deformation, beam building, plate behavior, and roof arching - attempt to describe the general behavior that follows this stress relaxation. However, geologic conditions and pillar designs varying from mine to mine show that different failure phenomena dominate roof behavior under different mining conditions, and that one theory alone cannot fully describe the failure of mine roofs.

Upon excavation, the stresses in the rock surrounding a mine entry relax because the mass that initially confined the rock along the entry has been excavated, thereby removing the confining force initially opposing the stresses within the rock. The excavated opening in the rock mass therefore begins to relax, or "creep", and undergoes a series of failure mechanisms by either fracturing outright or undergoing a cataclastic flow until the opening has either closed or reached a point of stability. Mine roofs 
undergoing cataclastic flow sag at the centerline of the entry as the rock displaces vertically downwards, while at all other points along the roof the rock flows vertically and horizontally towards the center of the opening (Peng 2008). This buckling, the result of tensile and shear stresses, can occur along bedding planes and laminations both in rock strata and along beams. As shear and compressive stresses increase, the roof takes on arching action, wherein the roof and ribs begin to fracture around the entry to form a more stable arch shape. The roof will then reach temporary (possibly permanent) stability until utlimately resulting in caving and a collapse of the mine roof. The application of a roof bolt can counteract this series of events by applying compressive forces to the rock in which it is anchored, while the bolt itself is in tension.

Mark (2000) and Peng (2008) offer an authoritative examination of mine roof reinforcement mechanisms. Mark (2000) identifies four different reinforcement mechanisms in which roof bolts may be employed: simple skin control, suspension, beam building, and supplemental support (see Figure 2.3). In skin control operations, the mine roof is composed of strong, competent rock that can effectively support itself as the mine is developed. In these instances, roof bolts are primarily used to prevent localized failure along joints, cracks, or faults by bolting across the failure plane to effectively prevent rock falls. Peng (2008) highlights how roof conditions that require beam building and suspension typically consist of strata with laminations or bedding planes where failure is likely to occur. Bedded planes overlain by a competent rock are bolted together and supported from the competent rock to prevent movement along the rock's bedding planes and laminations. Thinly bedded strata without a competent overlying rock are bolted together so that they collectively form a beam, using friction to minimize horizontal movement along the bedding planes and compression to hold together fractured rock masses. Finally, mine roofs can become extremely fractured or stressed, leading to advanced roof failure. Cable bolts, trusses, and standing supports can therefore be used to bear the actual load of the roof, while roof bolts themselves primarily act as a skin control mechanism against immediate roof failure. 
A

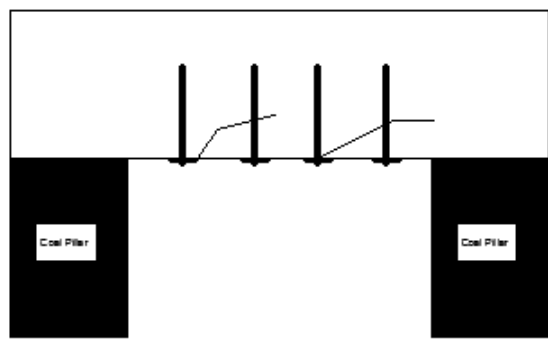

C

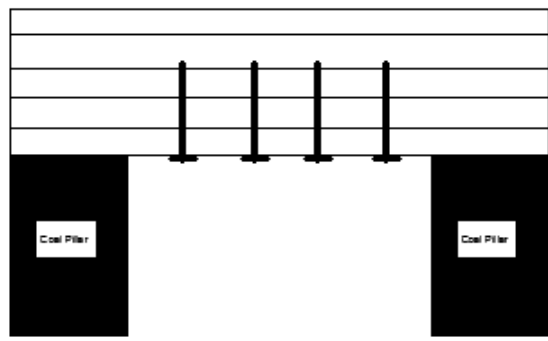

B

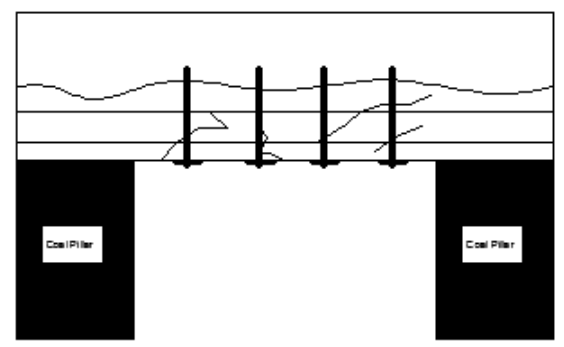

D

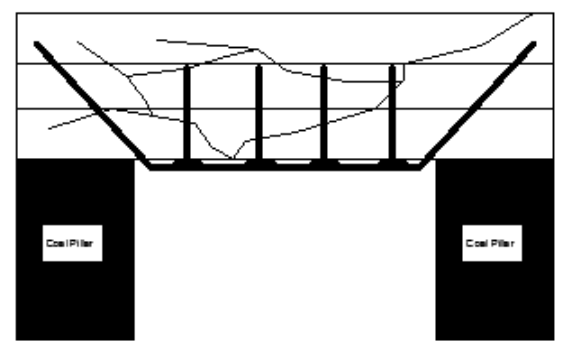

Figure 2.3: Roof Reinforcement Mechanisms (after Mark 2000)

A. Simple skin control; B. Suspension; C. Beam building, and D. Supplemental support

\subsubsection{Bolt and Anchorage Types}

Mark (2000) and Peng (2008) additionally provide a detailed examination of roof bolt types and anchorage mechanisms. Peng (2008) identifies two basic types of roof bolts that are used for mine roof support: point/mechanical/conventional and fullygrouted resin bolts, as well as combination bolts, tensioned rebar bolts, resin-assisted mechanically anchored bolt, and cable bolts. Bolts can additionally be classified by anchorage mechanism (point anchor or resin), with bolts other than mechanical and resin bolts existing as variations of these two mechanisms and sometimes utilizing both concepts. Mark (2000) specifically highlights that bolts do not provide specific reinforcement mechanisms. Instead, the reinforcement mechanism required and bolt selection are determined by the geology and stresses of the mine roof. Table 2.1 compares the anchorage methods and designs of these various types of bolts, while Figure 2.4 offers a visualization of how these bolts operate.

Mechanical roof bolts were the original type of roof bolt used in early bolting plans (Peng 2008). These bolts consist primarily of a smooth shank with threads at 
Table 2.1: Roof Bolt Classifications (after Mark 2000; Peng 2008)

\begin{tabular}{cccc}
\hline Bolt Type & Anchoring Mechanism & Bolt Surface & Tension \\
\hline Point-anchored bolt & Mechanical (shell anchor) & Smooth & Yes \\
Point-anchored, resin-assisted bolt & Mechanical (shell anchor encapsulated in resin) & Smooth & Yes \\
Combination bolt & Resin (point) & Rebar and smooth & Yes \\
Tensioned rebar bolt & Resin (point or fully) & Threaded/rebar & Yes \\
fully-grouted resin bolt & Resin & Threaded/rebar & No \\
Cable bolt & Resin (point or full) & Cable & Yes \\
\hline
\end{tabular}

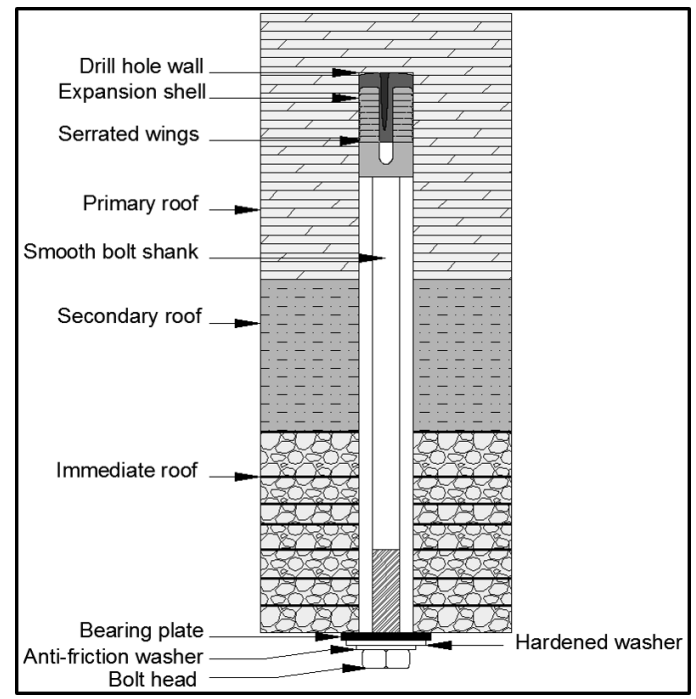

(a) Mechanical bolt (after Peng 2008)

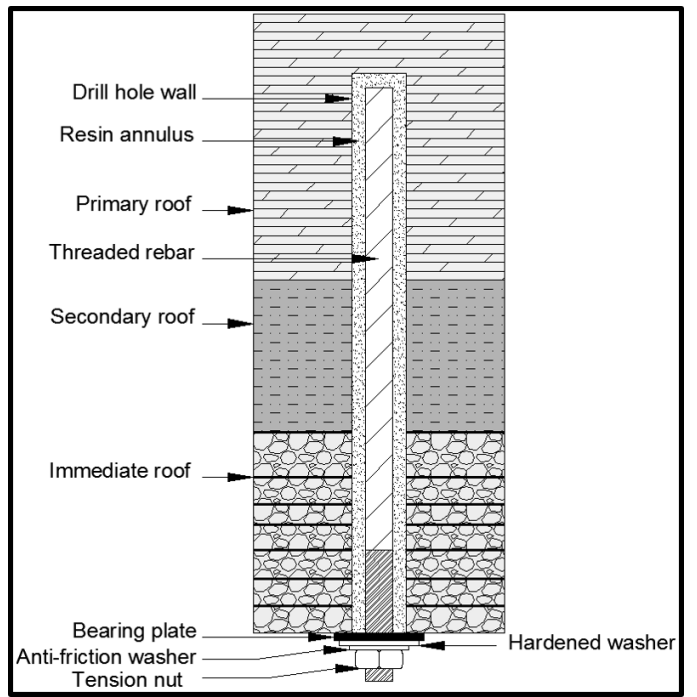

(b) fully-grouted resin bolt (after Peng 2008)

Figure 2.4: Bolt Installation Layout 
one end and a bolt head at the other, as well as an anchor shell threaded onto the shank and a bearing plate and low-friction washer located adjacent to the bolt head (Lang et al. 1979). Anchor shells used a wedge shape to drive the anchor's wings into the bolt hole in the past, and now also include serrations on the wings/leaves of the shell to ensure increased gripping along the bolt hole walls. After the bolt hole is drilled, the bolt is installed and rotated by a roof bolter to achieve a predetermined level of torque that places the bolt under tension and the surrounding rock under compression (Mark 2000). The low-friction washer assists this action by lowering the resistance between the bearing plate and the bolt head. The shank of the bolt throughout this process does not contact the drill hole wall, instead transferring the load to the anchor shell and the collar. Additionally, purely mechanical bolts are rarely used in U.S. mines in contemporary times as mine operators instead opt for mechanically anchored, resin-assisted bolts. These bolts are installed with high bolt tension by combining the advantages of mechanical bolts' fast installation and resin bolts' anchorage capacity.

The other class of bolts, resin bolts, offers an improvement on conventional bolt anchorage. Peng (2008) highlights that fully-grouted roof bolts are often much stronger than their surrounding rock strata, in large part because the concept of the resin bolt developed in order to counteract large shear forces experienced in certain loading conditions by providing anchorage along the full bolt length (Bureau of Mines 1987). After a bolt hole is drilled, a tube of 2-part resin is inserted in the hole. Then, a bolt is installed to rupture the resin tube and rotated to mix the resin mastic and catalyst. The resin cures and provides maximum frictional interlocking between the bolt surface, the grout particles, and the rough rock surface of the hole's wall (Mark et al. 2001; Signer 1990). Adhesion only plays a smaller, secondary role to the interlocking of rock, bolt, and grout. Longer bolt lengths then provide larger surfaces along which the grout can distribute this frictional interlocking and shear resistance to rock movements. Ensuring the bolt is long enough to distribute the load properly is therefore critical to bolt size selection. Additional factors contributing to the grout's ability to interlock with the rock particles include the hole annulus, bolt hole 
rifling, and bolt diameter (Mark et al. 2002). Rifling the bolt hole, increasing the bolt diameter, and using bolts with rebar-like patterns, for instance, increases the rough surface area with which grout can interact. An annulus size of 0.125 in., meanwhile, provides the optimum spacing for grout to interact with both the bolt and rock face. Signer (1990) concurs with this assessment, while Jalalifar et al. (2005) also include confining pressure, as well as rock and grout strength.

Two subsets of fully-grouted resin bolts exist as well: the point-anchored and fullyanchored tensioned rebar bolt (Mark 2000; Peng 2008). In fully-grouted tensioned rebar bolts, two resins are installed so that the anchor point cures faster than the bolt's shank and provides the point from which the rest of the bolt shank is tensioned prior to final resin curing. In point-anchored tensioned rebar bolts, meanwhile, a shorter resin cartridge is used to create a point anchor reminiscent of a mechanical anchor at the anchoring point, while the rest of the shank remains ungrouted and transmits tension between the anchor and bolt head. There is still considerable debate over the role of tension during the installation of resin bolts, with Mark (2000) examining both those who believe that installing pre-tensioned resin bolts further increases their yield capacity, as well as those who oppose this idea. At the end of this examination, however, there is insufficient evidence on both sides to definitively settle the argument. Additionally, there is a lack of comparative studies between the three methods and the use of anecdotal evidence where variables in the bolt design may not have been held constant as primary reasons that neither side can be validated at this time.

Finally, cable bolts operate under conditions where normal bolt designs will not offer sufficient support (Peng 2008). These bolts are typically employed in extremely weak rock or where the required length for suspension is much longer than what mechanical or resin bolts can provide. Comprised of one central strand surrounded by six supporting strands, the cable bolt is installed with resin and consequently generates much higher anchorages than mechanical or resin bolts. One variation of the cable bolt, the polyurethane injectable cable bolt, was developed in order to encapsulate the bolt against corrosion (Faulkner 2012). An unintentional benefit found while deploying these bolts is the polyurethane's ability to permeate roof cracks and fissures, 
thereby improving roof stability and minimizing the volume of water leaking into the mine. Injected polyurethane may expand or maintain its original volume depending upon the specific chemical reactions involved (Craig and Murnane 2013; Snuparek and Soucek 1999). Polyurethanes with higher expansion ratios, and thus larger volumes of froth, possess lower compressive strengths than those with a 1:1 expansion ratio. For instance, Snuparek and Soucek (1999) found that the UCS of polyurethane resins decreased from $\sim 75 \mathrm{MPa}$ to $\sim 25 \mathrm{MPa}$ with an increase in the expansion factor from 1:1 to 1.5:1. The integration of polyurethane with the surrounding rock grains and fissures creates a conglomerate "geocomposite" (Bodi et al. 2012). The strength of these geocomposites in large part depends on the degree of cementation around the rock grains, which can vary from fully encapsulating a particle to only binding the interconnected pores between grains. This cementation is also dependent on the grain density and expansion ratio, since froth bubbles will decrease the amount of polyurethane bonding two interfaces while extremely compacted grains may prohibit polyurethane from penetrating between the grains' contact interfaces.

\subsubsection{Bolt and Anchorage Failure Mechanisms}

Resin bolt failure typically occurs due to movements in the roof (Mark et al. 2002). The bolts typically fail either at the bolt head/mounting plate; along the bolt length due to tension and/or bending; or at the point of anchorage. Points of anchorage for grout bolts are typically at the tip of the roof bolt. Hartman and Mutmansky (2002) discuss several of the benefits of resin anchor bolts as opposed to purely mechanical bolts. Rock lining the bolt hole often splits above the mechanical anchor and is crushed at the anchor itself, allowing the anchor to slowly pull out. Resin anchors, by contrast, do not split the rock above the anchor and do not create stress concentrations at the anchor. Bolts will also tend to elongate under load and will concentrate stress at the bearing plate and bolthead of a mechanically anchored bolt. Resin bolts will only elongate for a short length due to their rebar composition and will not concentrate stress at the bearing plate. Because resin bolts do not create the stress concentrations, rock fractures, or experience the elongation of mechanical 
bolts, resin anchor bolts are a stronger and more reliable choice of anchoring bolt.

Signer (1990) examined resin anchor failure and found that, if the grouted bolt is of an adequate length and properly installed, failure generally occurs when the maximum load on the bolt exceeds the yielding load of the steel. This study found that yield zones in the rock along bolt lengths can vary from 4 to 22 in., thereby requiring lengths in excess of 22 in. in order to ensure loads can be transferred from the bolt to the surrounding rock strata. Mark et al. (2002), meanwhile, surveyed literature for anchorage pullout tests and found that, according to a study from the Bureau of Mines, roof bolts needed to have an average of 31 in. of grouted length when in coal or shale seams in order for $90 \%$ of tested bolts to fail due to the yield load of the steel, rather than insufficient anchorage length. Sandstone required an average of $18 \mathrm{in}$. of bolt length, while limestone required $12 \mathrm{in.} \mathrm{of} \mathrm{bolt} \mathrm{length.} \mathrm{The} \mathrm{key} \mathrm{is}$ thus ensuring proper load transfer. Ensuring resin bolts are sufficiently long enough and contain enough grout to properly support the surrounding rock makes ultimate failure contingent upon the type and diameter of the steel used in the bolt. While bolt failure is the primary concern in mechanically anchored bolts, it is also necessary to consider the surrounding geology, rock movements, and proper installation, as any of the above could lead to crushing at the anchor site, the release of tension on the bolt, or anchor creep and premature bolt failure (Mark 2000).

\subsubsection{Bolt Design and Anchoring Test Method}

Despite the variations in bolt anchoring methods and load transfer mechanisms, bolt length, bolt capacity, and anchorage strength are critical design factors across classes of bolts. Mark et al. (2001) utilized statistics from roof bolt case studies to develop a roof bolt design program called Analysis of Roof Bolt Systems (ARBS) to evaluate the overall bolting plan based on these inputs. Additionally, ARBS considers geologic properties such as horizontal stress, depth of cover, and rock mass rating (RMR), as well as bolting pattern design parameters including the span of the mine roof to be supported, the entry width, the number of bolts per row of bolting, and the spacing between those rows. The length of bolt calculation $L_{B}$ for ARBS, however, is 
a logarithmic equation based on the roof span $I s$, coal mine roof rating (CMRR) or RMR, and the depth of cover $H$ such that

$$
L_{B}=\left(\frac{I s}{13}\right) * \log _{10} H *\left(\frac{100-C M R R}{100}\right) 1.5
$$

A similar but earlier study by Mark (2000) examined some empirical-based models of bolt length from Lang and Bischoff (1982); Bieniawski (1987); Unal (1984), such as

$$
\begin{gathered}
L_{B}=I s^{\frac{2}{3}} \\
L_{B}=\frac{I s}{3} \\
L_{B}=\left(\frac{I s}{2}\right) *\left(\frac{100-R M R}{100}\right)
\end{gathered}
$$

Mark (2000) then based a bolt length design upon a beam building model and the equation from Unal (1984) and converted it to metric units so that

$$
L_{B}=0.12 *(I s) *\left(\log _{10} 3.25 H\right) *\left(\frac{100-C M R R}{100}\right)
$$

The principle behind all of these studies and equations, however, is the dependence of bolt length upon the roof span and RMR/CMRR without any direct measures of the mechanisms working at the individual bolt level. No direct meaning is ascribed to a bolt's anchorage ability, but only to its yield capacity $C$ described as

$$
C=\left(\frac{\pi}{4}\right) * G * d^{2}
$$

where $G$ is the grade of steel in thousands of psi and $d$ is the bolt's cross-sectional diameter. Mechanical bolt anchorage is generally considered synonymous with yield capacity, with pullout tests showing anchorage adequate if the pullout load exceeds the yielding capacity of the bolt. While anchor creep can lead to bolt failure, this 
scenario is unlikely in mechanically anchored, resin-assisted bolts.

Amongst resin bolts, meanwhile, a standard pullout test might only result in the breakage of the bolt since fully-grouted resins can exceed the yielding capacity of the bolt, and so these tests provide little useful information on anchorage (Mark et al. 2002). As a result, a method was developed for calculating the required bolt length to provide enough surface area for grouted resin to effectively resist rock movements. These tests, dubbed short encapsulation pullout tests (SEPTs), are performed on grouted bolts in which the bolt's top 12 inches are grouted within the bolt hole. After a bolt hole has been drilled, a 12 in. resin cartridge is inserted in the bolt hole. A bolt with a pulling harness on it is then installed in the hole and the resin allowed to set. After the resin has cured, a handpump incrementally applies a load to the bolt until the bolt pulls out of the resin. The load at which the bolt pulls out is known as the maximum SEPT load.

This study identified an equation for the "Gripping Factor", also known as the "Bond Factor", defined as the bolt's resistance to pullout per inch, by dividing the maximum SEPT load by the 12 inches of anchor:

$$
G F=\frac{S E P T}{12}
$$

The authors then describe several different types of bolt length: anchor length, full resistance length, and total bolt length. Total bolt length $L$ is the nominal bolt length specified by the user. The anchor length $L_{\text {Anch }}$ is described as the length of the bolt active in the anchoring process, while the full resistance length $L_{F R}$ is the bolt length where a force equal to or greater than the bolt's yielding load actively resists rock movement. The anchor length and full resistance length equations therefore relate to the gripping factor such that

$$
\begin{gathered}
L_{A n c h}=C / G F \\
L_{F R}=L-L_{\text {Anch }}
\end{gathered}
$$


These equations provide a method of designing a resin anchoring system to meet a maximum load based on the resin anchor length that can then be compared to experimental results for quality control and assurance. The SEPT results applied to a given resin bolt length can then be compared to the pullout test results from a mechanical bolt to identify under which conditions either system might develop stronger anchorage.

\subsubsection{Resin and Bolt Performance in Extreme Environments}

Mechanical and resin bolts are used in various operational environments around the Earth, and manufacturers often provide data on their products' capabilities to customers. Any data on operations in low temperatures would therefore provide critical information on the applicability of this technology to the low $\left(-94--328^{\circ} \mathrm{F}\right.$, $70--200^{\circ} \mathrm{C}$ ) temperature environment of space. The U.S. Bureau of Mines has found that, while resin strength decreases at a high rate when temperatures exceed $100{ }^{\circ} \mathrm{C}$, compressive strength increased with decreasing temperature up to $0^{\circ} \mathrm{C}$ (Bureau of Mines 1987). Figure 2.5 displays the data found in the Bureau of Mines report.

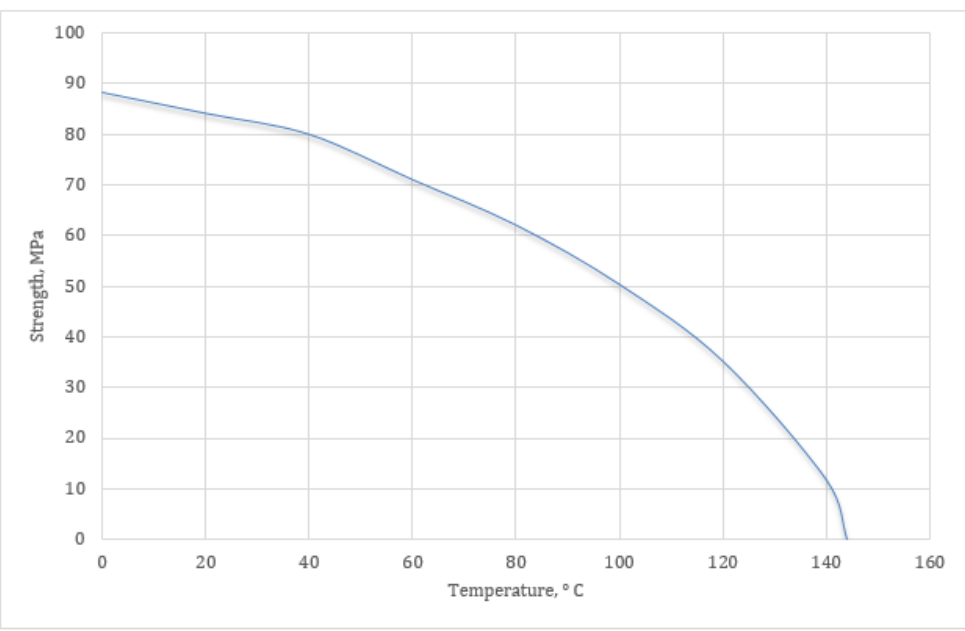

Figure 2.5: Resin UCS as a Function of Temperature (After Bureau of Mines (1987))

At temperatures below $0{ }^{\circ} \mathrm{C}$, the literature regarding resin performance becomes much less clear. Williams Form Engineering Corporation (2014) states that resin 
cure time is dependent on temperature and requires $15-30$ minutes to cure at $10^{\circ} \mathrm{C}$. Due to their instructions to allow temperatures to "normalize" at $10-21^{\circ} \mathrm{C}$ for two days prior to use if stored at low temperatures, it can be inferred that these resins would require longer curing times at the present study's target low temperatures. Similar warnings from the manufacturer of bolts and resins Minova America stress the temperature sensitivity of resin gel and cure times, which are based at $22^{\circ} \mathrm{C}$ and increase in cure time as temperatures decrease (Minova Americas 2009). With similar warnings of normalizing temperatures prior to use, both Minova and DSI recommend their respective products for use at temperatures down to $14^{\circ} \mathrm{F}\left(10^{\circ} \mathrm{C}\right)$ (DSI 2009). Though Orica International provides similar recommendations to the other three providers, they also provide a characterization of how the amount of time required for the resin to remain undisturbed after mixing changes with decreasing temperature (Orica International 2014). This characterization can be seen in Table 2.2 .

Table 2.2: Hold Time Variation with Temperature (After Orica International 2014)

\begin{tabular}{ccc}
\hline Temperture, ${ }^{\circ} \mathbf{C}$ & 30 Second Resin Hold Time, $^{\text {s }}$ & 60 Second Resin Hold Time, $\mathbf{s}$ \\
\hline 18 & 25 & 50 \\
16 & 30 & 55 \\
14 & 35 & 60 \\
12 & 50 & 75 \\
\hline
\end{tabular}

Most resins have not been tested at the low temperatures anticipated for space applications since underground mines tend to increase in ambient temperature with depth due to the thermal gradient of the rock. Compton and Oyler (2005) do mention that, as part of their experimental process to isolate variables, several bolts were installed with resin at either room temperature, a cold temperature, or with both cold resin and cold bolts in order to identify possible mechanisms for increasing the difficulty of installing bolts. Though not a quantitative analysis, theirs found that temperature did not significantly affect the difficulty of roof bolt installation. Construction industry standards for similar resin anchors to those used in mining, however, do exist for low temperature situations. Hoermann- Gast and Olsen (2015) 
states that the ACI 355.4 standards on post-installed adhesive anchors recognizes that tests for adhesive anchors installed in concrete may experience temperatures as low as $-40^{\circ} \mathrm{C}$, and that this lower temperature limit is not necessarily indicative of anchorage problems at lower temperatures, but purely the limit of existing data.

\subsection{Exogeologic Characteristics of Planetary Bodies}

The physical properties of moons, asteroids, and comets differ between themselves and within their own classes. Our knowledge of the properties of these bodies stems primarily from remote observation, as well as samples that have fallen to Earth and missions to those planetary bodies. The following sections compare the mineralogy, density, and porosity of asteroids, comets, and Earth's Moon to establish a baseline for the possible operating conditions of roof bolt-based anchoring technology used in space. It then concludes with a discussion of asteroid and comet material strengths.

\subsubsection{Mineralogy}

Asteroids are classified according to spectral reflectance type (Nelson et al. 1993). These types, in turn, belong to asteroid "groups". The overwhelming majority ( $92 \%$ ) of asteroids fall into the C-, S-, and X-group categories (Williams 2015a). Additional groups according to the Tholen typology of spectral reflectance classification are the A-, D-, Q-, T-, V- and R-groups. The C-, S-, and X-groups can further be divided into several asteroid type categories, while the other groups all only contain their own nominal type category. While each asteroid type typically consists of at least some olivine and pyroxene minerals, the range of content of these minerals varies according to asteroid type. This degree of variation is in large part because many of the mechanisms at play during asteroid formation, such as igneous heating and metamorphic pressures from collisions, follow a mineralization scheme given by Bowen's reaction series (Blatt et al. 2006). Bowen's reaction series classifies the formation processes of minerals based on the maximum temperature to which a mineral was heated before it cooled. Mafic minerals form at higher cooling temperatures than felsic minerals, thus 
allowing the Bowen reaction series to provide an estimation of the formative temperatures of a rock or asteroid and some indication of the formative events. Though each asteroid type contains materials that distinguish each type from other asteroids outside of its type, it should not be assumed that asteroid type is indicative of mineralogy across all members of the asteroid type (Gaffey 2011). C-type asteroids, for instance, are expected to contain ice, amino acids, and carbonaceous materials, while M-type asteroids contain mostly metals and S-type asteroids contain both metals and silicates in such a wide range of ratios that multiple subgroups have been created for the S-type category (Chabot et al. 2014; Williams 2015a). C-type asteroids such as 2008 EV5 are anticipated to be the primary target type of future missions to asteroids due to their anticipated content of water and volatile gases. Table 2.3 further expands on the relationship between asteroid type and surface mineralogy.

Comets, like asteroids, contain many minerals generated from the cooling of molten materials. An examination of material sampled from Comet Halley has revealed the presence of silicates, crystalline olivine, amorphous olivine, enstatite, and orthopyroxene (Hanner and Bradley 2004). As mentioned in Section 2.1, Spohn et al. (2015) have assessed the presence of both water and dry ice intermingled with silicate dust to occur on comet $67 \mathrm{P} /$ Churyumov-Gerasimenko based on initial results from the Philae lander. Ice content of comets generally exceeds that anticipated for asteroids, thereby leading to comets actively gassing off water ice as they draw nearer to the Sun (Chodas and Baalke 2014). This phenomenon and ice content in general are therefore key factors defining the difference between the two types of bodies. 
Table 2.3: Asteroid Mineralogy and Meteorite Analogs (After Nelson et al. (1993))

\begin{tabular}{ccc}
\hline \multicolumn{2}{c}{ Inner Belt Asteroids } \\
\hline Type & Interpreted Surface Mineralogy & Meteorite Analogs \\
\hline V & Pyroxene, feldspar & HED association \\
A & Olivine or olivine-metal & Brachinites \\
S & Metal, olivine, pyroxene & Pallasites, mesosiderites, CV/CO chondrites, OC \\
M & Metal, trace silicates, enstatite & Irons, enstatite chondrites \\
R & Pyroxene, olivine & None \\
B, C, F, G & Hydrated silicates, carbon, organics, silicates & CI, CM chondrites, black/gas-rich OC \\
Q & Olivine, pyroxene, metal & Ordinary chondrites \\
E & Enstatite & Enstatite achondrites \\
\hline & Outer Belt Asteroids & None \\
D & Organic-rich silicates, carbon & None \\
\hline
\end{tabular}

Finally, the mineralogy of Earth's own Moon offers a unique combination of similarities to both asteroid and terrestrial materials. The lunar surface is generally defined by the bright white "highland" and dark "mare" features and, similar to asteroids, contain pyroxene, silicates, and olivine (Schwandt et al. 2012). Additionally, however, anorthsite, basalt, ilmenite, and water-equivalent hydrogen (either water ice or water bound in minerals) have been identified on the Moon as well. These compounds bear particular significance for future missions seeking to use lunar resources for the production of metals, oxygen, and water in space.

\subsubsection{Density and Porosity}

Macroporosity in asteroid studies is calculated as a function of the asteroid's bulk porosity (Britt et al. 2002). Asteroid masses are calculated based on their gravitational impacts on neighboring bodies, while volumes are estimated using effective radii and imaging from spacecraft. Based on the subsequently calculated bulk density, as well as estimated grain densities and microporosities from meteorite analogs, the bulk porosity is then derived. Critically, these calculations assume similar mineralogical compositions not only between asteroids and meteorites, but throughout the asteroid's internal structure as well. The microporosity is then subtracted from the bulk porosity, thus solving for the macroporosity. While a similar method is used 
in rock and soil mechanics, the difference in the definition of these terms leads to major differences in the ratio between micro- and macroporosity (Stolf et al. 2011). For instance, the dataset of soils used in a Brazilian study show that microporosity is nearly always greater than macroporosity. Conceptually, this relationship occurs because the microcracks and micropores will naturally be greater in number than pores large enough to qualify as macropores. Because porosity data for asteroids relies on the definitions and methods used in literature by asteroid scientists, their definitions will be used in the following discussion, with "porosity" being used interchangeably with "macroporosity". Porosity values vary widely between asteroid types. C-type asteroids vary between 38 and $70 \%$ porosity, with an average porosity of $\sim 38 \%$ (Baer et al. 2011; Chabot et al. 2014). M-type asteroids share an average porosity of $\sim 37 \%$. Finally, S-type asteroids vary between 10 and 50\% porosities, with an average of $20 \%$. Porosities also vary within asteroid classes, with Itokawa, a representative sample of S-type asteroids, displaying a porosity of $40 \%$ while Ida and Eros, also S-type asteroids, have porosities of $20 \%$ (Michikami et al. 2008).

Mathematical models using grain densities from meteorite analogs and estimates of asteroid volume have been used to model porosity within asteroids, though it has been previously indicated that internal concavities were not considered in some studies (Baer et al. 2011). In addition to "internal concavities", further variations on porosity can occur due to compaction from impacts or the asteroid's potential genetic origin on high-mass bodies. As such, a numerical method of determining porosity should attempt to incorporate variables such as the distribution of heterogeneous compounds, grain packing, cementation, the effects of hydrating previously anhydrous silicates, compaction due to local gravitational/cohesive force effects, or grain sorting due seismic vibration. Density values, meanwhile, are dependent on initial mass and volume estimates. The work by Baer et al. (2011) contains a comprehensive listing of density estimates for specific asteroids, with bulk densities of asteroids as a whole varying between 0.80 and $5.80 \mathrm{~cm}^{3}$.

Comet materials appear to be much more porous than asteroids, with Britt et al. (2006) estimating general comet porosity to range from $55-77 \%$. Spohn et al. 
(2015), meanwhile, cite that a slightly lower estimate of $30-65 \%$ is consistent with the data garnered from 67P. Variations also exist in density estimates, with Britt et al. (2006) estimating densities from 0.18 to $0.62 \mathrm{~g} / \mathrm{cm}^{3}$ and Hughes (1985) citing earlier estimates between 0.5 and $1.1 \mathrm{~g} / \mathrm{cm}^{3}$. Initial results from Philae for 67P vary from $0.44-0.47 \mathrm{~g} / \mathrm{cm}^{3}$ (Biele et al. 2015; Spohn et al. 2015). These results indicate that, in general, asteroids will provide a denser target object to anchor than a comet, potentially requiring a more robust anchor. Table 2.4 consolidates some of these results for ease of comparison.

Table 2.4: Properties of Selected Asteroids and Comets (After Baer et al. (2011); Britt et al. (2006))

\begin{tabular}{ccc}
\hline \multicolumn{3}{c}{ Properties of Selected Asteroids } \\
\hline Name & Density g/cm3 & Porosity, \% \\
\hline Psyche (M) & $6.5-7.9$ & $10-13 \%$ \\
Eros (S) & 2.67 & $20 \%$ \\
Itokawa (S) & 1.9 & $40 \%$ \\
Antiope (C.) & 1.24 & $57 \%$ \\
\hline \multicolumn{3}{c}{ Properties of Selected Comets } \\
\hline 9P/Tempel 1 & 0.62 & $+0.47 /-0.33$ \\
19P/Borrelley & $0.18-0.3$ & $60 \%$ \\
81P/Wild 2 & $0.38-0.6$ & $67-84 \%$ \\
\hline
\end{tabular}

\subsubsection{Regolith Size Distribution}

Asteroid regolith is composed of fine particles thought to be either the remnants of ancient collisions between asteroids or the result of continued comminution of larger coherent masses on asteroids via space weathering effects (Miyamoto et al. 2007). The erosion effects generating regolith include meteor impacts, solar wind ion implantation, and micrometeorite bombardment (Clark et al. 2002). Additional processes that can be considered space weathering mechanisms include thermal fatigue, asteroid rotation, and impact-induced seismic vibrations (Chabot et al. 2014; Dombard et al. 2010; Miyamoto et al. 2007). These mechanisms collectively contribute to the darkening of surface material on asteroids, crater formation, boulder deposition, the breakdown of boulders, and regolith sorting and migration. Impacts from objects as 
small as $1 \mathrm{~cm}$ can potentially induce seismic accelerations on par with a small body's gravitational acceleration. Large impacts, meanwhile, are also believed to have induced regolith migration on the asteroid Itokawa, for instance, by creating seismic vibrations while dispersing regolith ejecta uniformerly around the asteroid surface. While Michikami et al. (2008) state that asteroid regolith is more poorly sorted than lunar regolith, they nonetheless conclude that seismic vibrations led to some particle migration based on size, with finer particles such as pebbles and cobbles migrating towards smoother terrains while boulders remained in place. Extremely fine particles, however, are typically lost to space or segregated to the interior of the asteroid via convection. This process is known as granular convection, wherein the largest rock bodies "flow" to the top of a body of regolith (Miyamoto et al. 2007).

The dynamics of asteroid regolith formation, flow, and ejection are critical to defining the regolith size distribution, or the mass percentage of particles at different particle diameters where those particle diameters are equivalent to a sphere of the same size. No experimentally derived particle size distribution, however, currently exists for asteroid regolith. Within the planetary science community, size distributions for lunar regolith have been used as a proxy for asteroid regolith size distributions (Sanchez and Scheeres 2013). Though asteroid size distributions are thought to trend towards coarser material than lunar regolith, the upper layers of lunar regolith have thus far been found to adequately represent the porosity and mineralogy of asteroid regolith and modelled simulants (Clark et al. 2002; Sanchez and Scheeres 2013). Table 2.5 highlights the individual size fractions and cumulative size distributions for four lunar regolith samples as reported in The Lunar Sourcebook (McKay et al. 1991). Figure 2.6 graphically compares the size distributions of particles in these samples.

\subsubsection{Material Strength of Asteroids}

A critical component in discussing the strength of asteroids and comets is defining "strength". Many terms have been used to qualify "strength", such as "mechanical strength", "material strength", and "bulk strength" (Holsapple 2009; Popova et al. 2011). These terms, meanwhile, have been defined variously as the uniax- 
Table 2.5: Lunar Regolith Size Fractions in Wt.\% (After McKay et al. 1991)

\begin{tabular}{ccccc}
\hline Size Classes & \multicolumn{5}{c}{ Regolith Sample } \\
& 71061.1 & 72441.7 & 15601.96 & 64501 \\
\hline$<\mathbf{2 0} \mathbf{~} \mathbf{m}$ & 17.98 & 25.84 & & \\
$\mathbf{2 0 - 4 5} \mathbf{~} \mathbf{m}$ & 12.21 & 18.79 & 17.37 & 15.6 \\
$\mathbf{4 5 - 7 5} \mathbf{~} \mathbf{m}$ & 8.39 & 12 & 14.45 & 10 \\
$\mathbf{7 5 - 9 0} \mathbf{~} \mathbf{m}$ & 3 & 4.1 & 5.48 & 3.5 \\
$\mathbf{9 0 - 1 5 0} \mathbf{~ j m}$ & 8.66 & 11.02 & 15.99 & 10 \\
$\mathbf{1 5 0 - 2 5 0} \mathbf{~ p m}$ & 7.04 & 8.37 & 13.13 & 8.2 \\
$\mathbf{2 5 0 - 5 0 0 ~} \mathbf{~ j m}$ & 7.08 & 8.55 & 11.91 & 8.9 \\
$\mathbf{0 . 5 - 1} \mathbf{~ m m}$ & 3.44 & & & \\
$\mathbf{1 - 2} \mathbf{~} \mathbf{~ m}$ & 6.15 & 3.67 & & \\
$\mathbf{2 - 4} \mathbf{~ m m}$ & 6.74 & 2.76 & & \\
$\mathbf{4 - 1 0} \mathbf{~ m m}$ & 10.16 & 1.01 & & \\
\hline
\end{tabular}

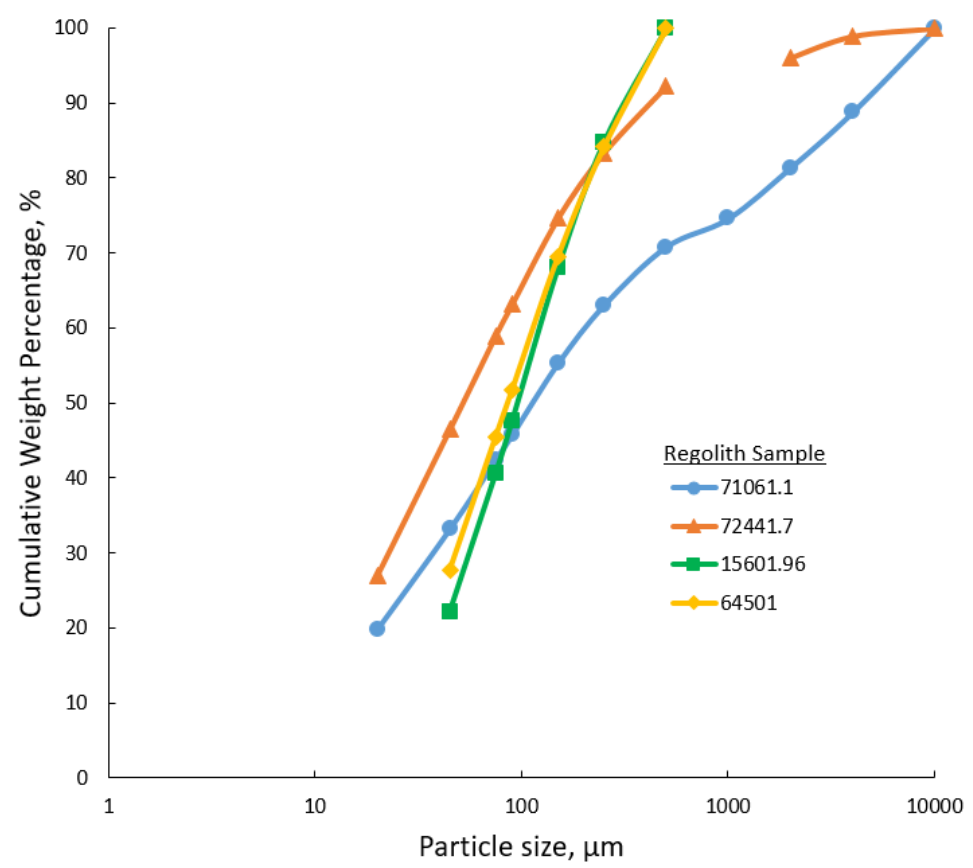

Figure 2.6: Lunar Regolith Cumulative Size Distributions (After McKay et al. 1991) 
ial/unconfined compressive strength, tensile strength, shear strength, and cohesive strength (Dombard and Freed 2002; Holsapple 2009; Housen and Holsapple 2003; Popova et al. 2011). No method is technically an "incorrect" way to define an asteroid's "strength" so long as that comparative method is maintained for all of the specimens examined in a given work. However, each type of strength has its own nuances that must be considered during comparisons between asteroids.

For geoscientists and mining engineers, a rock type's uniaxial or unconfined compressive strength (UCS) provides a general basis for comparison between rock types. The UCS of a rock plays an integral role in safety factor calculations in tunneling and mining designs. However, UCS is not an intrinsic property of a material. Rather, it depends on the material composition, loading conditions, and the geometry of the specimen being tested (Hudson and Harrison 2000). While UCS tests are performed on standardized rock cores, these tests generally tend to result in slightly higher strengths compared to the overall rock mass's UCS due to a size effect. Tensile strength is similarly dependent upon the material, specimen geometry, and loading conditions. Additionally, tensile strength tends to be several times less in magnitude than the UCS, and shares a similar decrease between specimen and rock mass strength. Tensile failure is brittle and manifests itself as rapid crack propagation, while compressive failure occurs as ductile yielding (Holsapple 2009).

Rock masses are generally weaker than subsamples taken from the mass due to the presence of joints, planes, and other discontinuities in the rock mass (Hudson and Harrison 2000). There are several criterions, however, that seek to relate specimen strength readings with larger rock mass strengths (see Table 2.6) (Holsapple 2009; Hudson and Harrison 2000). These criterions, such as the Mohr-Coulomb and Drucker-Prager criterions, have provided a means to estimate rock mass strength, in turn influencing the design of engineering systems. However, no criterion is comprehensive. For example, the Grady and Kipp criterion works well when modeling tensile spall, but not shear flow. Others, such as the Mohr-Coulomb criterion, are best suited for highly confining pressures. In almost no instance does a criterion consider the structure or degree of damage of a rock mass, though a revision of the Hoek-Brown 
criterion now considers measures of damage when modeling blasting in mining. As such, the Hoek-Brown empirical failure criterion has become a standard model for measuring impact damage and crater formation on asteroids, though others have occasionally been used (Holsapple 2009; Sanchez and Scheeres 2015). Holsapple has suggested the creation of a new criterion for use with asteroids that includes porosity, thermal effects, measures of damage, crack growth, stress pulse rate effect, and confining pressure as parameters contributing to the formation of a failure envelope, such as that found in the Mohr-Coulomb criterion, that encompasses all types of loading. Such a criterion would then allow a more accurate estimation of asteroid failure limits while minimizing the implicit biases currently found in rock failure criterions due to their understandable assumption of a terrestrial environment, gravitational force, and geologic formation processes.

Table 2.6: Rock Mass Failure Criteria (after Holsapple (2009); Hudson and Harrison (2000))

\begin{tabular}{|c|c|c|}
\hline Authors & Criterion & Variables \\
\hline \multirow[t]{2}{*}{ Drucker-Prager } & $\sigma_{\mathrm{e}}=\mathrm{a}+\mathrm{b}^{*} \sigma \mathrm{m}$ & $\tau=$ shear stress \\
\hline & & $\tau_{0}=$ cohesion \\
\hline \multirow[t]{4}{*}{ Mohr-Coulomb } & $|\tau|=\tau_{0}+\mu^{*} \sigma_{\mathrm{n}}$ & $\sigma_{\mathrm{n}}=$ normal stress \\
\hline & or & $\sigma_{\mathrm{C}}=$ uniaxial compressive strength \\
\hline & $|\tau|=0.5^{*}(\sigma 1-\sigma 3) * \sin \left(2^{*} \beta\right)$ & $\sigma \mathrm{m}=$ hydrostatic stress \\
\hline & & $\sigma_{\mathrm{e}}=$ equivalent stress \\
\hline \multirow[t]{3}{*}{ Hoek-Brown, 1980} & $\sigma 1-\sigma 3=\sigma_{\mathrm{c}} *\left(\mathrm{~m}_{\mathrm{i}} *\left(\sigma 3 / \sigma_{\mathrm{c}}\right)+1\right) 0.5$ & $\sigma 1=$ principle stress in $\mathrm{y}$-direction \\
\hline & & $\sigma 3=$ principle stress in $\mathrm{x}$-direction \\
\hline & & $\sigma_{\mathrm{t}}=$ uniaxial tensile strength \\
\hline \multirow[t]{8}{*}{ Hoek-Brown, 2003} & $\sigma 1-\sigma 3=\sigma_{\mathrm{c}} *\left(\mathrm{~m}_{\mathrm{i}} *\left(\sigma 3 / \sigma_{\mathrm{c}}\right)+\mathrm{s}\right) \mathrm{n}$ & $\beta=$ angle between shear and $x$-planes \\
\hline & & $\mu=$ coefficient of friction \\
\hline & & $\mathrm{a}=(2 / \sqrt{3}) *\left(\sigma_{\mathrm{c}} * \sigma_{\mathrm{t}}\right) /\left(\sigma_{\mathrm{c}}+\sigma_{\mathrm{t}}\right)$ \\
\hline & & $\mathrm{b}=(1 / \sqrt{3})^{*}\left(\sigma_{\mathrm{c}}-\sigma_{\mathrm{t}}\right) /\left(\sigma_{\mathrm{c}}+\sigma_{\mathrm{t}}\right)$ \\
\hline & & $\mathrm{mb}=$ constant based on particle interlocking \\
\hline & & $\mathrm{mi}=$ ratio of compressive to tensile strength \\
\hline & & $\mathrm{n}=$ constant based on rock mass \\
\hline & & $\mathrm{s}=$ constant based on degree of fracturing \\
\hline
\end{tabular}

Asteroid strengths thus far have been based primarily on computer models, experiments on simulated asteroid materials, and meteorites. Computer models and tests of simulated asteroid materials have focused on incorporating certain observable and 
inferable phenomena on asteroids to simulate their tensile, compressive, and cohesive strength characteristics (Dombard and Freed 2002; Housen and Holsapple 2003; Michikami et al. 2007; Sanchez and Scheeres 2013). Several studies have attempted to correlate ejecta velocity with compressive strength based on materials of varying strengths' responses to the same impact phenomenon (Housen and Holsapple 2003; Michikami et al. 2007). These models used experimental testing from the behavior of glass microspheres, a regolith simulant due to similar particle behavior, in order to constrain the samples' compressive strengths to between ${ }_{10} \mathrm{MPa}$ and the minimum strength before ejecta-minimizing compaction processes occur during impact, 0.1 MPa (Michikami et al. 2008). In their models, Michikami et al. (2008) used 0.5-5.5 $\mathrm{MPa}$ as asteroid strength estimates in their mass fraction of ejecta calculations for asteroids with bulk porosities of $40 \%$.

Others have focused on modeling asteroid behavior and strength based on thermal stresses (Dombard and Freed 2002). Coincidentally, the $10 \mathrm{MPa}$ limit used in Michikami et al. (2008) originates in the analysis of thermal stresses found in Dombard and Freed (2002). Dombard and Freed, believing lineations on Eros demonstrate internal strength and a plane of tensile-compressive stresses through Eros, theorize that extremes in surface temperatures on Eros induce internal stresses with magnitudes of $10 \mathrm{MPa}$. As such, the authors believe Eros to be monolithic with an internal strength of $\sim 10 \mathrm{MPa}$.

Because asteroids do not necessarily form in the presence of large gravity fields, it has been proposed that the dominating forces in rubble-pile asteroids are cohesive van der Waal forces between asteroid grains (Sanchez and Scheeres 2013, 2015). While these forces have played only a minor role on Earth, their importance is theorized to have played a much larger role in rubble-pile asteroid formation. The researchers, using discrete element analysis, modelled the behavior of individual asteroid grains, the forces acting between the grains, and the forces between these grains and larger boulders. Their study found that a realistic estimate for the cohesive strength of regolith is $25 \mathrm{~Pa}$ assuming random grain distribution, a grain size of $10 \mu \mathrm{m}$, and the cohesion of lunar regolith. A distinction must be made that this is the regolith, and 
not the rock mass/asteroid block, strength. Just as soil strengths are at least one order of magnitude less than those of terrestrial rocks, regolith cohesive strengths would appear to be several orders of magnitude less than those of meteorites or, presumably, asteroid blocks (Chabot et al. 2014).

Most of the strength data currently in use originates from meteorites. These measurements have been based on observation-based ram pressure estimates and experimental testing of meteorite samples (Popova et al. 2011). "Bulk" strength, defined here as the ram pressure at which the meteorite fractures in the Earth's atmosphere, is calculated using the equation

$$
P=\rho_{h} * v_{h}^{2}
$$

Where $\rho_{h}=$ the atmospheric density at the height of the fragmentation and $\mathrm{v}_{h}=$ the velocity of the meteorite fireball at the height of the fragmentation (Popova et al. 2011).

Ram pressure, recalculated for each point at which a fragmentary fireball occurs, increases from between 0.04 and $5.9 \mathrm{MPa}$ at the point of first fragmentation, to a maximum of 0.4-11.8 $\mathrm{MPa}$ at final fragmentation, depending on the meteorite. Each fragmentation event can be thought of as the propagation of a microcrack due to atmospheric loading, with the first breakup consisting of small fragments detached from the meteorite and the final breakup consisting of the final disruption of the meteorite's body before the debris particles begin to decelerate. Should the initial breakup prove violent, the final breakup could occur at a lower ram pressure due to cracking induced by the violent breakup.

The examination of these meteorites' fragments, however, revealed much higher compressive and tensile strengths (Popova et al. 2011). The average compressive strength for the stony meteorites is 188.6-207.4 MPa, while the average tensile strength for these meteorites ranges between 24.7-28.5 MPa. Carbonaceous meteorites displayed an average tensile strength of 29.5 MPa, though some are "weaker and more crumbly than these two examples". A similar survey found that the average compres- 
sive strength of stony meteorites is $200 \mathrm{MPa}$, while the average compressive strength of iron meteorites is $430 \mathrm{MPa}$ (Petrovic 2001). This survey found that failure behavior between the two meteorite types differed with changes in temperature. Specifically, iron meteorites display ductile behavior above 145-200 K depending on the meteorite, while they display brittle failure below this transition temperature. Stony meteorites, by contrast, exhibited purely brittle behavior. Based in the combination of this data with fragmentary observations, stony asteroid compressive strengths are estimated to realistically fall between 1 and $5 \mathrm{MPa}$. Table 2.7 summarizes all strength findings from the literature, while Figures 2.7 and 2.8 provide a visual representation of comparative compressive and tensile strengths from Table 2.7.

Table 2.7: Material Strength of Asteroids, Meteorites, and Regolith by Strength Type

\begin{tabular}{cccc}
\hline Strength Type & Material Type & Strength & Determintion Method \\
\hline Compressive & Eros (S-type) & $10 \mathrm{MPa}$ & Thermal stress modeling ${ }^{1}$ \\
Compressive & S-Type asteroid & $0.1-5.5 \mathrm{MPa}$ & Impact ejecta modeling $^{2}$ \\
Compressive & Iron meteorite & $430 \mathrm{MPa}$ & Mechanical test $^{3}$ \\
Compressive & S-Type asteroid & $1-5 \mathrm{MPa}$ & Breakup observation $^{3}$ \\
Compressive & Stony meteorite & $200 \mathrm{MPa}$ & Mechanical test $^{3}$ \\
Compressive & Stony meteorite & $188-207 \mathrm{MPa}$ & Mechanical test $^{4}$ \\
Compressive & Tagish Lake CC meteorite & $2.2 \mathrm{MPa}$ & N/A $^{5}$ \\
Compressive & Bunburra Rockhole AC meteorite & $0.9 \mathrm{MPa}$ & N/A $^{5}$ \\
Tensile & Stony meteorite & $21.8-29.5 \mathrm{MPa}$ & Mechanical test $^{3}$ \\
Tensile & Iron meteorite & $43 \mathrm{MPa}$ & Mechanical test $^{3}$ \\
Tensile & Stony meteorite & $24.7-28.5 \mathrm{MPa}$ & Mechanical test $^{4}$ \\
Tensile & Carbonaceous meteorite & $29.5 \mathrm{MPa}$ & Mechanical test $^{4}$ \\
Ram/ first breakup & Stony meteorite & $0.04-5.9 \mathrm{MPa}$ & Breakup observation $^{4}$ \\
Ram/ final breakup & Stony meteorite & $0.4-11.8 \mathrm{MPa}$ & Breakup observation $^{4}$ \\
Cohesive & Asteroid regolith & $25 \mathrm{~Pa}$ & Soft sphere DEM $^{6}$ \\
\hline $\begin{array}{l}1=\text { Dombard and Freed (2002), } 2=\text { Michikami et al. (2008), 3=Petrovic (2001), } \\
\text { and Scheeres (2013) }\end{array}$ & & &
\end{tabular}

\subsubsection{Material Strength of Comets}

The scientific community's knowledge of the material strengths of comets is currently under revision due to the information gained from the Rosetta mission. Previously, knowledge of cometary strengths was confined by the results of Deep Impact, 


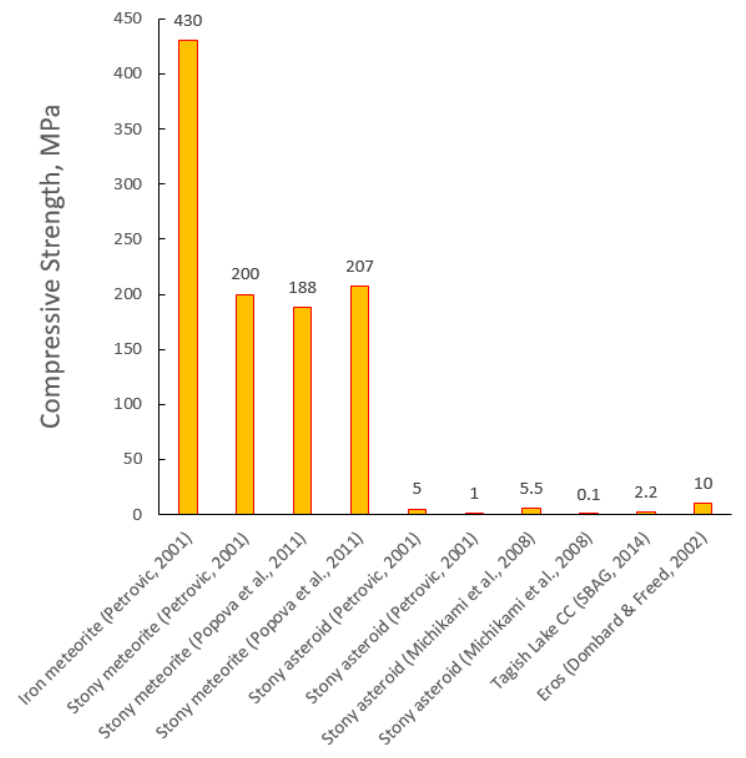

Figure 2.7: Compressive strengths of asteroids and meteorites

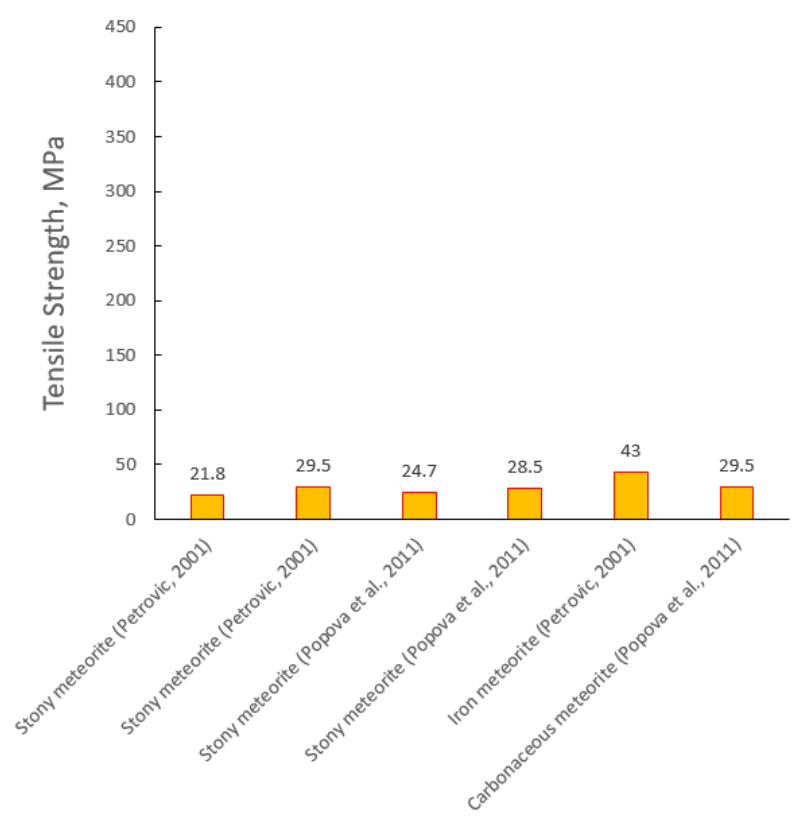

Figure 2.8: Tensile strengths of asteroids and meteorites 
a cometary science mission wherein the satellite, a ballistic impactor, collided with Tempel-1 to learn more about its structure (Biele et al. 2009). Initially estimated at $<65 \mathrm{~Pa}$ (shear) strength, models of Deep Impact's collision have since revised these strength estimates to $1-10 \mathrm{kPa}$, with $1-5 \mathrm{kPa}$ being most consistent with the data but estimates up to $100 \mathrm{kPa}$ still considered feasible. Estimates from Rosetta's observation of the collision place the strength at $50 \mathrm{kPa}$, though this strength is not specified as tensile, shear, cohesive, or compressive. Cometary analog materials consisting of ice, dust, and gas have similarly been found to possess compressive strengths of $30 \mathrm{kPa}$ to $1 \mathrm{MPa}$ and tensile strengths of 1 - $10 \mathrm{kPa}$. Meanwhile, lunar regolith compressive strength is cited at $1.6-68 \mathrm{kPa}$ and Martian regolith at $5-10 \mathrm{kPa}$.

The materials used as cometary analogs, whether extraterrestrial or simulated on Earth, all share one common feature with models of comet behavior: they are considered to be granular and follow granular behavior (Biele et al. 2009). Though Biele et al. (2009) mention that comets likely have surface crusts and may even be further differentiated below the surface, little exists in literature to further examine this possibility. While the models may accurately describe regolith behavior on the surface of a comet (or asteroid), they may not be representative of subsurface materials, similar to how sand and soil on Earth do not demonstrate the same behavior as granite. A direct outcome of this possibility lies in Section 2.1, where comet subsurface material demonstrated strengths above $2 \mathrm{MPa}$ and likely above $4 \mathrm{MPa}$ (Biele et al. 2015). Future anchoring system design should therefore consider the cases of high as well as low uniaxial compressive strengths so that a robust, utilitarian anchor can be employed in a wide range of potential operating environments while minimizing the chances of under-designing the system.

\subsection{Summary of Knowledge Gaps}

All of the currently identified properties of asteroids are based on either indirect measurement or direct testing of meteorite analogs. This lack of direct interaction with and testing of asteroid materials means that there is no real way of verifying 
the accuracy of models of asteroid behavior during anchoring operations. Data from the Philae lander offers an initial glimpse of the need for developing anchoring technology that can operate in both low-strength and high-strength environments. This anchoring technology should additionally minimize any complexity in design in order to reduce the potential points of failure in the system. Additionally, there is no current information on how roof bolts behave in regolith or regolith simulants at low temperatures with varying ice content. This study will therefore provide a first-order examination of the effects of these variables on bolt anchorge in order to identify which, if any, roof bolt anchorage mechanisms are appropriate for utilization in space. 


\section{Chapter 3}

\section{Methodology}

\subsection{Design}

The structure of asteroids, comets, and small orbital bodies can generally be considered somewhere on the spectrum between "rubble piles" and monolithic bodies. This study was therefore designed to comparatively assess anchor performance within these two strength regimes in order to identify what differences in anchorage, if any, might occur between anchors installed in regolith and anchors installed in a more competent asteroid. Under the "monolithic body/boulder" strength regime, bolts were tested in boulders of different rock strength and at various drilling depths. Variation in rock strength was tested due to the role of rock strength in bolt behavior on Earth, with some bolts performing better in stronger rock than in weaker rock and vice versa. Hole drilling depths, meanwhile, were altered in order to identify the possibility of anchoring a bolt shorter than $12 \mathrm{in}$. in an asteroid since each inch of hole drilled in an asteroid will cost time, energy, and increase the possibility of disrupting the asteroid and dissassociating it into its constitutent pieces. The "rubble pile/regolith" regime, meanwhile, tested bolt performance in regoliths of varying compactions, ice contents, and operating temperatures. Regolith, being much more susceptible to compaction than solid rock, is more likely to display local variation in compaction on an asteroid, and so identifying compaction's role in anchoring in regolith will help improve the security of asteroid anchoring. In this study, compaction was studied using the proxy 
Table 3.1: Summary of Test Conditions

\begin{tabular}{ccccc}
\hline Variable & Variable Type & Boulder & Regolith & Range \\
\hline Rock strength & Exogeologic & $\checkmark$ & & 4,335 to $35,250 \mathrm{psi}$ \\
Drilling depth & Operational & $\checkmark$ & & 2 to $12 \mathrm{in}$. \\
Temperature effects & Environmental & & $\checkmark$ & $-9.4^{\circ} \mathrm{F}$ to $75^{\circ} \mathrm{F}$ \\
Ice content & Exogeologic & & $\checkmark$ & 0 to $10 \%$ \\
Compactive load & Exogeologic & & $\checkmark$ & 0 to $70 \%$ \\
\hline
\end{tabular}

"compactive load", or the change in a known mass's density by applying a given load and measuring the change in volume as a percent difference from the initial volume reading. Ice content, meanwhile, may contribute to increased regolith coherence, with its presence indicating a more coherent body than initial detection methods may estimate. These behaviors were measured across a range of temperatures, with the maximum temperature occuring at $75{ }^{\circ} \mathrm{F}$ to provide a comparison to anchors tested in room-temperature boulders. Testing at lower temperatures, meanwhile, provided a more accurate investigtion of how anchors behave in the low-temperature environment of space. Table 3.1 provides an overview of the variables tested under each strength regime. In this study, "boulders" and "regolith" materials were used to represent behavior in larger "monolithic body" and "rubble pile" asteroid/comet mass conditions.

A full factorial examination of these parameters, wherein each variable combination is tested, would result in 9 boulder tests and 27 regolith tests per anchor type, for an overall number of 108 tests. A Box-Behnken experimental design frame was used to structure the test series in order to properly test these variables while decreasing the overall number of tests required. Box-Behnken experimental designs treat the overall characterization of an experiment as a cube, with each geometric vertex and midpoint representing a testing state. The Box-Behnken method tests only some of these points in order to generate the full response surface that the experiment is attempting to obtain. Box-Behnken experiments are defined using the equation $N=2 * k *(k-1)+C_{0}$, where $k$ is the number of variables and $C_{0}$ is the number of central points or controls against which variations in the variables are compared (Amini et al. 2016; Ferreira et al. 2007). Amini (2014) offers one example of how 
such a design can be used to efficiently test a mulivariate experimental design in a typical mineral processing application. In the current study, the boulder and regolith tests each look at a different set of variables, and so each must have a separate BoxBehnken design for each test series. Furthermore, each test series must be replicated once each for the point anchors, fully-grouted roof bolts, and polyurethane bolts so that a comparison of the variables across the three bolting methods can be made. Using two variables in the boulder test series and three center point tests for the Box-Behnken test design generated seven boulder tests per anchor type, or 21 boulder tests overall. Using three variables in the regolith test series, meanwhile, with three center point tests generated 15 regolith tests per bolt type, or 45 regolith tests overall. It should be noted, however, that this design is not intended to facilitate the generation of response surfaces for the bolt types. Instead, the principle allowing fewer tests to be conducted in order to characterize anchor behavior is being applied to ensure different variable combinations are examined that can be directly compared to control tests for each bolt type.

Table 3.2: Box-Behnken Design Variable Key

\begin{tabular}{ccccc}
\hline Test Series & Variable & \multicolumn{3}{c}{ BB Test Level } \\
& & $\mathbf{- 1}$ & $\mathbf{0}$ & $\mathbf{1}$ \\
\hline Boulder & Strength & $8,875 \mathrm{psi}$ (sandstone) & $32,250 \mathrm{psi}$ (diabase) & 4,335 psi (limestone) \\
Boulder & Hole Depth & $2 \mathrm{in}$. & $12 \mathrm{in}$. & $6 \mathrm{in}$. \\
Regolith & Temperature & $32{ }^{\circ} \mathrm{F}$ & $-9.4{ }^{\circ} \mathrm{F}$ & $75{ }^{\circ} \mathrm{F}$ \\
Regolith & Ice Content & $0 \%$ & $5 \%$ & $10 \%$ \\
Regolith & Compactive Load & $0 \%$ & $30 \%$ & $70 \%$ \\
\hline
\end{tabular}

The Box-Behnken design is generally placed in tabular form and uses the values -1 and 1 to differentiate variable values other than the control value, while the control value for that variable is represented as a 0 . Table 3.2 displays the variables for the boulder and regolith tests and their corresponding Box-Behnken design value. In the boulder tests, the diabase boulder and $12 \mathrm{in}$. lengths were set as the control values in order to identify how anchorage values might differ when bolting in weaker rock and shallower depths. Limestone and sandstone were used to provide a broad range of boulder strength values, while depths of 6 in. and 2 in. were examined to identify 
if a point anchor needed to be totally submerged in a bolt hole to anchor to the rock. Table 3.3 demonstrates the Box-Behnken design for the boulder tests, while Table 3.4 displays the actual design parameters for these boulder tests.

Table 3.3: Boulder Test Series Box-Behnken Design

\begin{tabular}{ccc}
\hline Experiment & Strength & Hole Depth \\
\hline 1 & -1 & 0 \\
2 & 1 & 0 \\
3 & 0 & -1 \\
4 & 0 & 1 \\
C & 0 & 0 \\
C & 0 & 0 \\
C & 0 & 0 \\
\hline
\end{tabular}

Table 3.4: Boulder Test Series Parameter Configurations

\begin{tabular}{ccc}
\hline Experiment & Rock Strength/Type & Hole Depth \\
\hline 1 & $8,875 \mathrm{psi} /$ Sandstone & $12 \mathrm{in}$. \\
2 & $4,335 \mathrm{psi} /$ Limestone & $12 \mathrm{in}$. \\
3 & $35,250 \mathrm{psi} /$ Diabase & $2 \mathrm{in}$. \\
4 & $35,250 \mathrm{psi} /$ Diabase & $6 \mathrm{in}$. \\
$\mathrm{C}$ & $35,250 \mathrm{psi} /$ Diabase & $12 \mathrm{in}$. \\
$\mathrm{C}$ & $35,250 \mathrm{psi} /$ Diabase & $12 \mathrm{in}$. \\
$\mathrm{C}$ & $35,250 \mathrm{psi} /$ Diabase & $12 \mathrm{in}$. \\
\hline
\end{tabular}

The Box-Behnken design for the regolith tests took a similar approach to the boulder tests. Regolith at $-9.4^{\circ} \mathrm{F}, 5 \%$ moisture content, and $30 \%$ compactive load established the initial control point in order to identify if the ice behavior would change as the regolith cooled below the $32^{\circ} \mathrm{F}$ freezing temperature of water, while a $75^{\mathrm{O}} \mathrm{F}$ temperature provided a maximum temperature value to allow comparisons of anchor behavior in boulders and regolith at room temperature. Ice content extremes were placed at $0 \%$ and $10 \%$ weight by mass water content in order to provide an examination of how an anchor might perform in both a purely "dusty" asteroid and in a C-type asteroid with higher water contents. Varying the compaction of the regolith to $0 \%$ and $70 \%$, meanwhile, was intended to provide an examination of what 
role compaction might have on anchorage capabilities since little is currently known of actual asteroid compaction values. Table 3.5 lists the test series design for the regolith tests, while Table 3.4 demonstrates how these parameters translated into actual test configurations.

\subsection{Comparison of Anchoring Methods in the Rock Strength Regime}

\subsubsection{Boulder Core Strength Tests}

The diabase, limestone, and sandstone boulders were each characterized through unixial compressive strength (UCS) tests in order to identify the material strengths in which the bolts were anchoring. Diabase boulders were sourced from Gettysburg, PA, while the limestone boulder was sourced from a vendor of stone from the Indiana Limestone formation. The sandstone boulder originated from the Berea Sandstone formation. Each core used in the testing was derived from the bolt holes drilled into the boulders. After measuring each core's nominal diameter length of 0.785 in., core lengths twice that of the diameter were cut so that cores approximately 0.785 in. in diameter and 1.575 in length were made for each rock type. These cores can be seen in Figures 3.1athrough 3.1c.

Six cores for each rock type were then tested in a MTS load frame for their uniaxial compressive strengths. Figure 3.1b displays a typical test setup. The results for each test are tabulated in Table 3.7. Taking the average for each set of measurements, uniaxial compressive strengths of 35,250 $+7,883 \mathrm{psi}, 8,876 \pm 321 \mathrm{psi}$, and 4,335 $+2,463$ psi were ascribed to the diabase, sandstone, and limestone boulders, respectively. These results confirm that the diabase boulder is the "high strength" boulder sample used in the anchor testing, while limestone is the "low strength" boulder sample and sandstone possesses a strength between the two boulders. 
Table 3.5: Regolith Test Series Box-Behnken Design

\begin{tabular}{cccc}
\hline Experiment Run & Temperature, $\mathbf{0}$ C & Ice Content, \%wt. & Compaction, \% \\
\hline 1 & -1 & -1 & 0 \\
2 & 1 & -1 & 0 \\
3 & -1 & 1 & 0 \\
4 & 1 & 1 & 0 \\
5 & -1 & 0 & -1 \\
6 & 1 & 0 & -1 \\
7 & -1 & 0 & 1 \\
8 & 1 & 0 & 1 \\
9 & 0 & -1 & -1 \\
10 & 0 & 1 & -1 \\
11 & 0 & -1 & 1 \\
12 & 0 & 1 & 1 \\
C & 0 & 0 & 0 \\
C & 0 & 0 & 0 \\
C & 0 & 0 & 0 \\
\hline
\end{tabular}

Table 3.6: Regolith Test Series Parameter Configurations

\begin{tabular}{cccc}
\hline Experiment Run & Temperature, ${ }^{\circ} \mathrm{F}$ & Ice Content, \%wt. & Compaction, \% \\
\hline 1 & $32^{\circ} \mathrm{F}$ & $0 \%$ & $30 \%$ \\
2 & $75^{\circ} \mathrm{F}$ & $0 \%$ & $30 \%$ \\
3 & $32{ }^{\circ} \mathrm{F}$ & $10 \%$ & $30 \%$ \\
4 & $75^{\circ} \mathrm{F}$ & $10 \%$ & $30 \%$ \\
5 & $32^{\circ} \mathrm{F}$ & $5 \%$ & $0 \%$ \\
6 & $75^{\circ} \mathrm{F}$ & $5 \%$ & $0 \%$ \\
7 & $32^{\circ} \mathrm{F}$ & $5 \%$ & $70 \%$ \\
8 & $75^{\circ} \mathrm{F}$ & $5 \%$ & $70 \%$ \\
9 & $-9.4{ }^{\circ} \mathrm{F}$ & $0 \%$ & $0 \%$ \\
10 & $-9.4{ }^{\circ} \mathrm{F}$ & $10 \%$ & $0 \%$ \\
11 & $-9.4^{\circ} \mathrm{F}$ & $0 \%$ & $70 \%$ \\
12 & $-9.4^{\circ} \mathrm{F}$ & $10 \%$ & $70 \%$ \\
$\mathrm{C}$ & $-9.4{ }^{\circ} \mathrm{F}$ & $5 \%$ & $30 \%$ \\
$\mathrm{C}$ & $-9.4{ }^{\circ} \mathrm{F}$ & $5 \%$ & $30 \%$ \\
$\mathrm{C}$ & $-9.4{ }^{\circ} \mathrm{F}$ & $5 \%$ & $30 \%$ \\
\hline
\end{tabular}




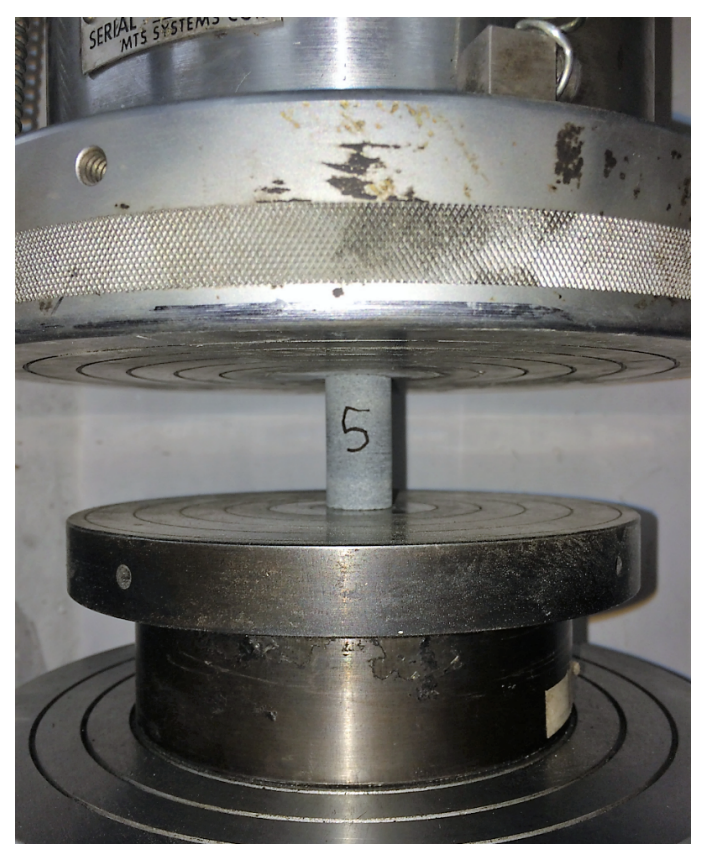

(a) Diabase Core Prepared for UCS Testing

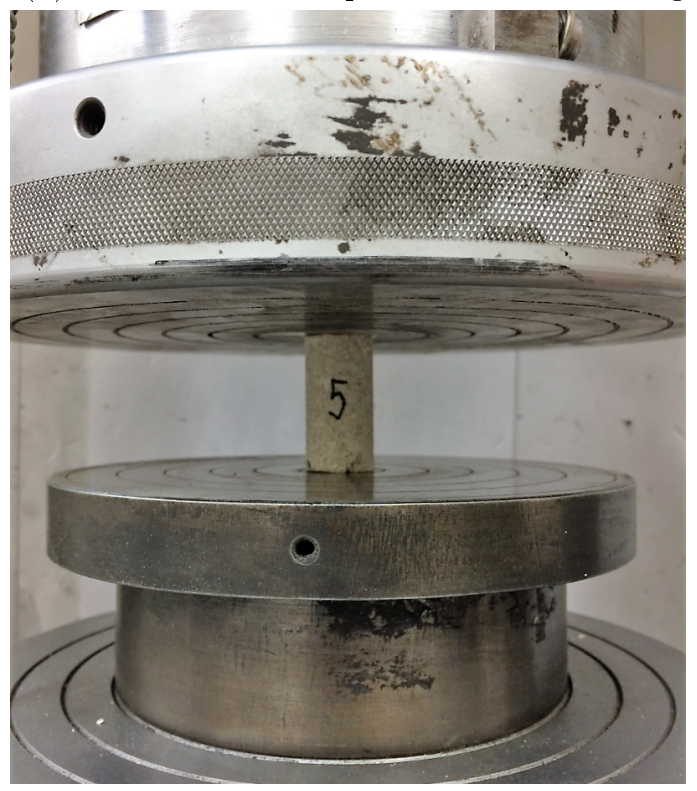

(c) Limestone Core Prepared for UCS Testing

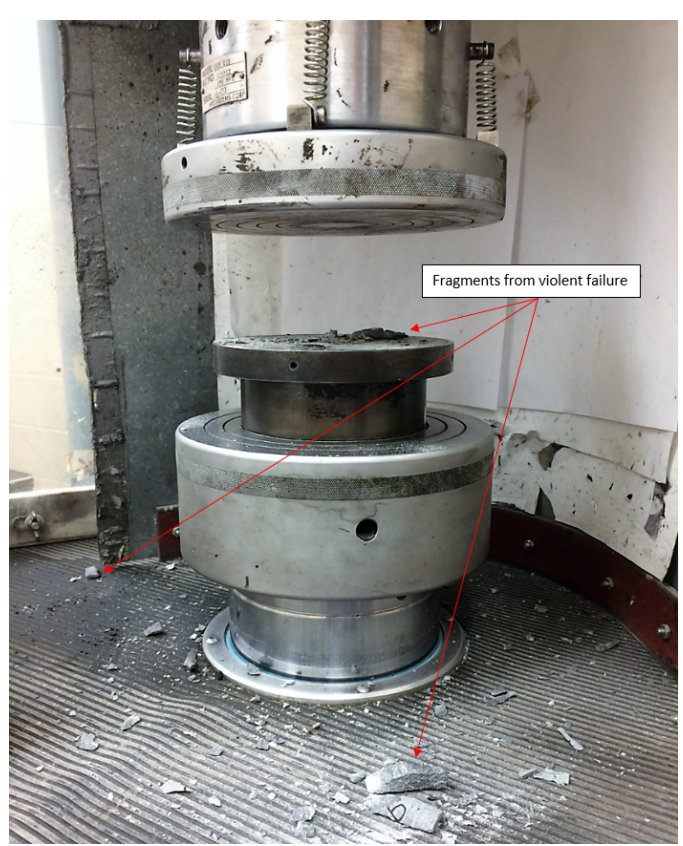

(b) Diabase Core Post-UCS Failure

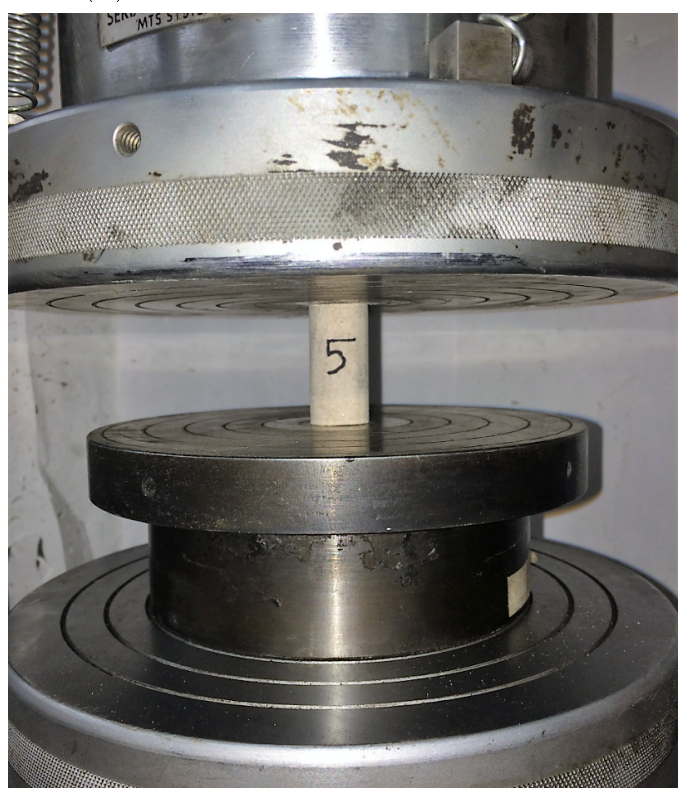

(d) Sandstone Core Prepared for UCS Testing

Figure 3.1: Uniaxial Compressive Strength Testing 
Table 3.7: Boulder Uniaxial Compressive Strength Test Results

\begin{tabular}{cccc}
\hline Sample No. & Diabase, psi & Limestone, psi & Sandstone, psi \\
\hline 1 & 26,890 & 4,670 & 5,178 \\
2 & 37,811 & 4,220 & 9,572 \\
3 & 42,583 & 4,307 & 12,357 \\
4 & 22,060 & 4,830 & 10,138 \\
5 & 40,610 & 3,989 & 9,892 \\
6 & 41,582 & 3,974 & 6,135 \\
Average & 35,250 & 4,335 & 8,876 \\
Stan. Dev. & 7,883 & 321 & 2463 \\
\hline
\end{tabular}

\subsubsection{Boulder Pull Test Setup}

Multiple bolt holes were drilled into each boulder so that no bolt hole would be tested twice. A Milwaukee Cat. No. 4090 Dymodrill coring drill with a nominal 1.0 in. diameter bit was used to core all of the drill holes needed for the boulder test series, which amounted to 21 bolt holes in total. The point anchor bolts had a 14.5 in. length and $0.875 \mathrm{in}$. diameter with a $1.0 \mathrm{in}$. diameter bolt hole. These lengths provided the bolts with 12 in. of anchorage and the remaining length providing room for a pull test collar above the bolt hole. The rebar bolts, meanwhile, were 15 in. long, 0.90 in. in diameter, and designed to provide 12 in. of anchorage. The hole annulus generated by the point anchor bolts was 0.125 in., which fell within the $0.1-0.25$ in. annulus range recommended by Mark et al. (2002). The rebar bolts, meanwhile, had a hole annulus of 0.1 in., which was also within the limits recommended by Mark et al. (2002). The bolts were grade 55 in each test series, with a thread yield strength of 27,700 lbf and thread tensile strength of 41,600 lbf for the point anchor bolts.

The boulder test series evaluated the anchorage of fully-grouted resin bolts, pointanchored mechanical bolts, and polyurethane-seated bolts under "weak", "moderate", and "strong" conditions as they would occur on monolithic orbital bodies. "Weak" bodies were represented by limestone, "moderate" bodies by sandstone, and "strong" bodies by diabase. The diabase block used during testing had dimensions of $36 \mathrm{in}$. by $30 \mathrm{in.}$ by $36 \mathrm{in.}$ The sandstone block was $16 \mathrm{in}$. by $11 \mathrm{in}$. by $7 \mathrm{in}$., while the limestone block was 15 in. by 17 in. by 5 in. Following the procedure in the Box- 


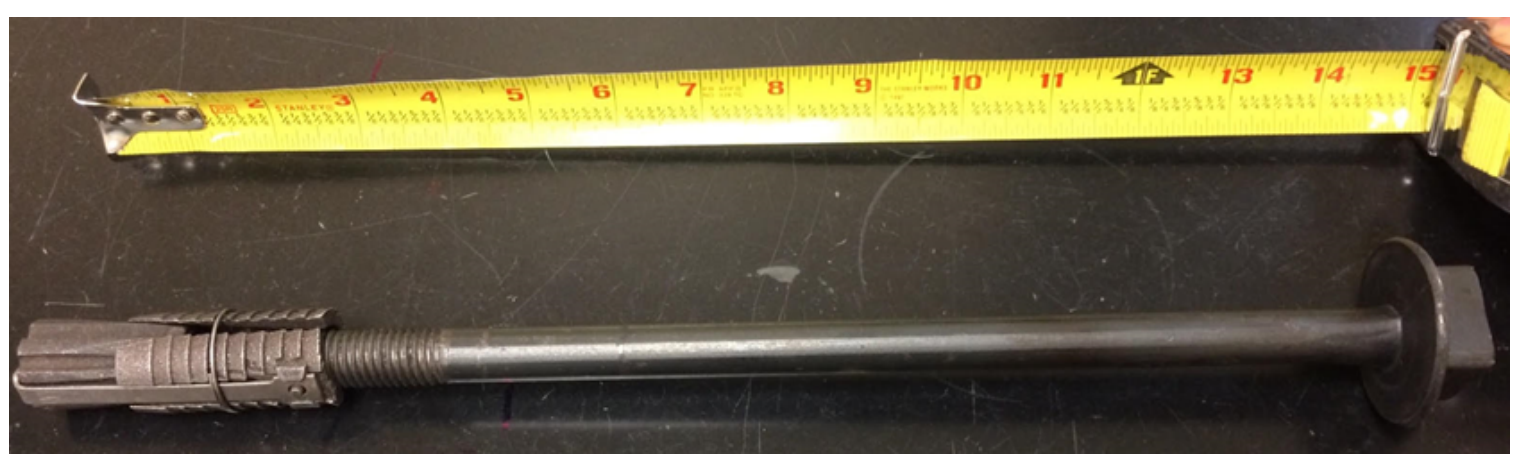

(a) Point Anchor Roof Bolt

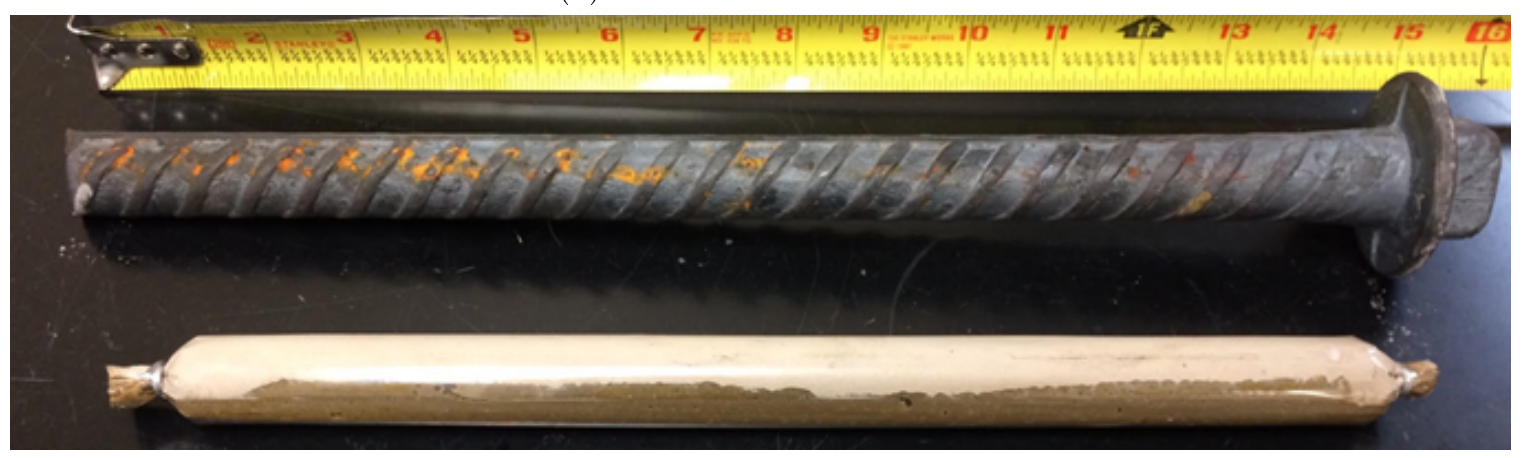

(b) Fully-grouted Rebar Bolt and Resin

Figure 3.2: Bolt Design

Behnken design in Table 3.4, five bolt holes were drilled into the diabase boulder for each of the anchor types for a total of fifteen bolt holes, with an additional three bolt holes each drilled into the sandstone and limestone blocks. In the diabase boulder, each anchor type had three anchors installed for the full 12 in. bolt length "nominal case" and one anchor each anchored at 2 in. and 6 in. of depth to evaluate the effect of hole depth on anchorage, for a total of nine 12 in. anchors, three 6 in. anchors, and three 2 in. anchors in the diabase boulder. All limestone and sandstone anchors were anchored at the full 12 in. length to investigate only the role of boulder strength in anchorage for each anchor type. Bolt holes were separated by 2-3 in. of spacing, equivalent to two or three bolt diameters, to avoid interaction effects between bolts.

After the bolt holes had been drilled, each point anchor had a pull collar attached immediately below the bolt head. All rebar bolts were of sufficient yield strength for the pull claw to pull on their resepective bolt heads. The top ends of the point anchor bolts were then threaded with 3 in. long shells that would provide anchorage in the bolt hole by expanding and grabbing the edges of the bolt hole. After threading the 
shell onto the point anchor, the bolt was lightly tapped into the bolt hole. A 30 ft.-lb. torque was then applied to the point anchor to ensure the shell had expanded and gripped the bolt hole surface. While the manufacturer-recommended torque is 125-225 ft.-lbs. for these bolts, the torque was lowered considerably to the $30 \mathrm{ft} .-\mathrm{lb}$. range where a drill could effectively torque the bolt.

Fully-grouted resin bolts, meanwhile, utilized a part of the 12 in. two-part resin capsules for anchorage. During installation of fully-grouted bolts in mines, tubes of resin as long as the rebar bolt are first installed in the roof using a human-operated vehicle known as an hydraulic roof bolter. The rebar bolt is then installed and rotated by the roof bolter at a high rotational speed until the resin has fully mixed and begun setting, usually in less than one minute. For this study, however, the use of a roof bolter was considered unfeasible due to the size and cost of the machine versus the small number of shallow holes that would require bolting. Instead, resin bolts were prepared for the laboratory study by cutting the $12 \mathrm{in}$. cartridge in half and then, using only half of the cartridge, cutting open the 6 in. of film on each side that separated the two parts of the resin. The two components of the resin were then scooped out of the cartridge and hand-mixed for 5-10 sec. before being inserted into the bolt hole. The rebar bolt was then lightly tapped into the bolt hole and rotated by hand for 15 seconds or until it had become firmly lodged in place. The bolts were then left to cure for 2 hours in the same temperature environment as that in which they would be tested. This method of curing would then demonstrate if lowering the temperature of the resin itself would play any adverse effect in its load bearing capacity. This process most likely slowed the curing time for the resin. The low temperature environment of space, however, will require this curing to occur at even lower temperatures, and so effects of low temperatures on cure times should be further investigated.

The cutting and hand-mixing process was necessary because the full 12 in. tube contained too much resin to fully compress into the hole, with the resin remaining within the plastic cartridge even when installed with full-length cuts on both sides of the cartridge. Additionlly, the rebar bolts could not be rotated by hand fast enough to 
mix the two parts of the resin together, and so hand-mixing the resin became the only available option to prepare the resin for installation. The subsequent anchorage of the fully-grouted roof bolts in the diabase and limestone boulders has subesequently validated that this installation method can generate the desired results. Chemical roof bolting, meanwhile, consisted of rebar bolts identical to those used with the resin and a two-part polyurethane typically pumped into cable bolts under low or high pressure to provide secondary support to a fractured rock mass. When mixed in a 1:1 ratio, this polyurethane creates an exothermic reaction and cures after about one minute of mixing. The two parts of the polyurethane were therefore mixed in $6.75 \mathrm{fl}$. oz. $(200 \mathrm{~mL})$ batches with $3.38 \mathrm{fl}$. oz. (100 mL) of each part per the manufacturer's guidence for 30 seconds and then poured into a bolt hole until the hole was full of the polyurethane. Pouring the polyurethane into the bolt hole at 30 seconds ensured that the polyurethane would be within the bolt hole prior to its initial cure time of 45 - 60 seconds. A rebar bolt was then installed into the bolt hole, displacing some polyurethane and rotated by hand until the bolt had cured beyond the point of rotation. The samples were then left to cure for two hours in the same temperature environment as that in which they would be tested.

Once all of the bolt holes were drilled and the bolts installed, a pull claw from an ENERPAC RCH302 30-ton loading cylinder was connected to either the pull collar under the point anchor bolt heads or under the bolt heads themselves for the fullygrouted resin bolts and polyurethane bolts. An ENERPAC P392 hydraulic jack connected to the loading cylinder was pumped until the cylinder had filled with enough hydraulic oil to exert a load on the bolt. A dial gauge was then installed on the top of the loading cylinder to measure the amount of bolt displacement during the subsequent loading. The jack was then pumped in 1-ton intervals, during which bolt displacement readings were taken at each load increase. For the polyurethane tests, these intervals were lowered to 0.5 tons due to some initial pull out failures for these anchors at 1.5-2.0 tons. In general, testing ended when either the bolts were unable to sustain a load or until the limits of the pull cylinder had been reached. In the former instance, this failure generally resulted in the jack being incapable of 
sustaining a load beyond 1.5-2 tons while the displacement continued to increase. At this point, bolts were considered to have failed. The pull cylinder's maximum load of 30 tons, meanwhile, meant that no test could exceed this limit. To ensure equipment operability and safety, this limit was lowered to 28 tons. Setup of the pull test system can be seen in Figure 3.3. Bolts mounted in the diabase and sandstone system can be seen in Figure 3.4, while Figure 3.5 portrays the limestone boulder both prior to and after point anchor-induced failure.

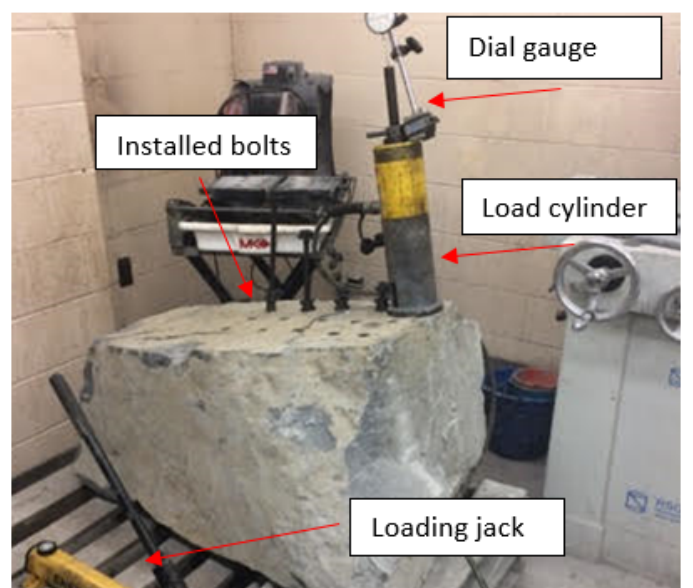

(a) Pull Test System Mounted On The Diabase Boulder

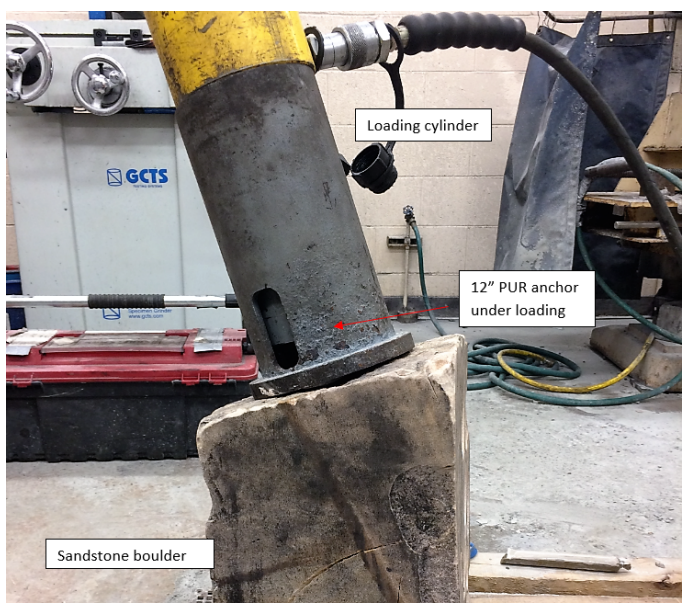

(b) Pull Test System Mounted On The Sandstone Boulder

Figure 3.3: Pull Test System Setup

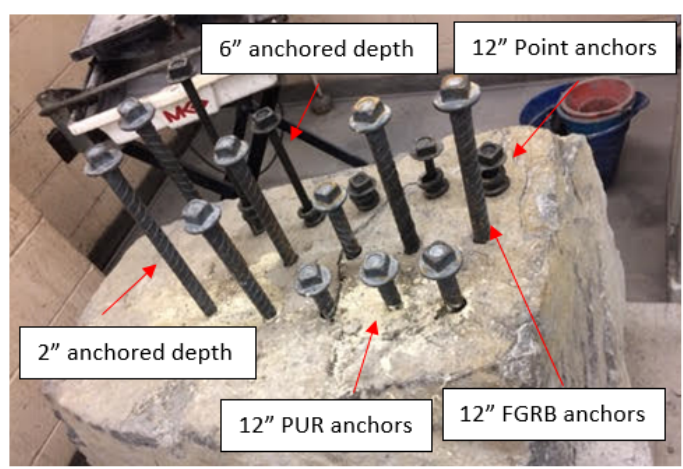

(a) Bolts Installed In The Diabase Boulder

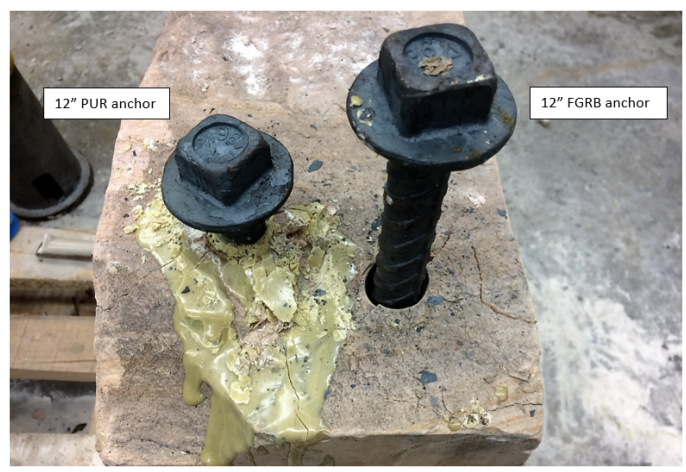

(b) Bolts Installed In The Sandstone Boulder

Figure 3.4: Bolts Installed in Diabase and Sandstone Boulders 


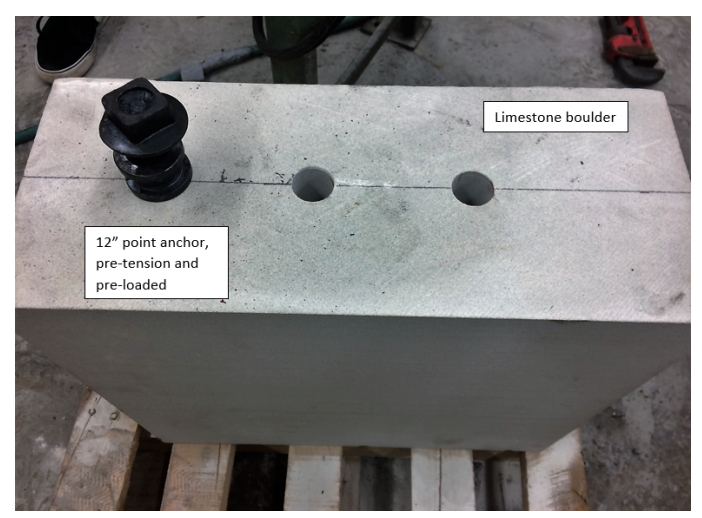

(a) Point Anchor Installation In A Limestone Boulder

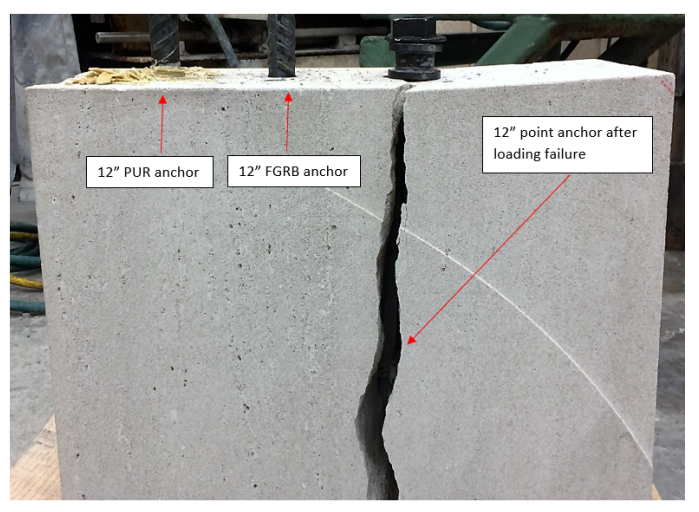

(b) Post-Torque Failure In Limestone

Figure 3.5: Limestone Boulder Pre- and Post-Failure

\subsection{Comparison of Anchoring Methods in the Re- golith Strength Regime}

\subsubsection{Regolith Simulant Preparation}

Asteroid regolith size distributions are relatively unknown, though models of their composition exist based on computer simulations of granular physics (see Section 2.3.3). In this experiment, the lunar size distributions were used as a starting point for the creation of an asteroid regolith size distribution since it is the only experimentallyderived data available. Using the lunar regolith size classes as a guide, the asteroid regolith simulant was prepared by first cutting slices of diabase, which is mineralogically similar to most asteroids due to its igneous formation and mineral contents, out of a boulder. These slices were then crushed in a Sturtevant Jaw Crusher and a Sturtevant Laboratory Roll Mill to generate comminuted particles. Since ultrafine $(<90 \mu \mathrm{m})$ particles comprise $45-63 \%$ of regolith particles by mass according to Figure 2.6, the crushed simulant was next sorted in a Sweico Vibro-Energy Separator wet sieve to ensure that these particles were properly sorted into their respective size classes. The particles nominally larger than $90 \mu \mathrm{m}$ were then dry sieved using a ROTAP vibratory sorter into the same size classes as the lunar regolith samples: +4 
mm, $4 \mathrm{~mm}$ x $2 \mathrm{~mm}, 2 \mathrm{~mm}$ x $1 \mathrm{~mm}, 1 \mathrm{~mm}$ x $500 \mu \mathrm{m}, 500 \mu \mathrm{m}$ x $250 \mu \mathrm{m}, 250 \mu \mathrm{m}$ x $150 \mu \mathrm{m}, 150 \mu \mathrm{m}$ x $90 \mu \mathrm{m}$, and a bottom collection plate for any misclassified <90 $\mu \mathrm{m}$ particles. These samples were then stored in 5 gallon buckets and labelled with the appropriate size class.

The $<90 \mu \mathrm{m}$ particles, whether misclassified during the initial sorting or suspended in the water used to wet sieve the regolith, were consolidated together and then dewatered using a pump connected to a SEPOR filtering stand with $<5 \mu \mathrm{m}$ tolerance filter paper and a collection tank for the water. Once these particles were filtered out, the resulting sludge was placed in aluminum pans and heated in an oven to $104{ }^{\circ} \mathrm{F}$ to remove any remaining moisture. In order to avoid the time-consuming method of repeatedly wet-sieving and dewatering particles into ultrafine size classes only to combine those size classes later during regolith construction, a particle size analysis using a Cilas 1190 Particle Size Analyzer was instead performed to identify the volumetric size distribution of particles within a representative sample. The analysis can be found in Figure 3.6, with Table 3.8 providing a breakdown of how each size class was represented in the sample.

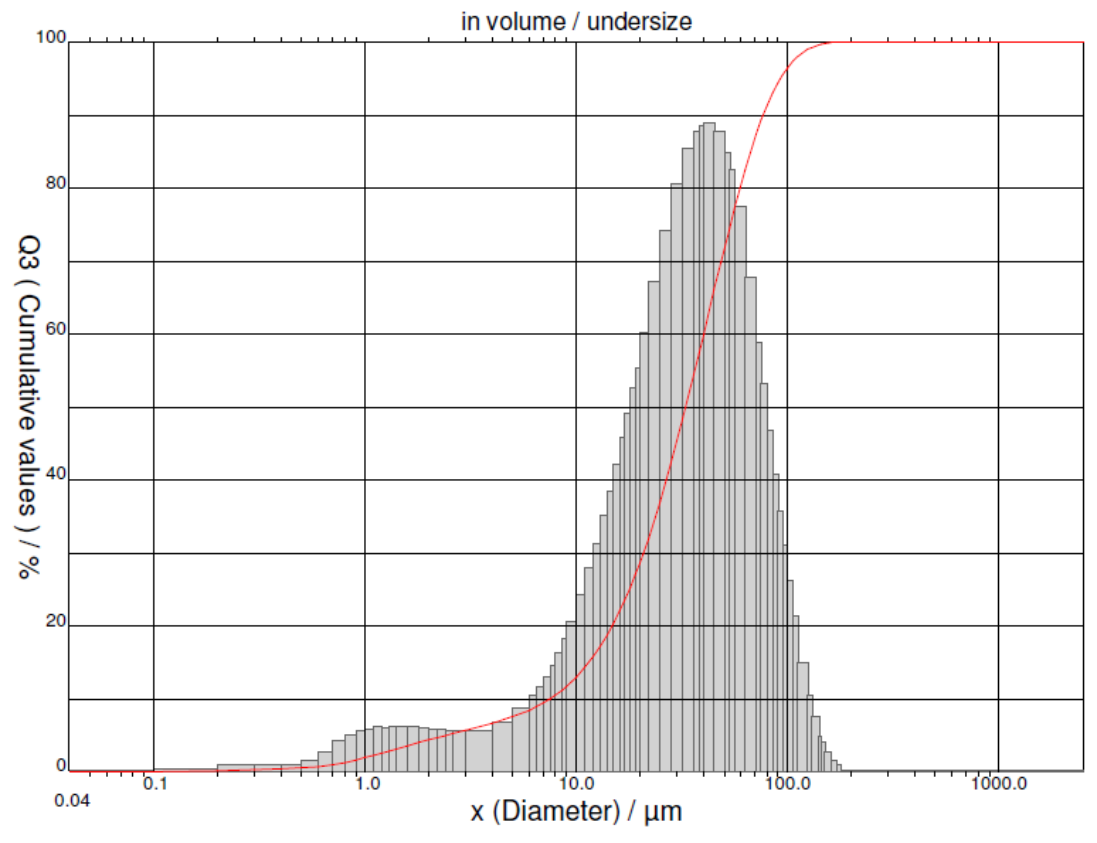

Figure 3.6: Particle Size Analysis Results of Asteroid Simulant 
Table 3.8: Particle Size Analysis Size Distributions

\begin{tabular}{cc}
\hline Size Class & Cumulative Volumetric Fraction, $\%$ \\
\hline$<20 \mu \mathrm{m}$ & 25.69 \\
$<45 \mu \mathrm{m}$ & 45.36 \\
$<75 \mu \mathrm{m}$ & 61.86 \\
$<90 \mu \mathrm{m}$ & 67.81 \\
$<150 \mu \mathrm{m}$ & 82.23 \\
$<250 \mu \mathrm{m}$ & 91.94 \\
$<500 \mu \mathrm{m}$ & 99.71 \\
\hline
\end{tabular}

The calculation for this sample considered $100 \%$ of the entire volume to be smaller than $500 \mu \mathrm{m}$, rather than the intended $90 \mu \mathrm{m}$ limit. This is because, following the seiving process, a hole was found to have formed in one of the sieves, leading to particle contamination Since the regolith particles are all of the same material, and thus the same density, the volumetric percentages are equivlent to cumulative mass percentages for particles $<90 \mu \mathrm{m}$. However, this calculation does not account for the full regolith simulant mixture, but only those particles in the dried sludge. Therefore, an iterative calculation was created in Excel using mass inputs to identify a projected cumulative mass distribution output. These mass inputs would represent the masses of each particle size that would be added to the final regolith simulant design. This design, initially based on the weight percentages that occur in Table 2.5, were then modified to represent the coarser distribution anticipated for asteroid regoliths. The initial size class masses used are listed in the first column of Table 3.9 and generated the "Initial Design" curve in Figure 3.7. The $<90 \mu \mathrm{m}$ cumulative mass was then multiplied by the $<90 \mu \mathrm{m}$ mass fractions derived from the PSA to refine the initial estimate of the regolith simulant design to match the actual size distribution of the $<90 \mu \mathrm{m}$ particles as opposed to that calculated from lunar regolith data. The modified mass inputs, represented in the second column of Table 3.9, then generated the final regolith simulant mass fractions and cumulative mass size distribution found in Figure 3.7 . 
Table 3.9: Regolith Simulant Size Classes

\begin{tabular}{cccc}
\hline Size Class & Initial Regolith Design, \% & Final Regolith Design, \% & Regolith Mass Added, kg \\
\hline$<20 \mu \mathrm{m}$ & 25 & 9 & 3.06 \\
$<45 \mu \mathrm{m}$ & 40 & 21 & 3.72 \\
$<75 \mu \mathrm{m}$ & 50 & 28 & 2.40 \\
$<90 \mu \mathrm{m}$ & 55 & 30 & 0.58 \\
$<150 \mu \mathrm{m}$ & 65 & 49 & 6.27 \\
$<250 \mu \mathrm{m}$ & 75 & 57 & 2.69 \\
$<500 \mu \mathrm{m}$ & 85 & 67 & 3.14 \\
$<1000 \mu \mathrm{m}$ & 90 & 79 & 4.00 \\
$<2000 \mu \mathrm{m}$ & 95 & 91 & 4.00 \\
$<4000 \mu \mathrm{m}$ & 100 & 100 & 3.00 \\
\hline D50 & $75 \mu \mathrm{m}$ & $165 \mu \mathrm{m}$ & 32.86
\end{tabular}

To provide a comparison between the initial and final simulant designs, each design had its $\mathrm{D}_{50}$ calculated, where the $\mathrm{D}_{50}$ represents the particle size at which half of the particles in the sample are smaller and half of the particles larger than that diameter. While the initial $\mathrm{D}_{50}$ was a design target based on the initial lunar regolithbased design, the final design $\mathrm{D}_{50}$ had to be calculated from the existing distribution. Since the $150 \mu \mathrm{m}$ and $250 \mu \mathrm{m}$ classes encompass the diameter that defines $50 \%$ of the total regolith distribution, the $\mathrm{D}_{50}$ was calculated using the equation

$$
\frac{250 \mu m-D 50}{250 \mu m-150 \mu m}=\frac{w t \%_{250 \mu m}-w t \%_{D 50}}{w t \%_{250 \mu m}-w t \%_{150 \mu m}}
$$

Rearranging the equation, D50 can be solved for such that

$$
D_{50}=250 \mu m-(250 \mu m-150 \mu m) * \frac{w t \%_{250 \mu m}-w t \%_{D 50}}{w t \%_{250 \mu m}-w t \%_{150 \mu m}}
$$

Inputting the values for each weight percentage, the D50 can thus be calculated as

$$
D_{50}=250 \mu m-(250 \mu m-150 \mu m) * \frac{56.97 \%-50 \%}{56.97 \%-48.79 \%}=164.8 \mu \mathrm{m}
$$




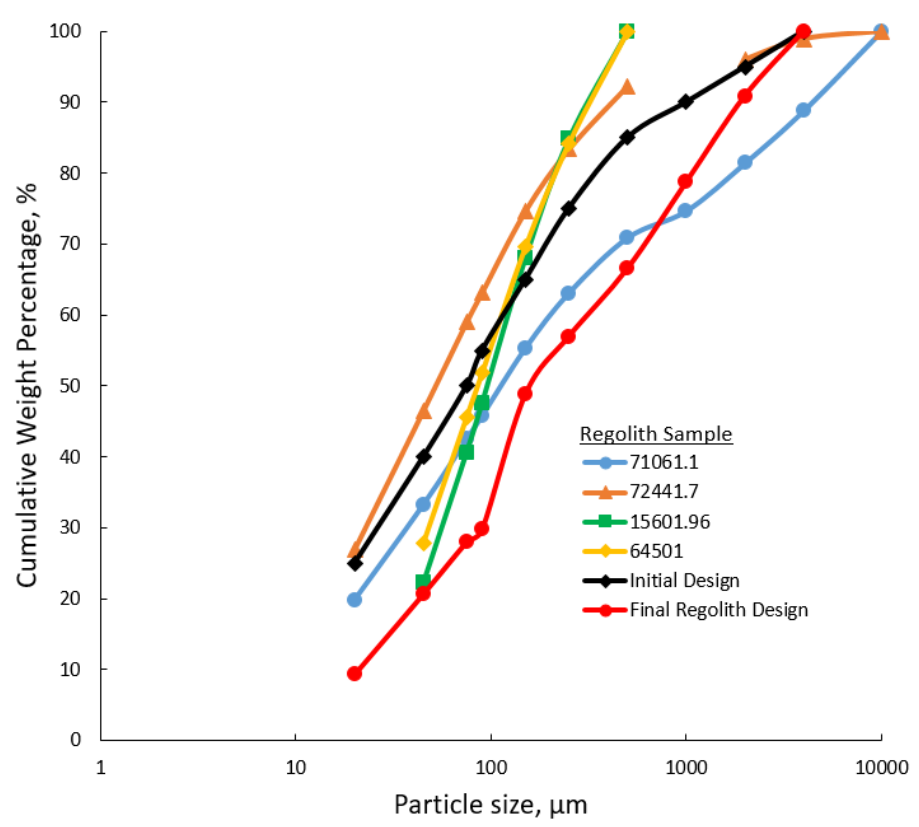

Figure 3.7: Comparison of Asteroid Regolith Size Distributions with Lunar Regolith

The $\mathrm{D}_{50}$ for the final design, $164.8 \mu \mathrm{m}$, is thus 2.2 times that of the initial lunar regolith-based design. To validate this finding, plotting the $\mathrm{D}_{50}$ on the regolith size distribution graph also generates a $\mathrm{D}_{50}$ in the range of $150-170$, thereby demonstrating that this interpolation is valid. This $\mathrm{D}_{50}$ therefore demonstrates that the goal of creating a coarser, more asteroid-like regolith has been achieved. Based on this design, masses for each size class were weighed out and mixed into a five gallon bucket using an electric mixer. The bucket was then mixed by hand to ensure particles were uniformly distributed throughout the bucket.

\subsubsection{Regolith Compactive Load Tests}

In order to test the role of regolith compaction on anchor performance, a method of consistently packing regolith to the same compaction percentage required development. A test method does exist in ASTM D698-12e2 to measure compaction. However, this method requires the dropping of a calibrated ball mass into a bed of soil and provided a method of measuring compaction after it had occurred, as opposed to applying the same degree of compaction to a surface. As a result, a new method and term were developed in order to serve as a proxy for compaction. "Compactive 
load" identifies the loads under which the simulant volume would change by $30 \%$ and $70 \%$ for a uniform initial volume and varying water contents. Since a soil would reach a fully compacted load at the point that the axial stress-strain loading rate becomes linear, e.g. at the minimum point where the tangent elastic modulus equals the rate of elastic deformation, this point was taken to be $100 \%$ compression. As a result, any UCS test performed on a regolith sample could then be used to calculate the load required to achieve $30 \%$ and $70 \%$ compactive loads at different water contents once this point of incompressibility was known.

In order to conduct these loading tests, a testing cylinder was constructed to contain regolith so that the applied force would solely propogate in the axial direction, thereby maximizing compactive load and minimizing radial expansion of the regolith sample. The test cylinder, shown in Figure 3.8, was constructed of 2.06 in. inner diameter PVC pipe cut to 2.5 in. in length. Loading "caps" were developed for the pipe so that the "caps", measuring 1.96 in. in diameter, would load the regolith without contacting the PVC pipe and could move into the pipe as far as necessary to properly load the regolith sample. These "caps" were cut from diabase cores to thicknesses of $0.25 \mathrm{in}$. for the bottom "cap" and $1.125 \mathrm{in}$. for the top "cap". The bottom cap was then glued to the PVC pipe using epoxy so that only one "cap" had mobility and could compress the regolith.

Testing was performed on regolith samples with $0 \%$ and $10 \%$ water content in order to fully identify the effects that varying water content might have on the compressibility of the regolith. Regolith mass and water were mixed at certain ratios in order to prepare regolith with these different water contents. Table 3.10 contains the masses for each bucket, the combined bucket and regolith mass, and the derived total and water masses. Based on the dry regolith masses, the equation below was used to calculate the amount of water required for the $5 \%$ and $10 \%$ water contents:

$$
\begin{gathered}
T-\left(W t . \%_{H 2 O}\right) * T=s \\
T-s=W
\end{gathered}
$$

Where $T$ is the total mass of regolith and water, $s$ is the dry regolith mass, and 
$W$ is the mass of water in the system. Based on the known inputs for $s, T$, and $W t . \%_{220}$, the calculation for the $5 \%$ water regolith thus becomes

$$
\begin{gathered}
T-(0.05) * T=9.758 \mathrm{~kg} \\
T=10.27 \mathrm{~kg} \\
10.27-9.758=0.514 \mathrm{~kg} \mathrm{H}_{2} \mathrm{O}
\end{gathered}
$$

Similarly, the calculation for the $10 \%$ water regolith becomes

$$
\begin{gathered}
T-(0.1) * T=10.05 \mathrm{~kg} \\
T=11.17 \mathrm{~kg} \\
11.17-10.05=1.12 \mathrm{~kg} \mathrm{H}_{2} \mathrm{O}
\end{gathered}
$$

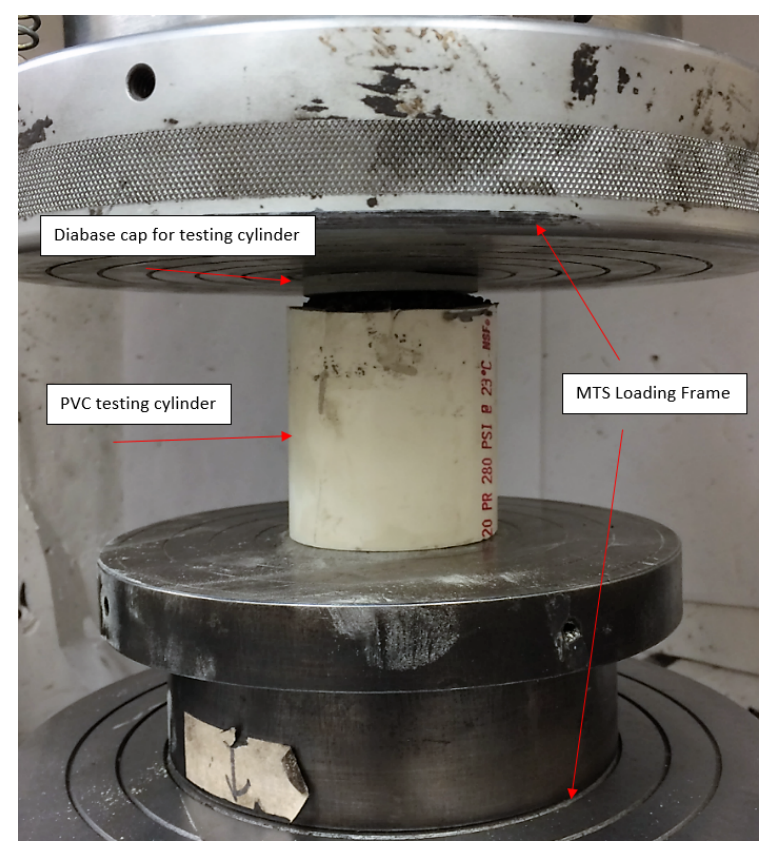

Figure 3.8: Compaction Test Setup 
Table 3.10: Regolith Masses

\begin{tabular}{lccccc}
\hline Sample & Bucket, kg & Bucket and Regolith, kg & Dry Regolith, kg. & Total Mass, kg. & Water Mass, kg. \\
\hline $0 \% \mathrm{H} 2 \mathrm{O}$ & 0.28 & 9.60 & 9.32 & 9.32 & 0.00 \\
$5 \% \mathrm{H} 2 \mathrm{O}$ & 0.28 & 10.04 & 9.76 & 10.27 & 0.51 \\
$10 \% \mathrm{H} 2 \mathrm{O}$ & 0.28 & 10.33 & 10.05 & 11.17 & 1.12 \\
\hline
\end{tabular}

The derived water masses were subsequently weighed out by adding water to a beaker resting on a scale. For each water mass, the scale was first zeroed with the beaker present and the water subsequently poured into the beaker using a graduated cylinder until the water mass had been reached. The beakers of water were then poured into their respective regolith buckets. Finally, the buckets were hand-mixed in order to ensure that no pockets of regolith remained unsaturated by the water.

The regolith compaction tests were initiated by first pouring regolith from the $0 \%$ water content sample into the cylinder until the entire cylinder volume had been filled with regolith. The top "cap" was then placed on top of the regolith, while the cylinder was placed in the MTS load frame. A testing procedure was then developed so that the MTS load frame would apply $10 \mathrm{lbf}$. of force to the sample per minute. This ensured the MTS load frame would accurately capture all of the loading that would take place prior to the initial elastic loading, information that would be critical in determining the point at which linear elastic loading first occurred. Once the program was initiated for each sample, the MTS load frame loaded the sample until the elastic deformation began to take place. At this point, the test was then concluded. This procedure was then repeated for the $10 \%$ water content sample.

Figure 3.9 provides a comparison of how the $0 \%$ and $10 \%$ water content samples performed as they were progressively loaded. The $10 \%$ specimen required the largest applied stress to achieve $100 \%$ compactive load, at 11.91 psi, while the $0 \%$ specimen required 8 psi to reach its full compactive load. The $5 \%$ sample's required load was calculated to be halfway between the $0 \%$ and $10 \%$ water content samples, at 9.96 psi. The results for how these stresses translated to $30 \%$ and $70 \%$ compactive loads are tabulated in Table 3.11. Once these stresses were known, they were each multiplied by the area of the test cylinders that would house the regolith for the pull tests, 28.3 
in. ${ }^{2}$, to find the compressive force required to reach the desired compactive load levels for each sample type.

Table 3.11: Compactive Load Test Results

\begin{tabular}{lccccccc}
\hline \multirow{2}{*}{ Sample } & \multirow{2}{*}{ Stress at $\mathbf{1 0 0 \%}$ compression, psi } & \multicolumn{3}{c}{ Stress } & \multicolumn{3}{c}{ Load, lbf. } \\
& & $0 \%$ & $30 \%$ & $70 \%$ & $0 \%$ & $30 \%$ & $70 \%$ \\
\hline $0 \% \mathrm{H} 2 \mathrm{O}$ & 8 & 0 & 2.4 & 5.6 & 0.0 & 67.9 & 158.3 \\
$5 \% \mathrm{H} 2 \mathrm{O}$ & 9.955 & 0 & 3.0 & 7.0 & 0.0 & 84.4 & 197.0 \\
$10 \% \mathrm{H} 2 \mathrm{O}$ & 11.91 & 0 & 3.6 & 8.3 & 0.0 & 101.0 & 235.7 \\
\hline
\end{tabular}

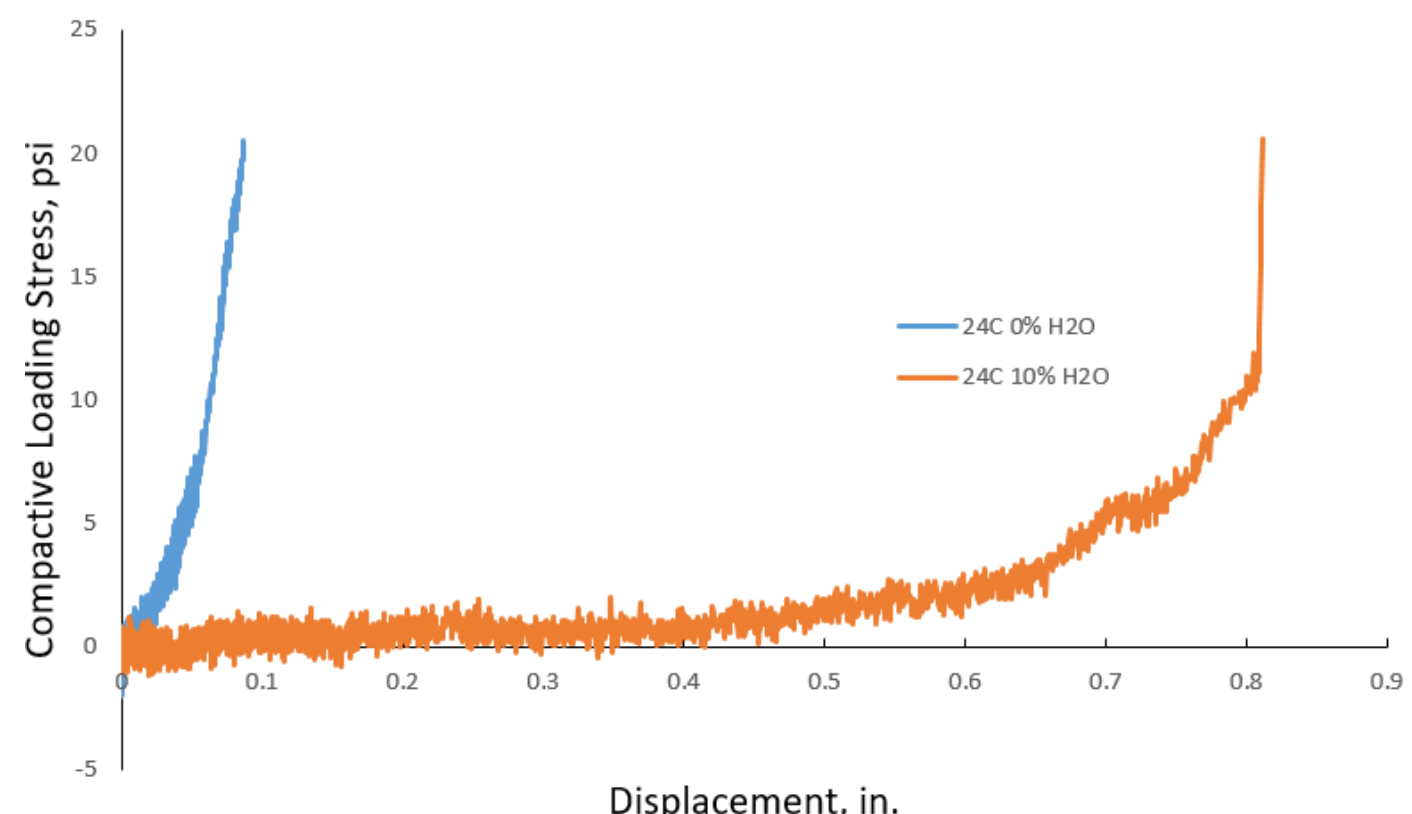

Figure 3.9: Compactive Load Test Results As A Function Of Water Content

\subsubsection{Regolith Pull Test Setup}

The regolith pull tests compared the performance of point anchored, fully-grouted resin, and polyurethane bolts as a function of moisture content, temperature, and compaction. Testing was conducted using plastic concrete molds to hold the regolith samples with 6 in. diameters and 12 in. lengths. To prepare a sample for a test, regolith would first be added to the test mold until the mold was completely full of regolith. Once the mold was filled with regolith it was placed on the MTS load 
frame. A metal cylinder was then placed on top of the regolith and a load applied by the MTS load frame based on the required compactive loading for the specific variable configuration being tested (see Figure 3.10). After the compactive loading, a bolt hole was drilled into the specimen using the Dymodrill coring drill. Because the height of each concrete mold was 12 in., the bolt holes used for the regolith testing were limited to $11 \mathrm{in}$. in order to ensure that the tip of the bolt would anchor in the regolith, rather than press flushly against the plastic mold. Hole and bolt diameters were maintained at $1 \mathrm{in}$. and $0.875 \mathrm{in}$., respectively. Anchors were then installed after the bolt hole had been drilled.

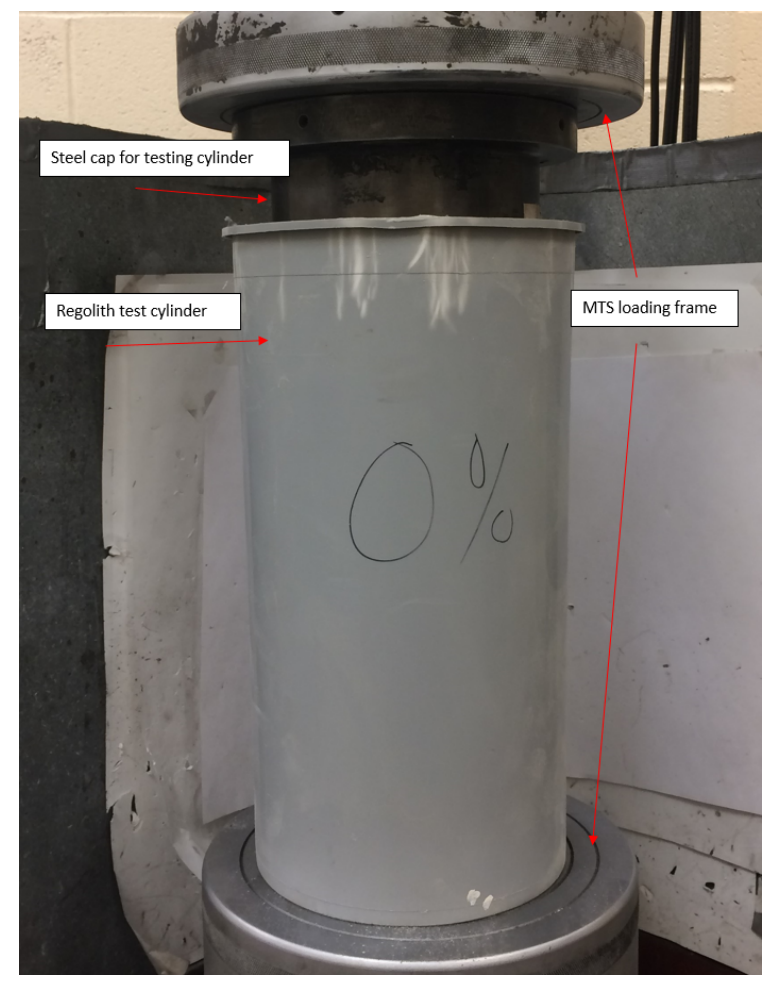

Figure 3.10: Setup for Sample Compactive Loading

During initial sample preparation, $0 \%$ water regolith samples could not have a core adequately extracted from its bolt hole due to the lack of internal cohesion. As a result, sample preparation was modified for the $0 \%$ samples by filling the mold with 
regolith around a PVC tube 11 in. long and 1 in. in diameter. A metal cylinder with a hole in the center typically used in direct shear tests was then used as the loading platform through which the MTS load frame could apply the compaction load to the regolith sample. This cylinder was re-positioned four times to ensure that the entire surface of the sample was compacted by the MTS load frame. After compacting the sample, the PVC tube was gently pulled out of the regolith mold and an anchor installed in the artificial bolt hole. Figure 3.11 demonstrates hole installation in a 5\% water content regolith samples, as well as the resulting bolt hole and the modified installation required for the $0 \%$ water content regolith. 


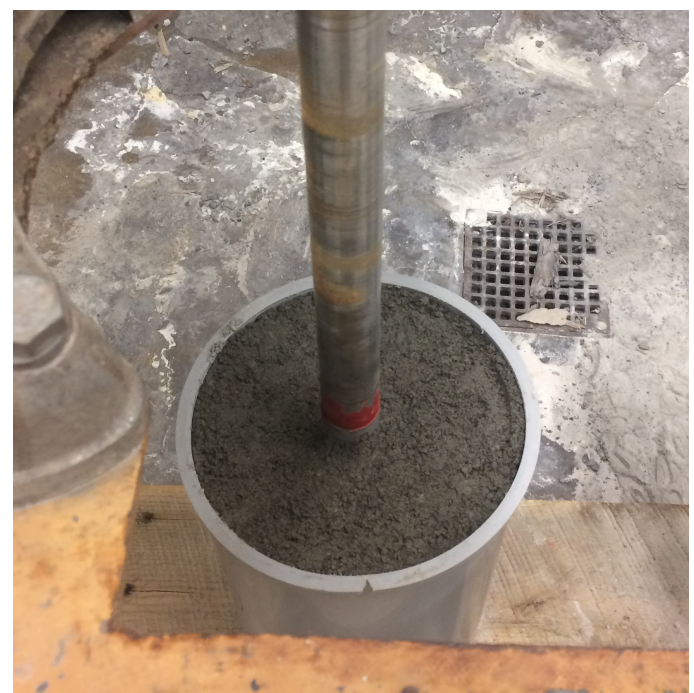

(a) Drilling a Bolt Hole in $10 \%$ wt. Regolith

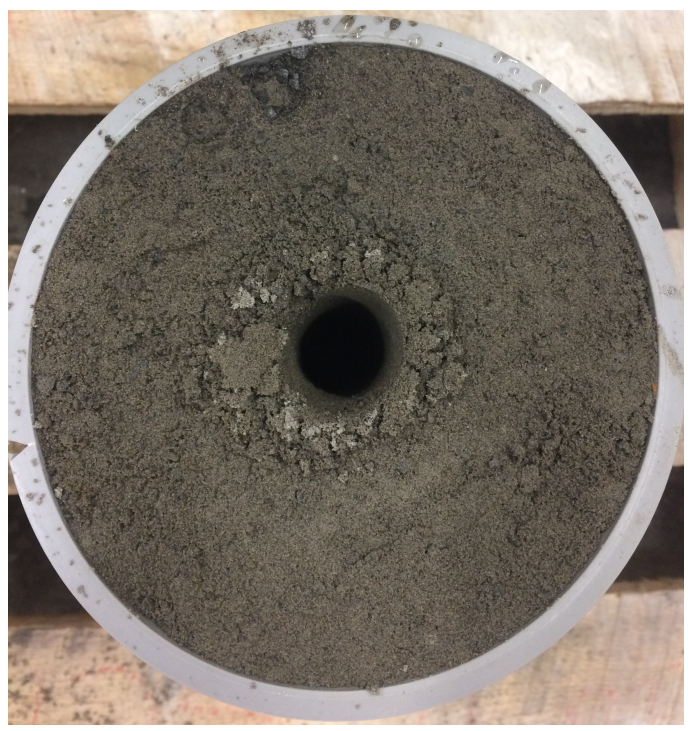

(b) Completed Bolt Hole in 5\%wt. Regolith

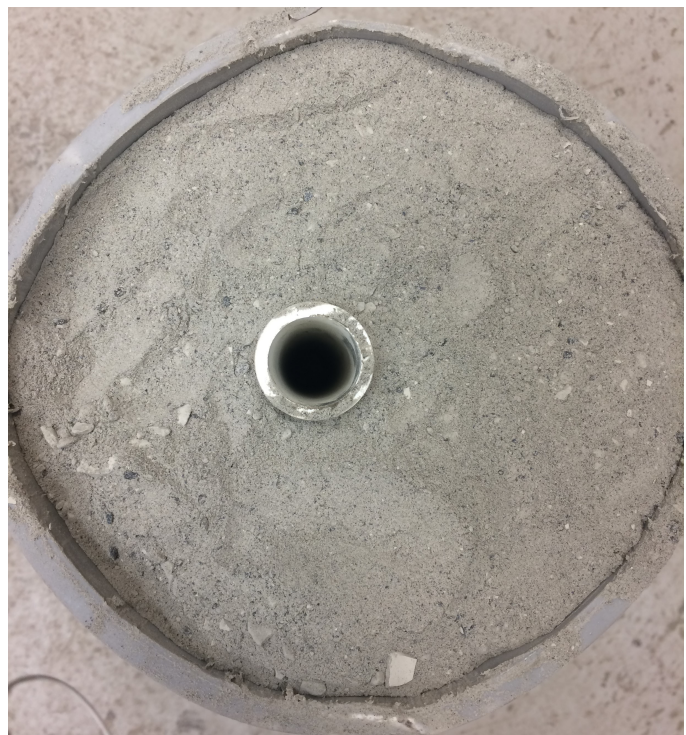

(c) Modified Bolt Hole Preparation for $0 \% \mathrm{wt}$. Regolith

Figure 3.11: Construction of Bolt Holes in Regolith

The specifics of anchor installation varied depending on the type of anchor being installed in the bolt hole. Point anchor installation first began with threading the expansion shell onto the bolt until the top of the shell's nut was flush with the bolt tip. Threading all expansion shells to the same point removed any possible variation in anchorage from premature or delayed shell expansion due to the expansion beginning at different lengths along the bolt. Once the shell was threaded onto the bolt, the bolt was then installed in the bolt hole by hand and rotated clockwise until the bolt could 
no longer be rotated by hand. This rotation ensured that the shell had expanded until the shell leaves had contaced the surface of the bolt hole, thereby anchoring in the bolt hole.

Fully-grouted resin bolts, meanwhile, were installed in a similar manner to the method used for the boulder testing. First, a 12 in. resin cartridge was cut down to $6 \mathrm{in}$. for use in anchoring the rebar bolt. The closed end and sides of this cartridge were then sliced open and the contents of the two-part resin were mixed by hand for 5-10 seconds. The mixed resin was then molded in a cylindrical shape and inserted in the bolt hole. A rebar bolt was installed immediately after the resin and pushed by hand into the hole until the bolt had displaced the resin along its length from the bottom of the hole. The bolt was rotated until the resin had hardened beyond the point of rotation. The resin and bolt were then allowed to cure for 2 hours in the environment at which it would be tested.

Polyurethane bolts were installed in the same manner as that used in the boulder tests as well. Using a 1:1 ratio, 3.38 fl.oz. (100 mL) of each of the two parts comprising the polyurethane were mixed together in a beaker for 30 seconds and then poured into the bolt hole. A rebar bolt was then immediately installed in the bolt hole and rotated until the polyurethane had hardened beyond the point of rotation. The bolt and polyurethane were then allowed to cure for 2 hours in the environment at which they would be tested.

Since temperature effects on anchorage were a key component of this test, the regolith molds required a method to regulate the regolith samples' temperatures at $75{ }^{\circ} \mathrm{F}, 32{ }^{\circ} \mathrm{F}$, and $-9.4{ }^{\circ} \mathrm{F}$. In the first instance, regolith samples were tested under the ambient air condition of $75{ }^{\circ} \mathrm{F}$. Samples could thus cure in the open air and room temperature. Tests examining anchorage at $32{ }^{\circ} \mathrm{F}$, meanwhile, required the regolith to be frozen to $32{ }^{\circ} \mathrm{F}$. Once the bolts being tested had been installed, the regolith molds were stored in a freezer for two hours until the sample had lowered to $32{ }^{\circ} \mathrm{F}$. After measuring the temperature of the regolith using a digital thermometer, the sample was then removed from the freezer and the pull test conducted. The -9.4 ${ }^{0} \mathrm{~F}$ tests, meanwhile, required cooling the regolith to a temperature lower than the 
freezer was capable of achieving. A new configuration for freezing these samples was therefore required and can be seen in Figure 3.12. First, two regolith samples to be frozen down to $-9.4{ }^{0} \mathrm{~F}$ were placed in an empty cooler per freezing iteration. Next, a thermal probe was inserted in a regolith cylinder and dry ice was poured over the regolith cylinders until they were submerged in dry ice. A sheet of thermal insulation was then draped over the cylinders with holes cut in the insulation through which the bolt heads protruded since the bolts' length prevented the cooler lid from completely shutting over top of the cylinders. The regolith cylinders were then left in the cooler until each had frozen to $-9.4{ }^{\circ} \mathrm{F}$. The exact time required for this freezing varied depending on the initial temperature of the regolith. Each cylinder would freeze for the longer time of either 1 hour or until the desired temperature had been achieved. Upon reaching the desired temperature, a cylinder was pulled out of the cooler and a pull test conducted. Once any test had been conducted, the regolith cylinder was allowed to thaw in a five-gallon bucket until the bolt could be extracted from the cylinder by hand. Once the bolt had been removed, the regolith was mixed back into its respective five-gallon storage bucket so that it could be re-used in another regolith test.

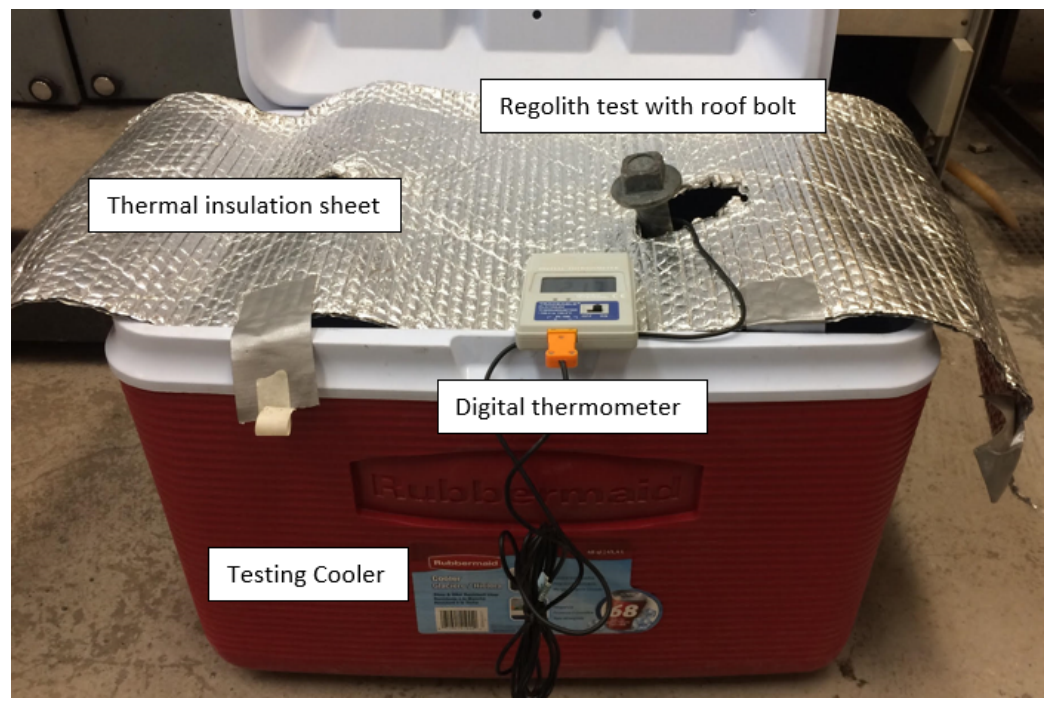

Figure 3.12: Low Temperature Regolith Configuration 
In a pull test conducted on rock, the pull test apparatus typically rests on the rock surface and, as the hydraulic pump is pumped, the loading cylinder will push on the rock while pulling on the bolt. Due to the low strength of the regolith, however, this was not possible since the loading frame would continuously push into the regolith rather than brace against the testing surface. A "bench" was therefore constructed to provide the load cylinder with a frame to brace against, and can be seen in Figure 3.13. A piece of plywood was cut into a circular shape with a diameter of 11 in. A hole 3 in. in diameter was then cut into the center of the plywood so that the bolt heads could fit through the plywood and be pulled by the load cylinder. Metal and wood blocks, meanwhile, were stacked on either side of the regolith mold up to its height of $12 \mathrm{in.}$ The plywood testing surface was then placed on top of the mold and supports, with the bolt head protruding through the central hole in the platform. The pull test loading cylinder was then connected to the bolt head and the hydraulic pump was pumped until the cylinder had been fully pressurized. Once the loading cylinder was fully pressurized, a dial gauge was attached to the top of the loading cylinder to measure displacement in the bolt as a load was applied. The test was then initiated by pumping the hydraulic pump so that the loading cylinder would load the bolt in 1-ton increments. The bolts were loaded until either the pump failed to sustain a load on the bolt, indicating bolt failure, or until the bolt had been subjected to the 28-ton upper limit imposed on the loading for safety.

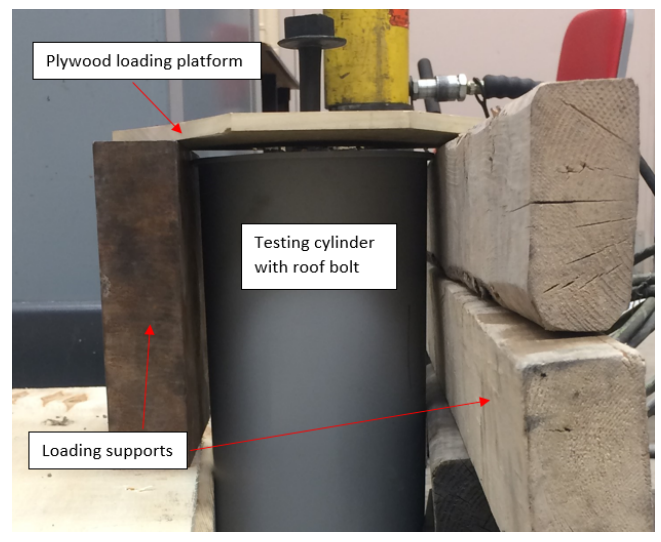

Figure 3.13: Pull Test Loading Platform 


\section{Chapter 4}

\section{Results and Analysis}

\subsection{Data Analysis}

Typical pull test results from a mine will record either the load at which the bolt failed or that the bolt did not fail. Additionally, displacement is recorded while the load is applied so that the loading behavior of the bolt can be better understood. During testing for this study, readings varied between anchorage failure without dis-

placement, failure with displacement, and no failure with displacement. After conducting a qualitative analysis of the results for each test series, a statistical study examined the significance of these apparent trends. This analysis for each test series was conducted using JMP statistical modeling software and allowed each variable's impact on bolt anchorage to be independently identified for each anchorage type.

\subsubsection{Boulder Tests}

A total of 21 tests were conducted in the boulder strength regime. A total of 8 tests failed at varying pullout loads, while the remaining bolts all withstood the 28 ton maximum applied load. The test results have been tabulated in Table 4.1. Of note are a few changes in test parameters that occurred during bolt installation and testing. Torquing the point anchors in sandstone and limestone led to fractures in the boulder and subsequent bolt failure. While the limestone anchor was able to 
hold an initial torque and applied pull load before failing, the sandstone anchor was not. No displacement data was therefore collected for this sandstone test. Similarly, difficulties were encountered during the first two attempts to install fully grouted resin bolts. While installation was partially successful, the bolts were only able to be installed to 6 in. depths due to the resin cartridge filling up the rest of the space in these two bolt holes. As a result, the anchor depths have been changed to reflect the actual, rather than planned, installation depths.

The experimental design, while seeking to replicate a Box-Behnken design, did not incorporate many tests outside of the diabase boulder. The dibase tests were intended to serve as the center point tests due to their mineralogical similarity with asteroid types. Because this study did not seek the development of a response surface, using the diabase as the center point was not thought to be a concern. However, the subsequent test results have shown that there is a potential for the diabase test results to bias the overall trends identified in this testing. The conclusions developed from this analysis should therefore be considered with caution.

An initial summary examining some of the effects between boulder strength, anchor depth, pullout load, and anchor type can be seen in Tables 4.2 and 4.3. In these tables, the average bolt load, bolt displacement, and bolt displacement rate are provided relative to the strength of the rock in which they were anchored and the depth to which they were anchored. Averages for each parameter were taken for each bolt type so that the behavior for a "typical" bolt under those conditions could be identified. In all three rock strength regimes and anchorage depths, fully grouted roof bolts demonstrated less displacement than either point or polyurethane anchors. Additionally, all failures occurred with anchors in 12 in. bolt holes in all three boulder types, while no failures occurred in the 2 in. or 6 in. depths in the diabase boulder. Finally, bolts anchored in sandstone (8875 psi) demonstrated the lowest pullout loads, while bolts anchored in diabase (35,250 psi) demonstrated some of the highest pullout loads achieved during testing. Pullout tests from the weaker limestone (4335 psi), meanwhile, generated larger pullout loads than the sandstone boulder as well. A hypothesis for these results is that, while the limestone boulder 
Table 4.1: Boulder Pull Test Results

\begin{tabular}{ccccc}
\hline Anchor Type & Rock Strength, psi & Anchor Depth, in. & Pullout Load, tons & Displacement, in. \\
\hline Point Anchor & 35,250 & 12 & 28 & 0.0083 \\
Point Anchor & 35,250 & 12 & 28 & 0.0033 \\
Point Anchor & 35,250 & 12 & 28 & 0.0029 \\
Point Anchor & 35,250 & 6.0 & 28 & 0.12 \\
Point Anchor & 35,250 & 2.0 & 28 & 0.035 \\
Point Anchor & 8875 & 12 & 0.0 & 0.0 \\
Point Anchor & 4335 & 12 & 7.5 & 0.32 \\
FGRB & 35,250 & 6.0 & 28 & 0.0005 \\
FGRB & 35,250 & 6.0 & 28 & 0.033 \\
FGRB & 35,250 & 12 & 28 & 0.033 \\
FGRB & 35,250 & 6.0 & 28 & 0.032 \\
FGRB & 35,250 & 2.0 & 28 & 0.023 \\
FGRB & 8875 & 12 & 2.5 & 0.082 \\
FGRB & 4335 & 12 & 28 & 0.0 \\
PUR & 35,250 & 12 & 2.0 & 0.13 \\
PUR & 35,250 & 12 & 3.5 & 0.045 \\
PUR & 35,250 & 12 & 1.0 & 0.14 \\
PUR & 35,250 & 6.0 & 28 & 0.033 \\
PUR & 35,250 & 2.0 & 28 & 0.049 \\
PUR & 8875 & 12 & 2.5 & 0.11 \\
PUR & 4335 & 12 & 9.0 & 0.087 \\
\hline
\end{tabular}

demonstrated an overall increase in pullout load, a feature of the sandstone, rather than a relationship with boulder strength, led to the poor performance in the 8875 psi strength regime.

Following this initial characterization, an analysis of variance was conducted using JMP software to identify any significant relationships amongst the anchoring variables and anchor types. Two tests were run per anchor type to identify how anchor pullout load and anchor displacement varied with rock strength and installation depth. Rock strength was identified as a significant parameter in point anchor pullout load. In this test, the $\mathrm{p}$-value for rock strength was $\mathrm{p}=0.00285$, while the $\mathrm{p}$-value for anchor depth was $\mathrm{p}=0.94089$. Additionally, anchor depth was found to be a signficiant parameter in polyurethane pullout load, with $\mathrm{p}=0.00283$ for anchor depth and $\mathrm{p}=0.43206$ for rock strength. These results, however, should be regarded with a measure of skepticism. Failures in the sandstone block regardless of anchor type are hypothesized to have 
Table 4.2: Average Bolt Behavior Relative to Rock Strength

\begin{tabular}{ccccc}
\hline Anchor Type & Rock Strength, psi & Pullout Load, tons & Displacement, in. & Displ. rate, in./ton \\
\hline Point Anchor & 35,250 & 28 & 0.034 & 0.0012 \\
FGRB & 35,250 & 28 & 0.024 & 0.00087 \\
PUR & 35,250 & 13 & 0.079 & 0.0063 \\
Point Anchor & 8875 & 0.0 & 0.0 & $\mathrm{~N} / \mathrm{A}$ \\
FGRB & 8875 & 2.5 & 0.082 & 0.033 \\
PUR & 8875 & 2.5 & 0.11 & 0.044 \\
Point Anchor & 4335 & 7.5 & 0.32 & 0.043 \\
FGRB & 4335 & 28 & 0.0 & 0.0 \\
PUR & 4335 & 9.0 & 0.087 & 0.0097 \\
\hline
\end{tabular}

Table 4.3: Average Bolt Behavior Relative to Anchor Depth

\begin{tabular}{ccccc}
\hline Anchor Type & Anchor Depth, in. & Pullout Load, tons & Displacement, in. & Displ. rate, in./ton \\
\hline Point Anchor & 12 & 23 & 0.084 & 0.0037 \\
FGRB & 12 & 20 & 0.038 & 0.0020 \\
PUR & 12 & 3.6 & 0.10 & 0.028 \\
Point Anchor & 6 & 28 & 0.12 & 0.0043 \\
FGRB & 6 & 28 & 0.022 & 0.00077 \\
PUR & 6 & 28 & 0.033 & 0.0012 \\
Point Anchor & 2 & 28 & 0.035 & 0.0013 \\
FGRB & 2 & 28 & 0.023 & 0.00083 \\
PUR & 2 & 28 & 0.049 & 0.0017 \\
\hline
\end{tabular}


originated with internal fractures within the sandstone block. These results, combined with the large number of successful diabase tests, likely generated this "false positive" data. The failures in sandstone, all using $12 \mathrm{in.}$ deep bolt holes, possibly biased the results of the anchor depth analysis and generated another set of "false positive" results. Further anchor testing in larger sandstone and limestone blocks with varying anchor depths would clarify if these initial results were biased or truly indicative of anchor depth acting as a significant parameter in pullout load.

\subsubsection{Regolith Tests}

Of the original 45 tests conducted in regolith, 30 tests failed prior to taking loading and displacement measurements. These failures are hypothesized to have occurred while pressurizing the loading cylinder prior to loading the bolt. During this process, the pull collar contacts the bolt head and exerts a small force on the bolt as each pump of the jack vertically displaces the loading cylinder's hydraulic fluid reservoir, thereby pressurizing the loading cylinder. The reaction force of the bolt's anchorage generally provides enough resistance for the load cylinder to be fully pressurized and begin loading the bolt head. During the regolith tests, however, it is hypothesized that the pull claw pulled the bolt out of its anchorage while the load cylinder continued to pressurize. Once the oil reservoir had reached its mechanical limit of extension, the load cylinder would then begin to reflect a "load" on the bolt

head and no displacement, with the "load" actually indicating a buildup of pressure inside the loading cylinder. This process culminated in results that would otherwise indicate that bolts had reached a 28 ton load with 0 in. of displacement. Each pressurizing pump of the jack is less than 1 ton of load, however, and so each test that failed in this manner must have failed at a load less than 1 ton. Since these failures occured while the loading cylinder was undergoing pressurization and the oil reservoir had not yet extended to its mechanical limit, the dial gauge had not yet been installed. No vertical displacement measurements therefore exist for these failed tests. The failed tests are recorded in Table 4.4. Of special note in Table 4.4 are the tests marked by an asterisk. These tests have been recorded as failures because the 
tests indicated 0 in. of displacement under loads of 28 tons. However, other tests under similar temperatures and water contents successfully anchored into the regolith. Tests in the $-9.4^{\circ} \mathrm{F}$ regolith in particular generated very low displacements, and so these "failed" tests may have actually been successful anchors with no displacement. Further testing of these conditions may clarify if the anchors truly fail under these conditions.

Table 4.4: Failed Regolith Pull Tests

\begin{tabular}{|c|c|c|c|c|}
\hline Anchor Type & Temperature, ${ }^{\circ} \mathbf{F}$ & Ice Content, \%wt. & Compactive Load, \% & Failure Load, tons \\
\hline Point Anchor & $75^{\circ} \mathrm{F}$ & $0 \%$ & $30 \%$ & 1 tons \\
\hline Point Anchor & $75^{\circ} \mathrm{F}$ & $5 \%$ & $0 \%$ & 1 tons \\
\hline Point Anchor & $32^{\circ} \mathrm{F}$ & $0 \%$ & $30 \%$ & 1 tons \\
\hline Point Anchor & $32^{\circ} \mathrm{F}$ & $5 \%$ & $0 \%$ & 1 tons \\
\hline Point Anchor & $32^{\circ} \mathrm{F}$ & $5 \%$ & $70 \%$ & 1 tons \\
\hline Point Anchor & $-9.4^{\circ} \mathrm{F}$ & $0 \%$ & $0 \%$ & 1 tons \\
\hline Point Anchor* & $-9.4^{\circ} \mathrm{F}$ & $5 \%$ & $30 \%$ & 1 tons \\
\hline Point Anchor* & $-9.4^{\circ} \mathrm{F}$ & $5 \%$ & $30 \%$ & 1 tons \\
\hline FGRB & $75^{\circ} \mathrm{F}$ & $0 \%$ & $30 \%$ & 1 tons \\
\hline FGRB & $75^{\circ} \mathrm{F}$ & $5 \%$ & $70 \%$ & 1 tons \\
\hline FGRB & $75^{\circ} \mathrm{F}$ & $10 \%$ & $30 \%$ & 1 tons \\
\hline FGRB & $32{ }^{\circ} \mathrm{F}$ & $0 \%$ & $30 \%$ & 1 tons \\
\hline FGRB & $32^{\circ} \mathrm{F}$ & $5 \%$ & $0 \%$ & 1 tons \\
\hline FGRB & $-9.4^{\circ} \mathrm{F}$ & $0 \%$ & 70 & 1 tons \\
\hline FGRB & $-9.4^{\circ} \mathrm{F}$ & $5 \%$ & $30 \%$ & 1 tons \\
\hline FGRB & $-9.4^{\circ} \mathrm{F}$ & $5 \%$ & $30 \%$ & 1 tons \\
\hline FGRB* & $-9.4^{\circ} \mathrm{F}$ & $10 \%$ & $0 \%$ & 1 tons \\
\hline FGRB* & $-9.4^{\circ} \mathrm{F}$ & $10 \%$ & $70 \%$ & 1 tons \\
\hline PUR & $75^{\circ} \mathrm{F}$ & $5 \%$ & $0 \%$ & 1 tons \\
\hline PUR & $75^{\circ} \mathrm{F}$ & $5 \%$ & $70 \%$ & 1 tons \\
\hline PUR & $75^{\circ} \mathrm{F}$ & $10 \%$ & $30 \%$ & 1 tons \\
\hline PUR & $32{ }^{\circ} \mathrm{F}$ & $0 \%$ & $30 \%$ & 1 tons \\
\hline PUR & $32{ }^{\circ} \mathrm{F}$ & $5 \%$ & $0 \%$ & 1 tons \\
\hline PUR & $32{ }^{\circ} \mathrm{F}$ & $5 \%$ & $70 \%$ & 1 tons \\
\hline PUR & $32^{\circ} \mathrm{F}$ & $10 \%$ & $30 \%$ & 1 tons \\
\hline PUR & $-9.4^{\circ} \mathrm{F}$ & $0 \%$ & $0 \%$ & 1 tons \\
\hline PUR & $-9.4^{\circ} \mathrm{F}$ & $0 \%$ & $70 \%$ & 1 tons \\
\hline $\mathrm{PUR}^{*}$ & $-9.4^{\circ} \mathrm{F}$ & $5 \%$ & $30 \%$ & 1 tons \\
\hline PUR* & $-9.4^{\circ} \mathrm{F}$ & $5 \%$ & $30 \%$ & 1 tons \\
\hline PUR* & $-9.4^{\circ} \mathrm{F}$ & $10 \%$ & $0 \%$ & 1 tons \\
\hline
\end{tabular}


The results of the remaining 15 tests may be seen in Table 4.5. Average displacement values were calculated for each anchor type based on these results and can be seen in Table 4.6. Dividing these average displacement values by the 28-ton maximum load each bolt received then generated the nominal displacement rate, while dividing the number of failed tests for a bolt by the number of total tests performed generated the success rate. Fully grouted roof bolts generated the lowest displacement, at $0.0034 \mathrm{in}$., and subsequently had the lowest displacement rate of 0.00012 in./ton. Point anchors edged out polyurethane anchors in both categories, at 0.0061 in. vs. 0.0077 in. and 0.00022 in./ton vs. 0.00028 in./ton, respectively. However, point anchors were the most reliable anchor type overall, with a success rate of $46.6 \%$ vs. the $33.3 \%$ for fully grouted roof bolts and $20 \%$ for polyurethane bolts (see Figure $4.1)$.
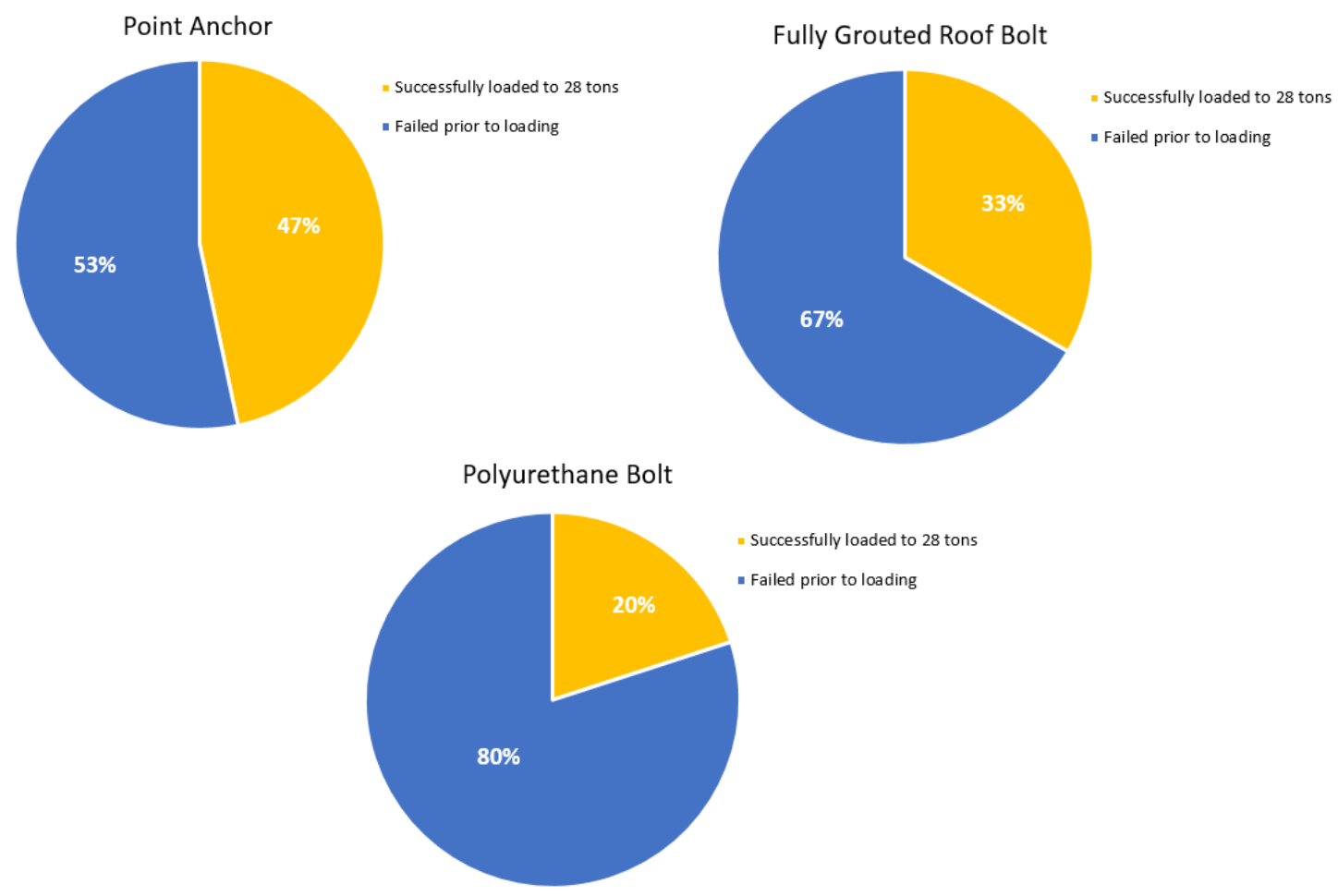

Figure 4.1: Overall Success Rates for Anchor Types

The results from Table 4.5 can also be reconstructed to provide useful trends on how the bolt behavior changed according to specific variables and bolt types. Tables 4.7, 4.8, and 4.9 show how bolt test success rate and average displacement 
Table 4.5: Regolith Pull Test Results

\begin{tabular}{ccccc}
\hline Anchor Type & Temperature, $^{\circ} \mathbf{F}$ & Ice Content, \%wt. & Compactive Load, \% & Displacement, in. \\
\hline Point Anchor & $75{ }^{\circ} \mathrm{F}$ & $5 \%$ & $70 \%$ & 0.0065 in. \\
Point Anchor & $75{ }^{\circ} \mathrm{F}$ & $10 \%$ & $30 \%$ & $0.0122 \mathrm{in}$. \\
Point Anchor & $32{ }^{\circ} \mathrm{F}$ & $10 \%$ & $30 \%$ & $0.0049 \mathrm{in}$. \\
Point Anchor & $-9.4{ }^{\circ} \mathrm{F}$ & $0 \%$ & $70 \%$ & $0.0045 \mathrm{in}$. \\
Point Anchor & $-9.4{ }^{\circ} \mathrm{F}$ & $5 \%$ & $30 \%$ & $0.011 \mathrm{in}$. \\
Point Anchor & $-9.4{ }^{\circ} \mathrm{F}$ & $10 \%$ & $0 \%$ & $0.0015 \mathrm{in}$. \\
Point Anchor & $-9.4{ }^{\circ} \mathrm{F}$ & $10 \%$ & $70 \%$ & $0.0024 \mathrm{in}$. \\
FGRB & $75{ }^{\circ} \mathrm{F}$ & $5 \%$ & $0 \%$ & $0.002 \mathrm{in}$. \\
FGRB & $32{ }^{\circ} \mathrm{F}$ & $5 \%$ & $70 \%$ & $0.0032 \mathrm{in}$. \\
FGRB & $32{ }^{\circ} \mathrm{F}$ & $10 \%$ & $30 \%$ & $0.0012 \mathrm{in}$. \\
FGRB & $-9.4{ }^{\circ} \mathrm{F}$ & $0 \%$ & $0 \%$ & $0.0055 \mathrm{in}$. \\
FGRB & $-9.4{ }^{\circ} \mathrm{F}$ & $5 \%$ & $30 \%$ & $0.0049 \mathrm{in}$. \\
PUR & $75{ }^{\circ} \mathrm{F}$ & $0 \%$ & $30 \%$ & $0.0088 \mathrm{in}$. \\
PUR & $-9.4{ }^{\circ} \mathrm{F}$ & $5 \%$ & $30 \%$ & $0.0028 \mathrm{in}$. \\
PUR & $-9.4{ }^{\circ} \mathrm{F}$ & $10 \%$ & $70 \%$ & $0.0115 \mathrm{in}$.
\end{tabular}

Table 4.6: Comparison of Bolt Types and Displacement in Regolith

\begin{tabular}{cccc}
\hline Anchor Type & Displacement, in. & Displacement Rate, in./ton & Success Rate, \% \\
\hline Point Anchor & 0.0061 in. & 0.00022 in $/$ ton & $46.7 \%$ \\
FGRB & 0.0034 in. & $0.00012 \mathrm{in} /$ ton & $33.3 \%$ \\
PUR & 0.0077 in. & $0.00028 \mathrm{in} . /$ ton & $20 \%$ \\
\hline
\end{tabular}

rate changed between bolt types as a function of water content, regolith temperature, and regolith compactive load, respectively. Figure 4.6 offers a visual representation of this data.

Qualitatively, several observations can be made regarding trends in anchor performance with respect to specific regolith variables. The success rate for conducting pull tests that did not fail prior to loading generally increased with increasing water content. Point anchors in particular demonstrated greater anchorage success as water content of the regolith increased. While fully grouted roof bolts did not demonstrate the same trend in success rate, they did slightly decrease in displacement rate as water content increased. All three anchorage types demonstrated net gains of 3-7\% in success rate between $75{ }^{0} \mathrm{~F}$ and $-9.4{ }^{0} \mathrm{~F}$. Point anchors demonstrated a slight decrease 
Table 4.7: Pull Test Success and Displacement Rates' Dependency on Water Content

\begin{tabular}{ccccc}
\hline Anchor Type & $\mathbf{H}_{\mathbf{2}} \mathbf{O}$ Content, \%wt. & Successful/Total Tests & Success Rate, \% & Displ. Rate, in./ton \\
\hline Overall & $0 \%$ & $3 / 12$ & $25 \%$ & $0.00022 \mathrm{in.} /$ ton \\
Overall & $5 \%$ & $6 / 21$ & $28.6 \%$ & $0.00018 \mathrm{in} . /$ ton \\
Overall & $10 \%$ & $6 / 12$ & $50 \%$ & $0.00020 \mathrm{in} . /$ ton \\
Point Anchor & $0 \%$ & $1 / 4$ & $25 \%$ & $0.00016 \mathrm{in} . /$ ton \\
Point Anchor & $5 \%$ & $2 / 7$ & $28.6 \%$ & $0.00031 \mathrm{in} . /$ ton \\
Point Anchor & $10 \%$ & $4 / 4$ & $100 \%$ & $0.00019 \mathrm{in} . /$ ton \\
FGRB & $0 \%$ & $1 / 4$ & $25 \%$ & $0.00020 \mathrm{in} . /$ ton \\
FGRB & $5 \%$ & $3 / 7$ & $42.9 \%$ & $0.00012 \mathrm{in} . /$ ton \\
FGRB & $10 \%$ & $1 / 4$ & $25 \%$ & $0.00004 \mathrm{in} . /$ ton \\
PUR & $0 \%$ & $1 / 4$ & $25 \%$ & $0.00031 \mathrm{in} . /$ ton \\
PUR & $5 \%$ & $1 / 7$ & $14.3 \%$ & $0.00010 \mathrm{in} . /$ ton \\
PUR & $10 \%$ & $1 / 4$ & $25 \%$ & $0.00041 \mathrm{in} . /$ ton \\
\hline
\end{tabular}

in displacement rate as temperature decreased, while fully grouted roof bolts had a slight increase in displacement rate. The overall success rate for tests generally increased when compactive load alone is examined, with a large increasing success rate for point anchors and a decreasing success rate for fully grouted roof bolts combining to create the more moderate overall increasing success rate. Fully grouted roof bolts showed a slight decrease in displacement rate when considering the role of compactive load.

While this analysis has thus far examined only the results of tests that did not fail, an analysis of variance (ANOVA) for all of the regolith pull tests was used to identify possible statistically significant relationships related to bolt strength and displacement. JMP was again used to conduct this analysis. Bolts that did not fail were assigned a pullout load of 28 tons since this was the maximum applied to the bolts. Bolts that did fail, meanwhile, were assigned a failure load of 1 ton since these bolts all failed to sustain loads above 1 ton. The displacement values for these bolts were assigned a value of 0 in. since the bolts failed prior to the recording of bolt displacements. The ANOVA analysis was then conducted for each bolt type twice, with bolt load serving as the dependent variable in one analysis and bolt displacement in the other. An analysis of the test results using displacement as the dependent 
Table 4.8: Pull Test Success and Displacement Rates' Dependency on Temperature

\begin{tabular}{ccccc}
\hline Anchor Type & Temperature, ${ }^{\circ} \mathbf{F}$ & Successful/Total Tests & Success Rate, \% & Displ. Rate, in./ton \\
\hline Overall & $75{ }^{\circ} \mathrm{F}$ & $4 / 12$ & $33.33 \%$ & $0.00026 \mathrm{in} . /$ ton \\
Overall & $32{ }^{\circ} \mathrm{F}$ & $3 / 12$ & $25 \%$ & $0.00011 \mathrm{in} . /$ ton \\
Overall & $-9.4{ }^{\circ} \mathrm{F}$ & $8 / 21$ & $38.1 \%$ & $0.00020 \mathrm{in} . /$ ton \\
Point Anchor & $75{ }^{\circ} \mathrm{F}$ & $2 / 4$ & $50 \%$ & $0.00033 \mathrm{in} . /$ ton \\
Point Anchor & $32{ }^{\circ} \mathrm{F}$ & $1 / 4$ & $25 \%$ & $0.00018 \mathrm{in} . /$ ton \\
Point Anchor & $-9.4{ }^{\circ} \mathrm{F}$ & $4 / 7$ & $57 \%$ & $0.00017 \mathrm{in} . /$ ton \\
FGRB & $75{ }^{\circ} \mathrm{F}$ & $1 / 4$ & $25 \%$ & $0.000071 \mathrm{in} . /$ ton \\
FGRB & $32{ }^{\circ} \mathrm{F}$ & $2 / 4$ & $50 \%$ & $0.000079 \mathrm{in} . /$ ton \\
FGRB & $-9.4{ }^{\circ} \mathrm{F}$ & $2 / 7$ & $28.6 \%$ & $0.00019 \mathrm{in} . /$ ton \\
PUR & $75{ }^{\circ} \mathrm{F}$ & $1 / 4$ & $25 \%$ & $0.00031 \mathrm{in} . /$ ton \\
PUR & $32{ }^{\circ} \mathrm{F}$ & $0 / 4$ & $0 \%$ & $\mathrm{~N} / \mathrm{A}$ \\
PUR & $-9.4{ }^{\circ} \mathrm{F}$ & $2 / 7$ & $28.6 \%$ & $0.00026 \mathrm{in} . /$ ton \\
\hline
\end{tabular}

Table 4.9: Pull Test Success and Displacement Rates' Dependency on Compactive Load

\begin{tabular}{ccccc}
\hline Anchor Type & Compactive Load, \% & Successful/Total Tests & Success Rate, \% & Displ. Rate, in./ton \\
\hline Overall & $0 \%$ & $3 / 12$ & $25 \%$ & $0.00300 \mathrm{in} . /$ ton \\
Overall & $30 \%$ & $7 / 21$ & $33.3 \%$ & $0.00016 \mathrm{in} . /$ ton \\
Overall & $70 \%$ & $5 / 12$ & $41.7 \%$ & $0.00020 \mathrm{in} . /$ ton \\
Point Anchor & $0 \%$ & $1 / 4$ & $25 \%$ & $0.00005 \mathrm{in} . /$ ton \\
Point Anchor & $30 \%$ & $3 / 7$ & 42.9 & $0.00033 \mathrm{in} . /$ ton \\
Point Anchor & $70 \%$ & $3 / 4$ & $75 \%$ & $0.00016 \mathrm{in} . /$ ton \\
FGRB & $0 \%$ & $2 / 4$ & $50 \%$ & $0.00375 \mathrm{in} . /$ ton \\
FGRB & $30 \%$ & $2 / 7$ & $28.9 \%$ & $0.00305 \mathrm{in} . /$ ton \\
FGRB & $70 \%$ & $1 / 4$ & $25 \%$ & $0.00011 \mathrm{in} . /$ ton \\
PUR & $0 \%$ & $0 / 4$ & $0 \%$ & $\mathrm{~N} / \mathrm{A}$ \\
PUR & $30 \%$ & $2 / 7$ & $8.9 \%$ & $0.00021 \mathrm{in} . /$ ton \\
PUR & $70 \%$ & $1 / 4$ & $25 \%$ & $0.00041 \mathrm{in} . /$ ton \\
\hline
\end{tabular}




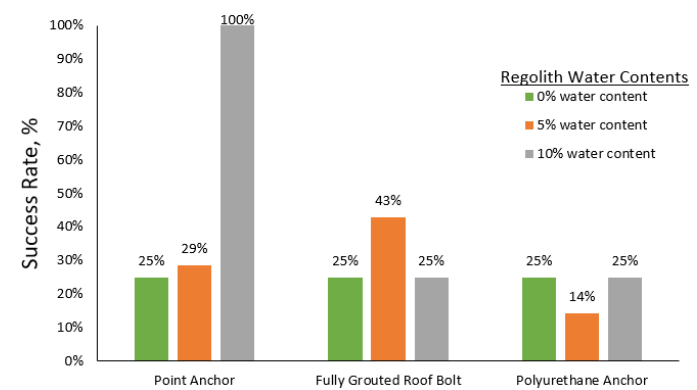

(a) Bolt Behavior With Varying Water Content

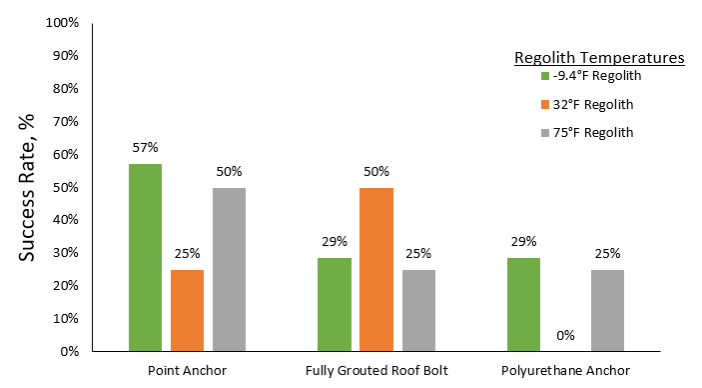

(b) Bolt Behavior With Varying Temperature

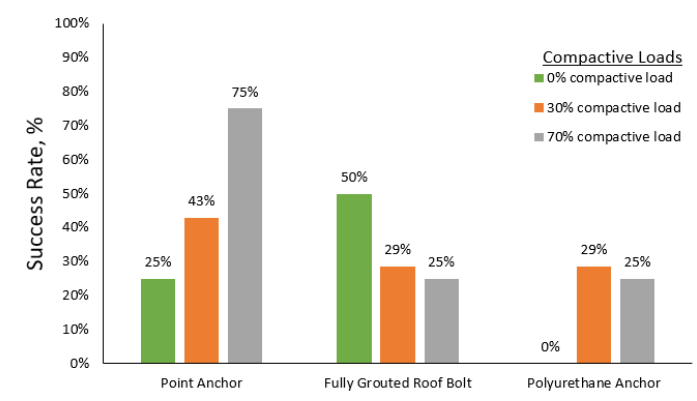

(c) Bolt Behavior With Varying Compctive Load

Figure 4.2: Comparison of Anchor Success Under Varying Conditions

variable found that no parameter played a significant role in bolt displacement.

Using bolt load as the dependent variable, some of the tested variables were found to be significant parameters, i.e. $\mathrm{p}<0.05$, for the point anchor tests. The $\mathrm{p}$-value for comparing regolith water content with pullout load for point anchors was found to be $\mathrm{p}=0.0323$ when including temperature $(\mathrm{p}=0.692)$ and compactive load $(\mathrm{p}=$ 0.127 ) in the analysis. After conducting an analysis with temperature removed from the calculation due to its high $\mathrm{p}$-value, the $\mathrm{p}$-value for water content decreased to $\mathrm{p}=$ 0.0260 and the $\mathrm{p}$-value for compactive load decreased to $\mathrm{p}=0.112$. The results for fully grouted roof bolt and polyurethane bolts, by contrast, did not identify any parameter as playing a significant role in anchor performance. The p-values for water content, temperature, and compactive load for fully grouted roof bolts were $p=1.00, p=0.991$, and $\mathrm{p}=0.548$, while the results for polyurethane anchors were $\mathrm{p}=1.00, \mathrm{p}=0.802$, and $\mathrm{p}=0.496$, resepectively. This is because the pullout loads were either 1 or 28 tons, and so any attempt to model the relationship will fall in between the two extremes. The variation in the models for all three bolts' relationship with compactive load is 
likely a result of more data points having accumulated at one pullout load extreme or the other, rather than any significant underlying relationship. Further testing with a more sensitive loading cylinder is necessary to confirm that this relationship is not the result of bias introduced by the premature bolt failures.

\subsection{Interpretation}

\subsubsection{Performance of Anchors}

The summary of the JMP results for the boulder and regolith test series in Table 4.10 provides one method of directly comparing the effects of different operating conditions on bolt anchorage. Several overarching trends may be identified based on trends identified during the analysis of the test data. First, fully grouted roof bolts outperformed point anchor and polyurethane bolts in terms of minimum displacement exhibited for any testing condition in the boulder test series. This result did not carry through to the regolith test series, where fully grouted roof bolts generated the same relative levels of displacement as point anchor and polyurethane bolts. Fully grouted roof bolts also sustained lower pullout loads than point anchors during the regolith tests, with only one third of the fully grouted roof bolts successfully resisting a load higher than 2 tons. In the boulder strength regime, fully grouted roof bolts exhibited an ability to anchor in diabase and limestone, with only one failure recorded in the sandstone strength regime. Similar polyurethane and point anchor failures in the sandstone regime indicate a failing in the boulder itself, rather than with the bolts.

The polyurethane bolts, by contrast, consistently performed at a lower level of effectiveness than point anchor or fully grouted roof bolts. Polyurethane bolts generated the largest amounts of displacement of any bolt type during the boulder tests while only sustaining pullout loads of 28 tons twice. These bolts did, however, successfully withstand loads of 28 tons at only 2 in. and 6 in. of depth. During regolith tests, the polyurethane bolts generated the same range of displacement values as other

bolt types. Only three tests successfully withstood pullout loads of greater than 2 
tons, the lowest amount of successful anchors of the three bolt types.

The point anchor bolts consistently sustained pullout load results either the same as or exceeding those of fully grouted roof bolts. The point anchor bolts all succeeded in sustaining 28 ton pullout loads in diabase, but failed in both the sandstone and limestone boulders. These failures are hypothesized to have occurred due to a lack of confining pressure around the boulders that would have increased their strength and resisted the bolt's installation torque. This issue could be resolved by anchoring in an area with a larger confining stress, which would strengthen the overall rock mass. The bolts' displacements were greater than those exhibited by fully grouted roof bolts, but this is not considered to be a concern because 1) the displacements were not significant enough to induce failure, and 2) the bolts require some initial displacement after installation in order for the serrated edges of the anchor shell to engage the walls of the bolt hole. In the regolith tests, meanwhile, point anchors became the bolt type with the largest number of tests to withstand the initial load of 2 tons, with seven out of fifteen tests loading to 28 tons. This success rate, combined with anchorage rates comparable to those generated by fully grouted roof bolts in the boulder strength regime, make point anchorage the preferable anchoring mechanism for a utilitarian satellite anchor design. 
Table 4.10: Summary of P-Test Results

\begin{tabular}{lccc}
\hline Anchor Type & Variable & Load p-value & Displacement p-value \\
\hline Point Anchor & Rock Strength, psi & 0.00285 & 0.17135 \\
Point Anchor & Anchor Depth, in. & 0.94089 & 0.56471 \\
Point Anchor & Water Content, $\%$ wt. & 0.03229 & 0.51418 \\
Point Anchor & Temperature, ${ }^{\circ} \mathrm{F}$ & 0.69195 & 0.28808 \\
Point Anchor & Compactive Load, $\%$ & 0.12645 & 0.54841 \\
FGRB & Rock Strength, psi & 0.43150 & 0.98271 \\
FGRB & Anchor Depth, in. & 0.86342 & 0.68781 \\
FGRB & Water Content, $\%$ wt. & 1.0 & 0.24908 \\
FGRB & Temperature, ${ }^{\circ} \mathrm{F}$ & 0.99065 & 0.25795 \\
FGRB & Compactive Load, $\%$ & 0.54828 & 0.84400 \\
PUR & Rock Strength, psi & 0.43206 & 0.88404 \\
PUR & Anchor Depth, in. & 0.00283 & 0.17693 \\
PUR & Water Content, $\%$ wt. & 0.80213 & $\mathrm{~N} / \mathrm{A}$ \\
PUR & Temperature, ${ }^{\circ} \mathrm{F}$ & 1.0 & $\mathrm{~N} / \mathrm{A}$ \\
PUR & Compactive Load, $\%$ & 0.49570 & $\mathrm{~N} / \mathrm{A}$ \\
\hline
\end{tabular}

\subsubsection{Anchor Design Considerations}

The initial intent of this study was to provide a nomogram for anchor selection based on how each anchor type responded to the different tested variables. At the conclusion of this study, however, experience gained during the course of the testing campaign highlighted possible difficulties with incorporating some of the bolt types into a satellite anchoring system. During test preparation, it quickly became clear that fully grouted roof bolts would probably not be a realistic option for satellite anchorage due to the previously mentioned difficulties in mixing and pouring the resin into a bolt hole. While a robotic operator could mix and inject the two-part resin at the speed and pressure require, the low temperatures anticipated in space could freeze water the resin prior to injection into the bolt hole. Such a system would require a method to drill a bolt hole, store the two resin components separately, store a rebar bolt, mix the components together, inject the resin, install the bolt into the bolt hole, and rotate the bolt until it has anchored in the resin. A heater could also possibly be required to prevent the resin components from freezing prior to injection. Even if the resin did not freeze, its components would become much more viscous in 
the low temperatures of space, possibly to the point that the resin loses its fluidity. In any event, such a system is overly complex and would use an excessive amount of storage volume on the satellite prior to deployment.

Polyurethane anchors generated similar concerns regarding bolt installation as the fully grouted roof bolts. There may be a similar need to heat the resin during storage to prevent freezing, as well as increases in fluid viscosity should the resin not require heated storage. A polyurethane bolt anchoring system would also require a method to drill a bolt hole, store the bolt and two resins, mix the resins together, inject the resin, and install the bolt. A hollow rebar bolt could be used so that the bolt is installed in the hole and the resin pumped through the bolt into the bolt hole, thereby encapsulating it in resin. The poor performance of polyurethane bolts during the regolith tests, however, indicate that, depending on the size of the satellite being anchored, these bolts might not provide the anchorage strength required to affix the satellite to the ground.

Based on the previous analyses and experiences with bolt installation, the point anchor bolt design is most conducive for incorporation into a satellite anchor. In addition to providing the most reliable method of anchorage in regolith testing, the bolts performed at the same high levels of success in pullout load as the fully grouted resin bolts. A point anchor system would not require the addition of any fluid reservoir space or injection system. Such a bolt would instead rely on a robotic operator to drill a bolt hole and then install the bolt with a certain amount of torque to ensure that the anchor shell had embedded in the bolt hole walls. A further optimization of the system could be the introduction of a self-drilling bolt head at the tip of the bolt. This head could perhaps be integrated with the anchor shell in such a way that the bolt could then act both as a drill and an anchor. The bolt, rotated by a robotic operator, would first drill a bolt hole while slowly being installed as the bolt continues to cut the hole. Once the desired depth had been reached, the bolt would then be rotated to generate the installation torque required for shell expansion.

In addition to the anchor type, variables in the operating environment were initially thought to influence anchorage in the asteroid. One observed phenomenon 
during test setup was the high difficulty in drilling bolt holes in the diabase boulder. Drilling took anywhere from 3.5 to 8 hours to drill one 12 in. bolt hole using a diamond coring bit. The sandstone and limestone boulders, by contrast, took 10-15 minutes to drill a hole of similar length. While a robotic drill would probably use a rotary percussive method of drilling a bolt hole and a tungsten carbide boring bit, anchoring in such a boulder would still require several hours to drill a 12 in. hole. Since diabase is mineralogically similar to other igneous rock types, drilling into asteroids with high igneous mineral contents, such as S-type asteroids, or high metal contents, such as M-type asteroids, may be difficult. If a satellite must be anchored to one of these types of asteroids during a short amount of time, therefore, it is advised that anchoring sites be selected based on high regolith content, rather than bare surfaces that may be difficult to drill. This regolith may then provide an easier mechanism into which the satellite can anchor. If time is not a major concern, then drilling into the coherent asteroid body will generate a more stable anchorage.

In the regolith strength regime, compactive load and temperature did not play a statistically significant role in the failure pullout load of the bolts. Only water content generated a significant result, and then only with point anchor bolts. This is hypothesized to occur due to the increased particle cohesion created by the addition of water to the regolith. This, in turn, created a stronger regolith mass that, through frictional interlocking of the regolith particles, provided an increased resistance to the point anchor's anchoring force. This effect may have shown itself only for the point anchor because it was the only anchor to generate enough data points to model the role of water. When frozen, this water will act as a lattice or matrix that further strengthens the cohesion of the regolith mass, and so will likely generate a more internally competent, and thus "stronger", regolith. The environmental conditions that generated significant findings during the boulder tests (anchor depth for polyurethane and rock strength for point anchor) both may have explanations beyond simple causation. In the former case, the success of the polyurethane bolts in sustaining 28 ton pullout loads at 2 in. and 6 in., but not at 12 in., most likely generated this "significant" result. This anchorage phenomenon may be due to a reaction between the polyurethane 
and the surrounding air that was able to take place at shallower bolt depths during the allotted cure time. The influence of rock strength on point anchors, meanwhile, is similarly due to the point anchor failures in the low- and medium-strength boulders and successes in the high-strength boulder. The only environmental property that may actually impact anchorage, therefore, is the internal strength of the body being anchored. This strength will depend on confining stresses, water/ice content, regolith cohesion, and the absence/presence of discontinuities within the orbital body. Based on the findings from the regolith and boulder tests, therefore, anchorage in bodies composed either of rock-like material or in regolith may be achieved if the anchorage design is based on a point anchor system and the body is strong enough to land on in the first place. 


\section{Chapter 5}

\section{Conculsions and Recommendations}

\subsection{Conclusions}

This work examined the potential for repurposing anchoring concepts used in mine roof support for use in designing a satellite anchoring system. Three different types of anchorage - point anchors, fully grouted resin bolts, and polyurethane anchors - were tested to identify which, if any, anchorage system would provide the best anchorage in an asteroid for a given set of environmental conditions. These anchors were tested in both a "bedrock/boulder" and a regolith medium, with variations in boulder strength and anchor depth as well as regolith compaction, water content, and temperature. While the hydraulic pump and load cylinder were overpowered for the regolith tests and led to many premature bolt failures, several useful conclusions were still gathered from the study:

1. Short anchor depths do not appear to affect the pullout strength of the anchors themselves. While some failures occurred in $12 \mathrm{in}$. bolt holes, none occurred in any of the $6 \mathrm{in}$. or $3 \mathrm{in}$. bolt holes. This indicates that, while there may be an effect if a bolt is loaded beyond 28 tons, no differences in anchor strength exist between the different anchor depths at pull loads $\leq 28$ tons.

2. Water content can play a significant role in the pullout strength of point anchors. This is possibly due to an increase in the cohesion of the regolith created by the water particles that, in turn, creates a stronger body of regolith in which the 
point anchors can embed. This, combined with the failure of most of the other tested parameters to generate significant results, appears to indicate that the single largest concern in the regolith strength regime is the internal strength of the regolith itself, rather than individual parameters that may or may not contribute to the strength of the regolith body.

3. Serious installation challenges may exist with incorporating a fully grouted roof bolt design. These challenges arise from the difficulty of mixing the resin, the possibility of the resin freezing in space, and the long set time that may be required for the resin to reach its full cured strength.

4. Point anchors overall proved most resilient to the applied pullout loads. While torque-induced bolt failures did occur in weaker rocks, this can be avoided in space environments by anchoring in either an area with a larger confining stress or in an area covered with regolith. The point anchor, therefore, appears to be the best anchorage mechanism for use in designing a satellite anchoring system.

\subsection{Future Work}

This initial work has provided as much of a guide of how not to anchor onto an asteroid as it has on how anchorage should occur. Selection of a point anchor-derived system, however, has provided a baseline from which future work can expand. One limitation of the current study was its inability to drill the bolt holes into the boulders and regolith at the low temperatures expected in space. This limitation was primarily due to the large size of the boulders and drill, as well as safety concerns for a human operator to use a drill in such conditions. Additionally, while the temperatures of the regolith samples were lowered and bolts installed in these low temperature samples, the anchor material itself was room temperature prior to installation in order to facilitate human handling of the materials during installation. Future tests with point anchor bolts should therefore take place in a testing chamber where the temperature can be lowered to $-40^{\circ} \mathrm{F}$ to $-94^{\circ} \mathrm{F}$ and a full vacuum created. Testing under these simulated asteroid conditions would then reveal deficiencies in anchor design or material 
selection. Additionally, conducting all drilling, bolt installation, and bolt testing in this chamber will be a closer analog to operating in an asteroid environment than conducting the tests in a typical lab setting. Testing in such conditions will reveal any potential problems with how the operations are conducted and whether the materials used are appropriate for use in a low temperature vacuum. In the event that the steel normally used on Earth for these bolts becomes too brittle to use in space, an anchor system could instead be constructed from fiberglass reinforced plastic, or FRP. This material is already in use for creating roof bolts that require high corrosion resistance and high tensile strength (JENNMAR USA (2017)). An investigation into the behavior of FRP bolts at low temperatures may find a lower degree of brittleness than that encountered by steel bolts, thereby providing another material option for use in constructing a satellite anchor.

Future testing should primarily focus on bolt design and anchoring depth in order to minimize the time required to drill and anchor into an asteroid or comet. As has previously been mentioned, integrating a self-drilling bolt head with the point anchor system may be one way to minimize the time, movement, and mass required for anchoring into the asteroid. Testing should therefore examine if such a cutting head can drill through asteroid regolith simulant at low temperatures with both low and high water contents. Since anchor depth did not affect anchor pullout loads in the boulder strength regime, a similar test should be conducted in regolith to identify if anchor depth plays a larger role in a granular environment. Results from this test could then determine if the anchoring system must be $12 \mathrm{in.} \mathrm{long} \mathrm{or} \mathrm{if} \mathrm{shorter} \mathrm{anchors}$ will be adequate. During this testing, it is strongly advised that a low-pressure jack and loading cylinder be utilized in order to capture loading data at the $<2$ ton interval. Additionally, regolith testing should take place in a lid-capped container with a hole on the top through which the bolts can protrude. This lid will need to be of sufficient strength to withstand the reaction force generated by the loading cylinder when the maximum load is applied. Otherwise the lid will fail and the dial gauge will generate an incorrect displacement and load despite this load no longer being actually applied to a surface. A final safeguard against erroneous readings is to limit the exposed bolt 
length above the test site to $1 \mathrm{in}$. Doing so will prevent the loading cylinder from fully pressurizing prior to the pull claw actually coming into contact with the pull collar or bolt head. Such a situation can otherwise occur if the pull claw vertically displaces far enough for the loading cylinder to pressurize prior to this contact. 


\section{Bibliography}

Amini, S. H. (2014). Ultra Clean Coal Production Using Dense Medium Separation for the Silicon Market. These and Dissertations-Mining Engineering. (Paper 14), University of Kentucky.

Amini, S. H., R. Honaker, and A. Noble (2016). Performance evaluation of a densemedium cyclone using alternative silica- based media.pdf. Powder Technology 297, $392-400$.

Baer, J., S. R. Chesley, and R. D. Matson (2011). Astrometric Masses of 26 Asteroids and Observations on Asteroid Porosity. The Astronomical Journal 141(143).

Bertini, I. (2013). Asteroids: Prospective Energy and Mineral Resources, Chapter 1: Asteroids Close-Up: What We Have Learned From Twenty Years of Space Exploration, pp. 1-34. Berlin: Springer-Verlag.

Biele, J. and S. Ulamec (2013). Preparing for Landing on a Comet: The Rosetta Lander Philae. 44th Lunar and Planetary Science Conference (2013), 4-5.

Biele, J., S. Ulamec, M. Maibaum, R. Roll, L. Witte, E. Jurado, P. Muñoz, W. Arnold, H.-u. Auster, C. Casas, C. Faber, C. Fantinati, F. Finke, H.-h. Fischer, K. Geurts, C. Güttler, P. Heinisch, A. Herique, S. Hviid, G. Kargl, M. Knapmeyer, J. Knollenberg, W. Kofman, N. Kömle, E. Kührt, V. Lommatsch, S. Mottola, R. Pardo de Santayana, E. Remetean, F. Scholten, K. J. Seidensticker, H. Sierks, and T. Spohn (2015). The landing(s) of Philae and inferences about comet surface mechanical properties. Science (New York, N.Y.) $349(6247)$. 
Biele, J., S. Ulamec, L. Richter, J. Knollenberg, E. Kuhrt, Mo, and D. Hlmann (2009). The putative mechanical strength of comet surface material applied to landing on a comet. Acta Astronautica 65, 1168-1178.

Biele, J., S. Ulamec, L. Richter, E. Kührt, J. Knollenberg, and D. Möhlmann (2006). The strength of cometary surface material: Relevance of deep impact results for philae landing on a comet. In H. U. Kaufl and C. Sterken (Eds.), Deep Impact as a World Observatory: Synergies in Space, Time, and Wavelength, Brussels, pp. 285-300. ESO Astrophysics Symposia.

Bieniawski, Z. T. (1987). Strata Control in Mineral Engineering. New York: John Wiley and Sons Inc.

Blatt, H., R. J. Tracy, and B. E. Owens (2006). Minerals and Their Textural Relations in Igneous Rocks. In Petrology: Igneous, Sedimentary, and Metamorphic (3rd ed.)., Chapter 2, pp. 30-31. New York: W. H. Freeman and Company.

Bodi, J., Z. Bodi, J. Scucka, and P. Martinec (2012). Polyurethane Grouting Technologies. In F. Zafar and E. Sharmin (Eds.), Polyurethane, Chapter 14, pp. 307-337. InTech.

Britt, D. T., S. J. Consolmagno, and W. J. Merline (2006). Small Body Density and Porosity: New Data, New Insights. Lunar and Planetary Science 37, 3-4.

Britt, D. T., D. Yeomans, K. Housen, and G. Consolmagno (2002). Asteroid Density, Porosity, and Structure. In Asteroids III, pp. 485-500. University of Arizona Press.

Bureau of Mines, . (1987). Appendix 3: State-of-the-art and physical properties of rock support systems. In Comparative Study of Rock Support Systems for a High Level Nuclear Waste Geologic Repository in Tuff (U.S. Depar ed.). Denver.

Chabot, N., P. Abell, D. Britt, J. Dankanich, J. Emery, A. Rivkin, and D. Sheeres (2014). Report of the Small Bodies Assessment Group Asteroid Redirect Mission Special Action Team. Technical report, National Aeronautics and Space Administration. 
Chodas, P. and R. Baalke (2014). Frequently Asked Questions. Near Earth Object Program, NASA Center for Near Earth Object Studies, http://neo.jpl.nasa.gov/faq/.

Clark, B. E., B. Hapke, C. Pieters, and D. Britt (2002). Asteroid Space Weathering and Regolith Evolution. In W. F. Bottke, A. Cellino, P. Paolicchi, and R. P. Binzel (Eds.), Asteroids III, pp. 585-599. Tucson: University of Arizona Press.

Compton, C. and D. Oyler (2005). Investigation of Fully Grouted Roof Bolts Installed Under In Situ Conditions. In Proceedings of the 24th International Conference on Ground Control in Mining, Morgantown, WV, pp. 302-312.

Craig, P. and B. Murnane (2013). In-situ pull testing of cable bolts encapsulated with injection polyurethane. In 2013 Coal Operator's Conference, Number 13th, University of Wollongong, pp. 131-136. The Australasian Institute of Mining and Metallurgy \& Mine Managers Association of Australia.

Dombard, A. J., O. S. Barnouin, L. M. Prockter, and P. C. Thomas (2010). Boulders and ponds on the Asteroid 433 Eros. Icarus 210(2), 713-721.

Dombard, A. J. and A. M. Freed (2002). Thermally induced lineations on the asteroid Eros : Evidence of orbit transfer. Geophysical Research Letters 29(16), 1-4.

DSI (2009). Mechanical Anchors and Rebar Rock Bolts. pp. Product catalog.

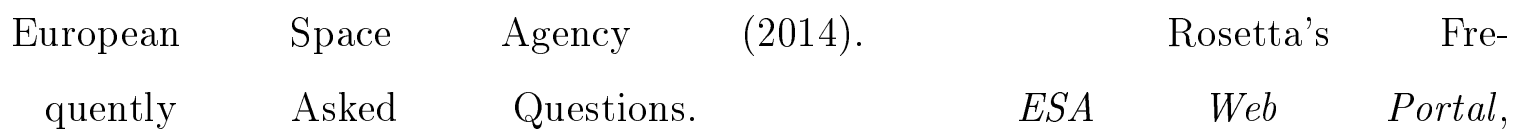

http://www.esa.int/Our_Activities/Space_Science/Rosetta/Frequently_asked_questions.

Fantinati, C. and K. Geurts (2015). Philae calling... Philae DLR Blog, http://www.dlr.de/blogs/en/desktopdefault.aspx/tabid-8684/15090_read-849/.

Faulkner, D. (2012). The Development and Application of Polyurethance Injectable Cable Bolts. In T. Barczak, D. Caudill, D. Opfer, S. S. Peng, S. Tadolini, M. Thompson, and B. Warnick (Eds.), 31st International Conference on Ground Control in Mining, Morgantown, WV, pp. 1-5. West Virginia University. 
Ferreira, S. L. C., R. E. Bruns, H. S. Ferreira, G. D. Matos, J. M. David, G. C. Brandão, E. G. P. da Silva, L. A. Portugal, P. S. dos Reis, A. S. Souza, and W. N. L. dos Santos (2007). Box-Behnken design: An alternative for the optimization of analytical methods. Analytica Chimica Acta 597(2), 179-186.

Fujiwara, A., J. Kawaguchi, D. K. Yeomans, M. Abe, T. Mukai, T. Okada, J. Saito, H. Yano, M. Yoshikawa, D. J. Scheeres, O. Barnouin-Jha, a. F. Cheng, H. Demura, R. W. Gaskell, N. Hirata, H. Ikeda, T. Kominato, H. Miyamoto, a. M. Nakamura, R. Nakamura, S. Sasaki, and K. Uesugi (2006). The rubble-pile asteroid Itokawa as observed by Hayabusa. Science 312(5778), 1330-4.

Gaffey, M. J. (2011). Mineralogy of asteroids. In AIP Conference Proceedings, Volume 1386, pp. 129-169.

Hanner, M. S. and J. P. Bradley (2004). Composition And Mineralogy Of Cometary Dust. In Comets II, pp. 555-564.

Hartman, H. and J. M. Mutmansky (2002). Introductory Mining Engineering. Hoboken: John Wiley \& Sons, Inc.

Hoermann- Gast, A. and J. Olsen (2015). The Effects of Temperature on Post installed Adhesive Anchors. ICC Evaluation Service.

Holsapple, K. A. (2009). On the "strength" of the small bodies of the solar system: A review of strength theories and their implementation for analyses of impact disruptions. Planetary and Space Science 57(2), 127-141.

Housen, K. R. and K. A. Holsapple (2003). Impact cratering on porous asteroids. Icarus 163(1), 102-119.

Hudson, J. A. and J. P. Harrison (2000). Engineering Rock Mechanics: An Introduction to the Principles. Oxford: Elsevier Science Ltd.

Hughes, D. W. (1985). The size, mass, mass loss, and age of Halley's comet. Monthly Notices of the Royal Astronomical Society 213(1), 103-109. 
Jalalifar, H., N. I. Aziz, and M. N. Hadi (2005). Rock and bolt properties and load transfer mechanism in ground reinforcement. In 20th World Mining Conference 2005: Mining and Sustainable Development, Iran, pp. 629-635. Geological Society of Iran.

JENNMAR USA (2017). Selected Ground Control Products. Pittsburgh: JENNMAR USA. Product catalog.

Kömle, N. I., A. J. Ball, G. Kargl, T. Keller, W. Macher, M. Thiel, J. Stöcker, and C. Rohe (2001). Impact penetrometry on a comet nucleus - Interpretation of laboratory data using penetration models. Planetary and Space Science 49(6), $575-598$.

Lang, T., J. Bischoff, and P. Wagner (1979). A Program Plan for Determining Optimum Roof Bolt Tension: Theory and Application of Rock Reinforcement Systems in Coal Mines. Technical report, United States Bureau of Mines, San Francisco.

Lang, T. A. and J. A. Bischoff (1982). Stabilization of rock excavations using rock reinforcement. In The 23rd US Symposium on Rock Mechanics (USRMS), pp. 935944. American Rock Mechanics Association.

Mark, C. (2000, June). Design of Roof Bolt Systems. In Proceedings of the New Technology for Coalmine Roof Support, pp. 111-131.

Mark, C., C. Compton, D. Oyler, and D. R. Dolinar (2002). Anchorage Pull Testing for Fully Grouted Roof Bolts. In S. S. Peng, C. Mark, A. W. Khair, and K. A. Heasley (Eds.), Proceedings of the 21st International Conference on Ground Control in Mining, Morgantown, WV, pp. 105-113. West Virginia University.

Mark, C., G. M. Molinda, and D. R. Dolinar (2001). Analysis of Roof Bolt Systems. In S. S. Peng, C. Mark, and A. W. Khair (Eds.), Proceedings of the 20th International Conference on Ground Control in Mining, Morgantown, WV, pp. 218-225. West Virginia University. 
Mazanek, D. D., D. M. Reeves, P. A. Abell, E. Asphaug, N. M. Abreu, P. S. Dubois, J. F. Bell, W. F. Bottke, D. T. Britt, H. Campins, P. W. Chodas, C. M. Ernst, M. D. Fries, L. S. Gertsch, D. P. Glavin, G. Space, C. M. Hartzell, A. R. Hendrix, J. A. Nuth, G. Space, and D. J. Scheeres (2016). Asteroid Redirect Mission (ARM) Formulation Assessment and Support Team (FAST) Final Report. Technical Report February, NASA Langley Research Center, Hampton.

McGee, T. G., D. A. Artis, T. J. Cole, D. A. Eng, C. L. B. Reed, M. R. Hannan, D. G. Chavers, L. D. Kennedy, J. M. Moore, and C. D. Stemple (2013). Mighty eagle: The development and flight testing of an autonomous robotic lander test bed. Johns Hopkins APL Technical Digest (Applied Physics Laboratory) 32(3), 619-635.

McKay, D. S., G. Heiken, A. Basu, G. Blanford, S. Simon, R. Reedy, B. M. French, and J. Papike (1991). The Lunar Sourcebook: A User's Guide to the Moon. Cambridge University Press.

Michikami, T., K. Moriguchi, S. Hasegawa, and A. Fujiwara (2007). Ejecta velocity distribution for impact cratering experiments on porous and low strength targets. Planetary and Space Science 55, 70-88.

Michikami, T., A. M. Nakamura, N. Hirata, R. W. Gaskell, R. Nakamura, T. Honda, C. Honda, K. Hiraoka, J. Saito, H. Demura, M. Ishiguro, and H. Miyamoto (2008). Size-frequency statistics of boulders on global surface of asteroid 25143 Itokawa. Earth, Planets and Space 60(1), 13-20.

Minova Americas, . (2009). Lokset (B) Resin Cartridge Anchors For Rock and Concrete Reinforcement Minova Americas. Product catalog.

Miyamoto, H., H. Yano, D. J. Scheeres, S. Abe, O. S. Barnouin-jha, A. F. Cheng, H. Demura, R. W. Gaskell, N. Hirata, M. Ishiguro, T. Michikami, A. M. Nakamura, R. Nakamura, J. Saito, and S. Sasaki (2007). Regolith migration and sorting on asteroid Itokawa. Science 316(May), 1011-1014. 
Nelson, M. L., D. T. Britt, and L. A. Lebofsky (1993). Review of Asteroid Composition. Resources of Near Earth Space, 493-522.

Olansen, J. B., S. Munday, J. Devolites, and M. Baine (2013). Project Morpheus: Lessons Learned in Lander Technology Development. In AIAA SPACE Conference and Exposition, San Diego, pp. 5310. American Institute of Aeronautics and Astronautics.

Orica International, . (2014). Lokset Resin Capsules: User's Information Pack. Product catalog.

Peng, S. (1998). Roof bolting adds stability to weak strata. Coal Age 103(12), 32-38.

Peng, S. S. (2008). Roof Bolting. In Coal Mine Ground Control (3rd ed.)., Chapter 4, pp. 145-224. Morgantown, WV: Department of Mining Engineering, College of Engineering and Mineral Resources, West Virginia University.

Petrovic, J. J. (2001). Mechanical properties of meteorites. Journal of Materials Science 36, $1579-1583$.

Popova, O., J. Borovicka, W. K. Hartmann, P. Spurny, E. Gnos, I. Nemtchinov, and J. M. Trigo-Rodriguez (2011). Very low strengths of interplanetary meteoroids and small asteroids. Meteoritics and Planetary Science 46(10), 1525-1550.

Rogers, W. F. (1972, June). Apollo Experience Report - Lunar Module Landing Gear Subsystem. Houston: NASA Manned Spacecraft Center.

Sanchez, P. and D. J. Scheeres (2013). The Strength of Regolith and Rubble Pile Asteroids. Meteoritics and Planetary Science 49(5), 788-811.

Sanchez, P. and D. J. Scheeres (2015). Scaling Rule Between Cohesive Forces and The Size of a Self-Gravitating Aggregate. In 46th Lunar and Planetary Science Conference.

Schwandt, C., J. A. Hamilton, D. J. Fray, and I. A. Crawford (2012). The production of oxygen and metal from lunar regolith. Planetary and Space Science 74(1), 49-56. 
Signer, S. (1990). Field Verification of Load Transfer Mechanics of Fully Grouted Roof Bolts. Report of investigation ri 9301, United States Bureau of Mines.

Snuparek, R. and K. Soucek (1999). Polyurethane Geocomposites: Mechanical Properties and Deformation. In International Mine Water Association Proceedings, Saville, pp. 657-661.

Spohn, T., J. Knollenberg, A. J. Ball, M. Banaszkiewicz, J. Benkhoff, M. Grott, J. Grygorczuk, C. Huttig, A. Hagermann, G. Kargl, E. Kaufmann, N. Komle, E. Kuhrt, K. J. Kossacki, W. Marczewski, I. Pelivan, R. Schrodter, and K. Seiferlin (2015). Thermal and mechanical properties of the near-surface layers of comet 67P/Churyumov-Gerasimenko. Science 349 (6247).

Stolf, R., Á. D. M. Thurler, O. Oliveira, S. Bacchi, and K. Reichardt (2011). Method to estimate soil macroporosity and microporosity based on sand content and bulk density. Revista Brasileira de Ciência do Solo 35(2), 447-459.

Ulamec, S. and J. Biele (2009). Surface elements and landing strategies for small bodies missions - Philae and beyond. Advances in Space Research 44(7), 847-858.

Unal, E. (1984). Empirical approach to calculate rock loads in coal mine roadways. In S. Peng (Ed.), Proceedings of the 5th Annual Conference on Ground Control in Mining. WV University, Morgantown, pp. 232-246. West Virginia University.

Williams, D. R. (2006). Surveyor to the Moon (1966-1968). NASA Space Science Data Coordinated Archive, http://nssdc.gsfc.nasa.gov/planetary/lunar/surveyor.html.

Williams, D. R. (2015a). Asteroids. NASA Space Science Data Coordinated Archive, Nssdc.gsfc.nasa.gov/planetary/text/asteroids.txt.

Williams, D. R. (2015b). Planetary Fact Sheet - Metric. NASA Space Science Data Coordinated Archive, http://nssdc.gsfc.nasa.gov/planetary/factsheet/.

Williams Form Engineering Corporation, . (2014). Using Williams Products. Product catalog. 